WHOI - 75-42

MOORING OPERATIONS OF THE WOODS HOLE BUOY GROUP FOR THE MID-OCEAN DYNAMICS EXPERIMENT

by

Robert H. Heinmiller, Jr.

WOODS HOLE OCEANOGRAPHIC INSTITUTION

Woods Hole, Massachusetts 02543

September 1975

TECHNICAL REPORT

Prepared for the Office of Naval Research under Contract N00014-74-C0262; NR 083-004 and NSF GX-29054.

Reproduction in whole or in part is permitted for any purpose of the United States Government. In citing this manuscript in a bibliogrophy, the reference should be followed by the phrase:
UNPUBLISHED MANUSCRIPT.

Approved for public release; distribution unlimited.

Approved for Distribution

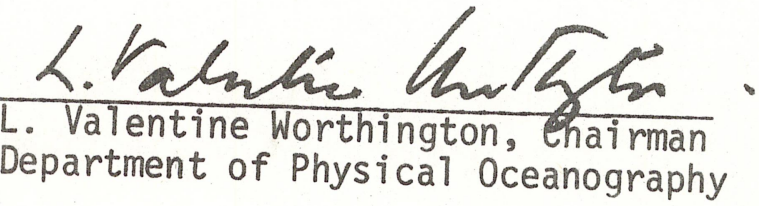




\section{Mooring Operations of the Woods Hole Buoy Group for the Mid-Ocean Dynamics Experiment}

by

Robert H. Heinmiller, Jr.

\section{Introduction}

The Mid-Ocean Dynamics Experiment was a long-term multi-institution effort to investigate meso-scale motions in the western North Atlantic Ocean. The Moored Array Project (Buoy Group) of the Woods Hole Oceanographic Institution participated with a series of moorings to measure both currents and temperatures. The main field experiment for MODE was scheduled for March to July, 1973. However, in 1971 it became clear that a series of preliminary experiments would have to be carried out to provide estimates of spatial and temporal scales for planning the main array experiment.

The first moorings were set in October of 1971. A minimum of two moorings was maintained in the MODE area until the beginning of the main array in March of 1973. In anticipation of possible future experiments the primary experiment was designated MODE-I. As the preliminary arrays developed, they were labeled MODE-O, to distinguish them from the main effort.

This report summarizes the mooring operations by the Institution's Buoy Group in support of MODE. It is restricted to the moorings and distribution of instrumentation and will not deal with the quality or quantity of data recovered.

The location of the MODE site is shown in Figure 1. The center is at $28^{\circ} \mathrm{N}, 69^{\circ} 40^{\prime} \mathrm{W}$. The western half of the site is abyssal plain at a depth of about 5,460 meters. The eastern half is slightly shallower and much rougher.

Appendix I of this report is a schematic chronology of the work reported on, Appendix II is a detailed tabulation of all moorings, and Appendix III includes detailed drawings of each mooring. 


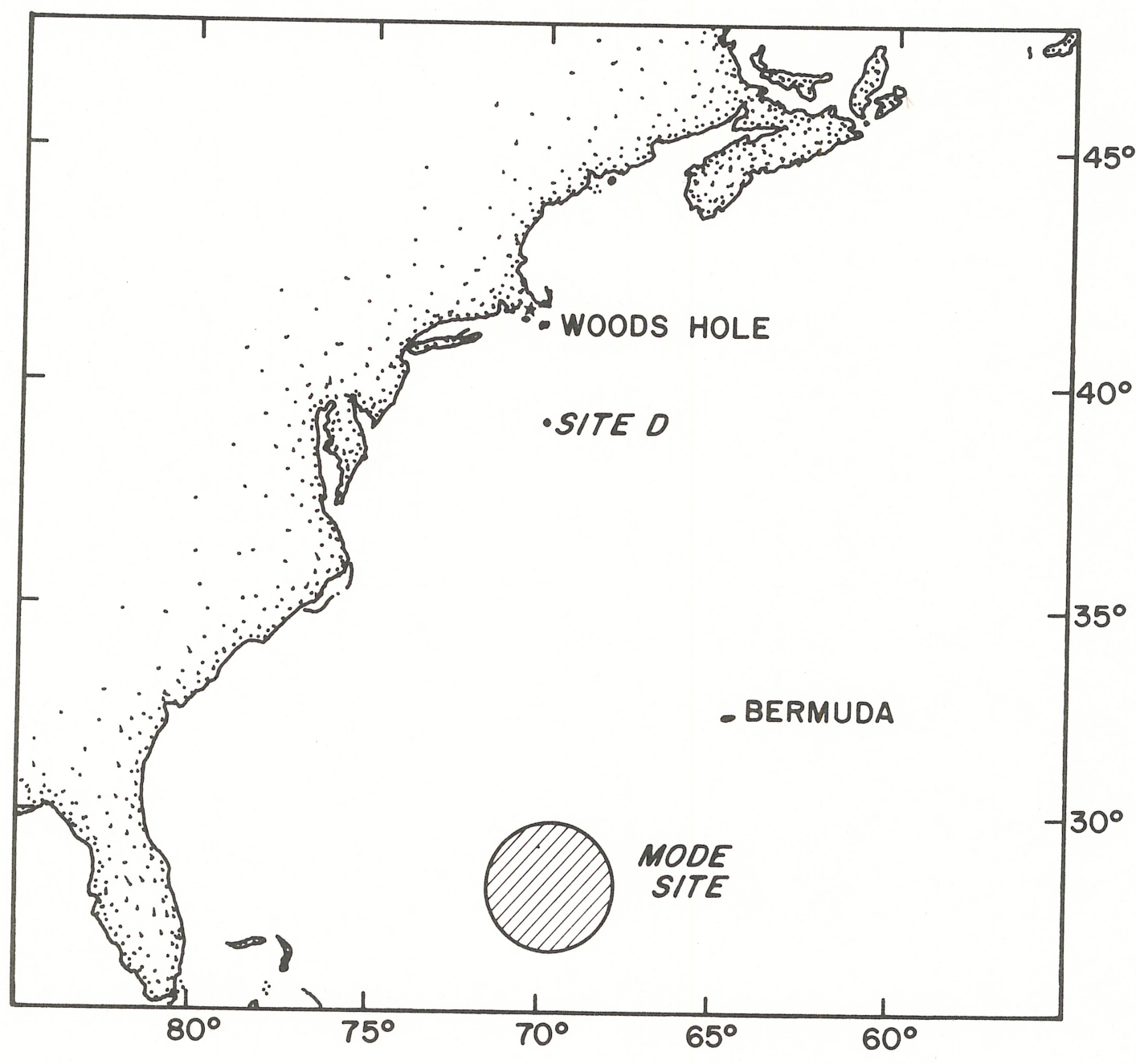

Figure 1

Location of MODE Site 
MODE-O

MODE-O was the designation given to a series of array experiments and site-maintenance moorings set from October, 1971 to March, 1973, in the area selected as the MODE site. Both surface and intermediate (sub-surface) moorings were used. All were compound; that is, they used steel wire above 2,000 meters and synthetic line below. ${ }^{1}$ Each used a back-up recovery system ${ }^{2}$ and an acoustic anchor release.

Both types of moorings were designed using estimated current profiles. For the sub-surface moorings, little concern was given initially to meeting any particular specifications on mooring performance (defined by the amount of variation in the depth of the top of the mooring in varying current profiles). Survivability and a "reasonably rigid array" were the design criteria.

\section{Array 1}

MODE mooring operations began with an array of two surface and five intermediate moorings in the western half of what was later to become the MODE-I Site. The entire array, consisting of station 406 through 412, was deployed on ATIANTIS II Cruise 63 in October, 1971. A narrative of the cruise is presented in the cruise report. ${ }^{3}$ All moorings were set without serious incident. The moorings in the array carried a total of nineteen current meters and one wind recorder. On one of the surface floats was an aircraft navigation radio transponder for use by Nova University. The antenna for this gear was damaged during launch and had to be repaired.

The configuration of the array is shown in Figure 2. The moorings were recovered in February, 1972 on CHAIN Cruise 101.4 The only loss of gear occurred during the recovery of station 407. The release and 


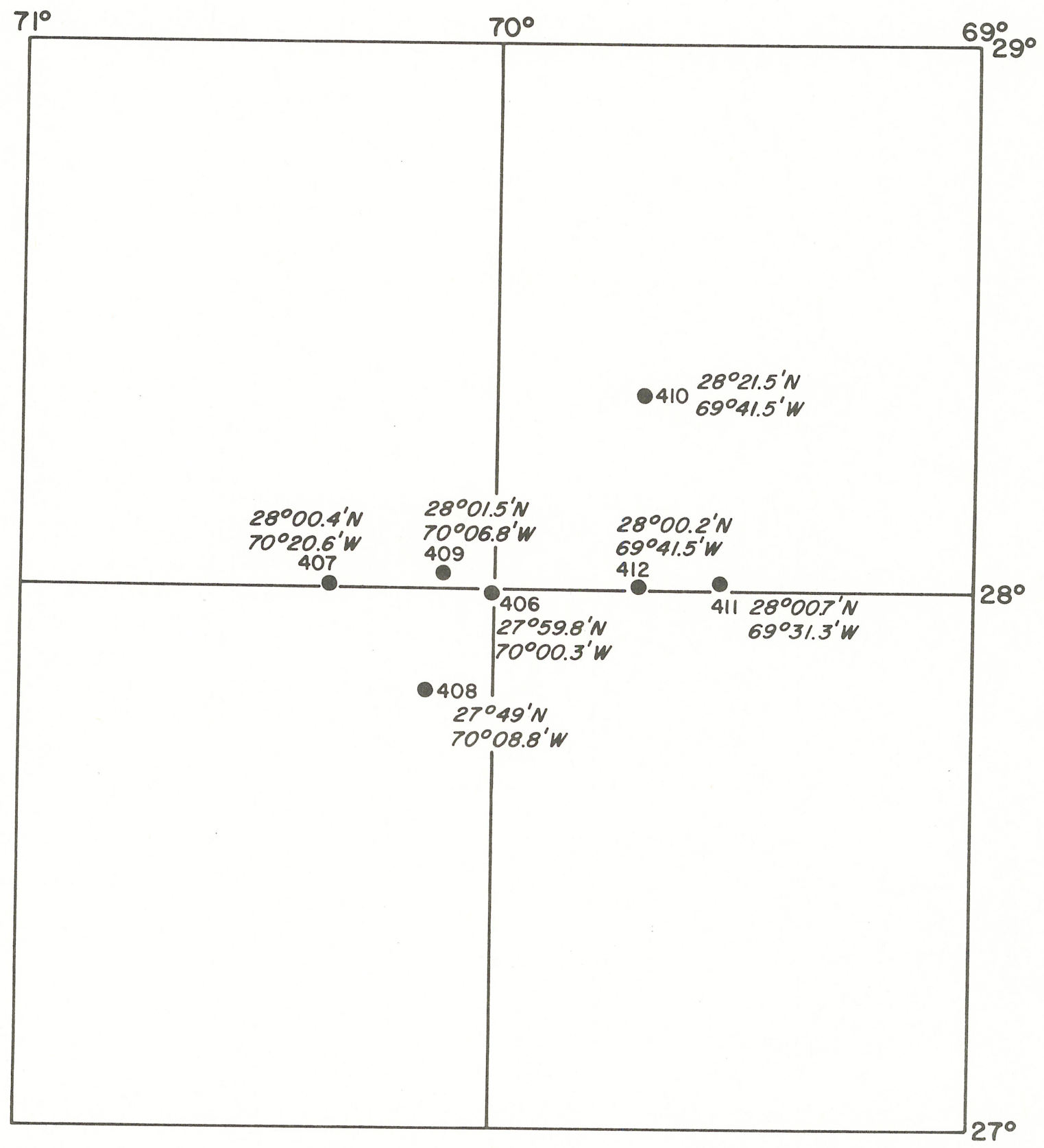

Figure 2

MODE-0, Array 1 
thirty-six glass spheres in the back-up recovery section apparently chafed off after the release had been actuated and had come to the surface. The spheres could not be found and the release was eventually determined by acoustic ranges to be on the bottom. All other moorings were recovered complete.

\section{Site Maintenance Moorings}

After the recovery of Array 1, two surface moorings were set. These moorings carried three current meters each and one had a wind recorder. Each mooring also carried a set of dummy versions of the Draper Lab temperature/pressure recorder to test for mechanical compatibility. A narrative of CHAIN 101 may be found in the cruise report. 4 Station 424 was set at $28^{\circ} 10^{\prime} \mathrm{N} ., 68^{\circ} 40^{\prime} \mathrm{W}$. and Station 425 at $28^{\circ} 00^{\circ} \mathrm{N} ., 69^{\circ} 40^{\prime} \mathrm{W}$., locations which came to be known as MODE East and MODE Center, respectively. The eastern mooring, station 424, had to be set ten nautical miles north of the intended location on $28^{\circ} \mathrm{N}$. due to difficulties in locating a spot in the rough bottom terrain flat enough to set.

Recovery of these two moorings was intended for KNORR Cruise 26 in May, 1972. On that cruise station 424 was recovered complete but Station 425, the western mooring, could not be found. No traces, either visual or acoustic, were located. However, this mooring had been inspected in March on CHAIN 103, thirty-seven days after launch, and it was on station then. ${ }^{5}$ The cruise report of KNORR 26 includes a detailed description of the cruise. 6

\section{Array 2}

In March, 1972 on CHAIN Cruise 103 Array 2 was set, consisting of five intermediate moorings (Figure 3 ). ${ }^{5}$ A total of ten current meters were on these moorings. The first two moorings, stations 430 and 431 , were set routinely. However, the third mooring, Station 432, was aborted when the improperly-secured end of a tagline on the launch winch was lost overboard. The gear was picked up and the mooring 


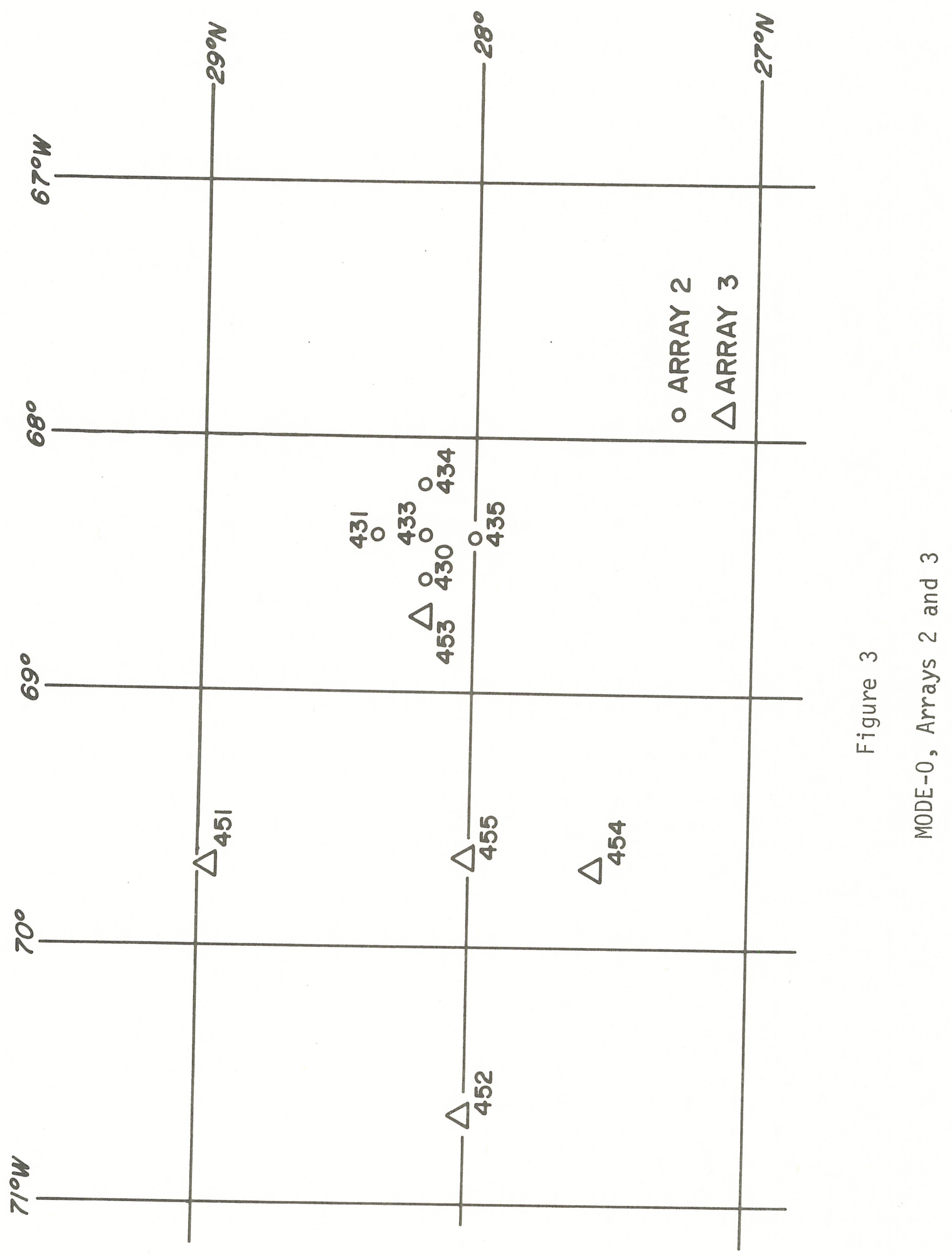


re-launched successfully as Station 433. Stations 434 and 435 completed the array. Station 435 included engineering instrumentation for an evaluation of the performance of the intermediate mooring. Also included in the work on CHAIN 103 was a bathymetric survey of a large section of the eastern half of the MODE Site. Array 2 was recovered complete without incident in May, 1972 on KNORR 26.

\section{Array 3}

Array 3, four surface and one intermediate moorings with a total of twelve current meters, one wind recorder, and four temperature/pressure recorders, was set on KNORR 26. The configuration of the array is shown in Figure 3. The array was recovered routinely on CHAIN Cruise 107 in
October, 1973.7

\section{Site-Maintenance Moorings}

The last set of MODE-O site-maintenance moorings, two intermediates, was set on CHAIN 107 in October, 1972. These moorings were both intermediates, with three current meters each. On Leg I of CHAIN Cruise 112 in March, 1973, they were recovered intact. 8 


\section{MODE-I}

The array of current-meter moorings deployed for the MODE-I experiment in March of 1973 was the largest such array ever deployed by the Buoy Project at the Woods Hole Oceanographic Institution, in terms both of number of moorings and of quantity of instruments. Logistic considerations forced departures from our usual methods of sea-going operations. In addition, long lead times on certain components of the moorings made it necessary to order gear before the adoption of final scientific specifications. This forced us to retain flexibility in the design. These factors all contributed to making the mooring operations for MODE-I somewhat different from our regular mooring operations.

\section{Basic Array Design}

An array of moorings was planned, centered on $28^{\circ} \mathrm{N}, 69^{\circ} 40^{\prime} \mathrm{W}$. The array was laid out in the form of a central mooring and three concentric circles, with the center mooring being a surface mooring (uninstrumented below the surface) and the rest of the intermediate type. ${ }^{1}$ The configuration of the array as planned is shown in Figure 4. The array was skewed counter-clockwise so that mooring \#8 was at the position of the MODE East site mooring. Mooring \#l was at the original MODE Center site. The distribution of instrumentation on the array as planned is shown in Table 1. Scientific background for the array is discussed in the MODE Executive Committee Plan. 9 The bottom topography was expected to be smooth over the western half of the array and rough in the eastern half.

\section{Logistic Considerations}

Estimates of the total weight and bulk of the mooring gear involved (including moorings to be handled in the site-D area $\left(39^{\circ} \mathrm{N} ., 70^{\circ} \mathrm{W}\right.$.) not part of MODE, but to be deployed on the same cruise) indicated that the entire array could not be deployed on a single leg of the cruise scheduled on R/V CHAIN. Primary consideration was bulk, particularly 


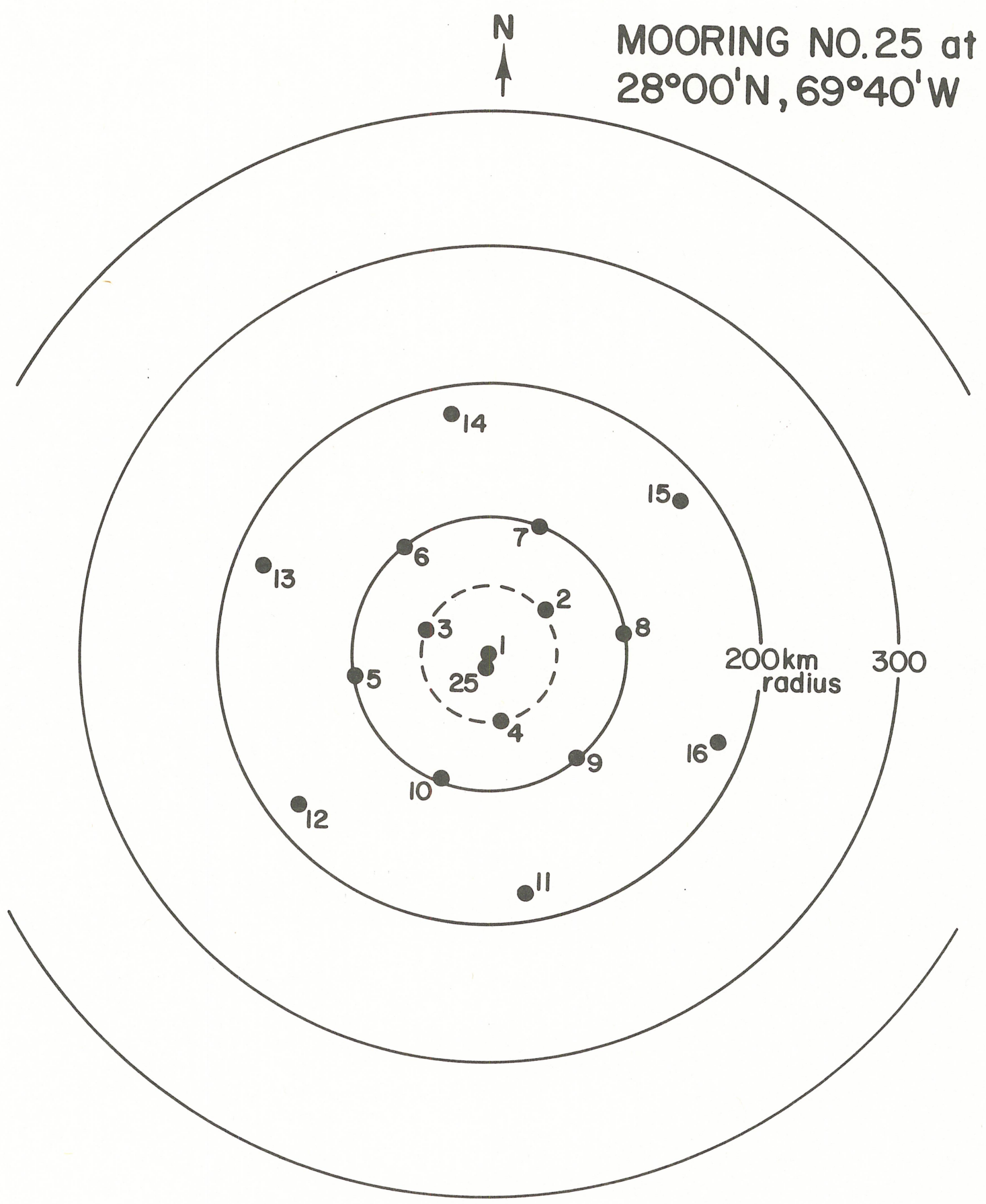

Figure 4

Positions of MODE-I Moorings to be Set by the Woods Hole Buoy Project 
Table 1

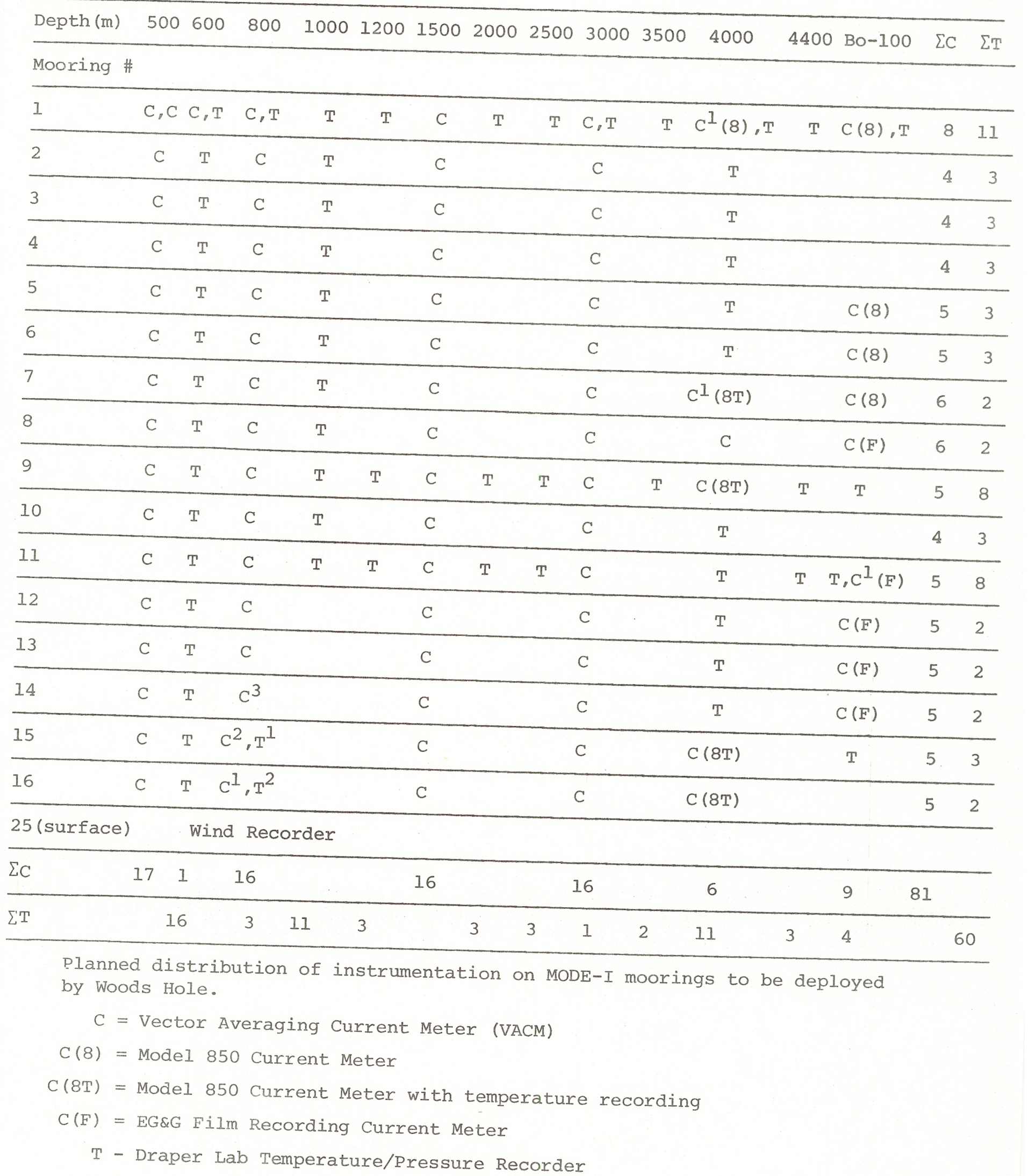


of the glass spheres used for buoyancy, but the weight of the anchors carried as deck cargo was also a factor. It was therefore decided to divide the cruise into two legs. Approximately half the MODE array would be carried on each leg. For the recovery, when the anchors would not be aboard and the wire could be jettisoned, it was felt that we could get by with one cruise leg with some crowding. The close. spacing of the moorings, at least in the inner rings, meant that not enough time would be available between moorings for preparation and rest for a single mooring crew, as was usually the case on our cruises. Therefore we decided to carry two complete mooring crews, each under an Assistant Chief Scientist, to carry out the actual launch and recovery operations. The two crews would alternate moorings.

\section{Mooring Design}

Due to a long lead time on the delivery of the factory cut and terminated wire shots, the design of the moorings had to be started before the instrument distribution as shown in Table 1 was available. Although a set of standard depths had been chosen, it was still not known whether a particular mooring would have an instrument at a particular depth. However, wire lengths had to be decided upon and ordered.

To avoid this difficulty a "universal mooring" was designed and standard wire shots chosen. This design would be adaptable for any mooring in the array when the instrument distributions were finally decided upon. The wire section of this mooring is shown in Figure 5. The section of the mooring below 2,000 meters (below the fishbite zone) 10,11 is Dacron. Since Dacron line can be measured and terminated in-house and on short notice it was not necessary to design the rest of the mooring at this stage.

The purpose of the "universal mooring" was to provide for any combination of instrumentation at standard depths while allowing us to order wire ahead of time. Allowance had to be made to maintain the 


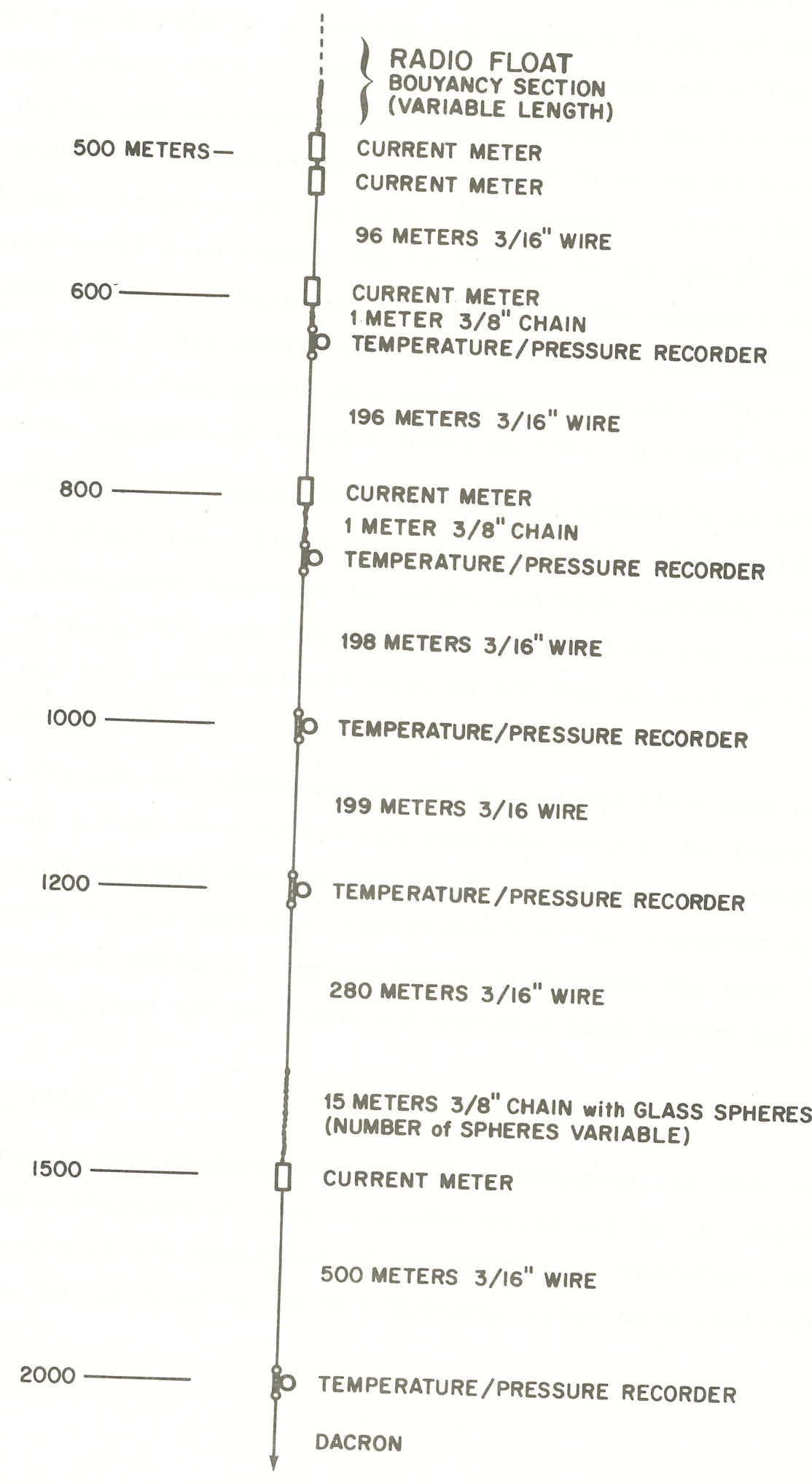

Figure 5

Wire Section of "Universal" MODE-I Mooring 
overall length of the mooring assembly if an instrument was missing from a particular spot on a mooring. A standard length of two meters for a current meter (VACM or EGEG Model 850) and one meter for the length of the Draper Lab pressure/temperature recorders was assumed. Provision was then made to insert one or two-meter sections of three-eighthsinch chain in place of "missing" instruments. Since the number of glass spheres would also change due to changes in the weight distribution, a maximum length of chain was specified for the buoyancy section at 1500 meter depth. This length was then kept fixed regardless of the number of spheres at that depth on a particular mooring. This contrasted with our usual approach of using a meter of chain for each sphere used.

This approach meant that we were not operating as efficiently as we could otherwise. Chain would be used where wire would ordinarily do, with a consequent increase in weight and more buoyancy needed. However, this approach did give the necessary flexibility and enabled us to order our wire shots without waiting for the scientific specifications to be completed.

A further consideration in the design was that when both a current meter and a temperature/pressure recorder were to be inserted at a particular location the two instruments should be separated by one meter to attempt to insulate the temperature/pressure recorder from any current-meter motions. Three-eighths inch chain was used for this purpose above 2,000 meters depth and one-half inch Dacron below.

\section{Design Inputs}

Engineering measurements on MODE-O intermediate moorings indicated that these moorings allowed excessive variation in the depths of the instruments at the upper end of the moorings. Therefore, more effort was made to optimize the MODE-I moorings using more realistic design inputs. 
A current profile was needed for the basic design studies on the moorings. An idealized profile was constructed from actual at-sea data supplied by William J. Schmitz, Jr.12 This profile was selected to approximate the actual profile as closely as possible while meeting the input requirements of the computer program. The operational or design profile is shown in Figure 6.

A computer program, written by Donald A. Moller and Susan S. Tapscott, which predicts mooring performance and calculates tensions and back-up recovery, was used both for the design phase and operationally at sea for final calculations.

A series of computer runs was made to produce a rough design of mooring \#2, using the design profile. This mooring was to be identical to moorings 3, 4, and 10, and was fairly representative of the array. By this time, the instrument positions on the moorings had been tentatively assigned. Once the rough design was complete (Figure 7) a series of runs was made to compare the performance of the mooring at various profiles. The results are listed in Table 2. While these profiles are difficult to interpret in terms of the real ocean, they provide a measure of comparison to look at the degraded performance of the mooring in higher currents, in terms of the dip of the top of the mooring.

A further series of runs was made to examine the effect of increasing the number of glass spheres at the top of the mooring. The design profile and the "30/15" profile were used for comparison. The dip is going from the lower to the higher profile is shown for various numbers of spheres at the top of the mooring in Table 3. Also shown is the tension at the anchor. If anchor tension is too high the larger anchor necessary will overstress the Dacron mooring line during launch. 


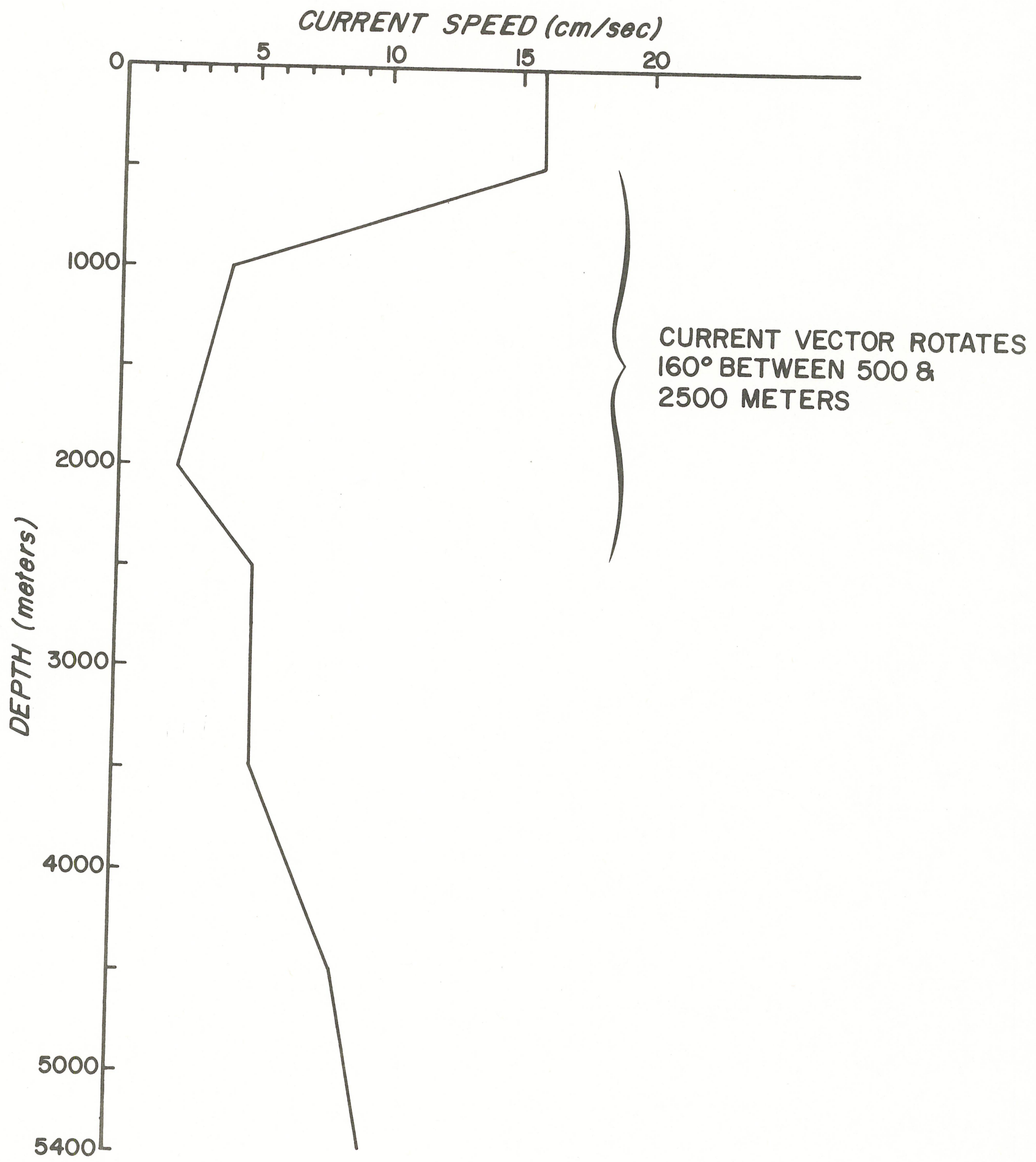

Figure 6

MODE-I Design Current Profile 


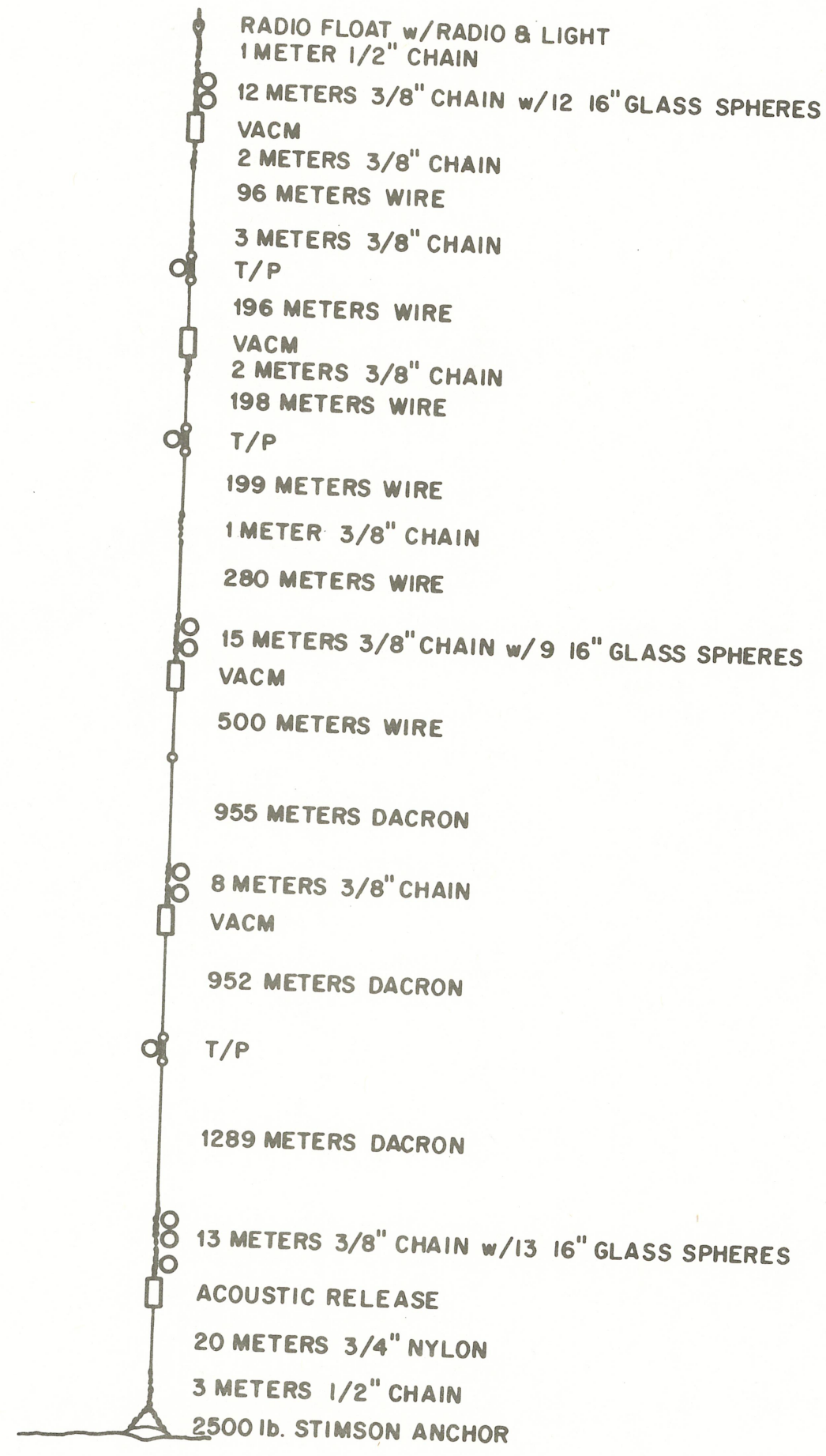

Figure 7

Rough Design of Mooring \#2 
Table 2

Performance of rough design of Mooring 2

in various current profiles

Profile

No Current

Design

$10 / 5$

$15 / 10$

$20 / 10$

$30 / 15$
Dip of Top of Mooring (m)

$-2$

0

0

15

26

102
Max. Tilt (Deg.)

0

1.3

1.9

3.8

5.7

9.5

"10/5" profile means $10 / \mathrm{cm} / \mathrm{sec}$ at surface decreasing linearly to correspondingly 
Table 3

Effect of Varying Number of Glass Spheres at Top of Mooring 2, Rough Design

Nunber of Spheres at Top

12

14

16

18

20
Total Excursion of Top (m)

102

95

76

75

75
Tension at Anchor (1b.)

916

955

1,095

1,184

1,274

"Total Excursion at Top" represents the total change in depth of the top of the mooring while the profile changes from the "standard" design profile to a profile varying linearly from $30 \mathrm{~cm} / \mathrm{sec}$ at the surface to $15 \mathrm{~cm} / \mathrm{sec}$ at the bottom. 


\section{Final Mooring Designs}

Using the Mooring \#2 basic design, the rest of the moorings were designed by adding or subtracting glass spheres at various locations depending upon the addition or elimination of instruments at various locations. A computer run was then made to adjust the buoyancy to insure that sufficient back-up recovery ${ }^{2}$ was on the mooring and to adjust the Dacron shots to put all instruments at their nominal depths. The design profile was used and the instruments adjusted to within five meters of their nominal depths at this profile. In each case it was assumed that a Dacron shot near the bottom of each mooring would be adjusted at sea after the actual depth had been measured.

All of the above calculations were made using sixteen-inch (Corning) glass spheres for convenience. The final adjustment to all moorings was to assign seventeen-inch (Benthos) spheres to some of the moorings, based on our inventory, and to recalculate the buoyancy sections for those moorings.

\section{Deployment}

A chronological description of the deployment field operations on CHAIN Cruise 112, Legs I and II, will be found in the cruise report. 8 Some changes were made in the moorings before setting to adjust to availability of instruments or equipment and to respond to specific problems. Table 4 shows the actual distribution of instruments on the moorings as set.

No problems were encountered in mooring launches until station 487 (MODE mooring \#13). This mooring was launched in the usual manner, the top end first and the anchor being dropped last over the intended mooring position. The transponder in the acoustic release was being routinely tracked to the bottom. However, at about 3,000 meters depth the range of the transponder began to decrease. The release was coming back up. The mooring was recovered and it was found that the twentymeter shot of nylon just below the release had chafed or been cut. It 
Table 4

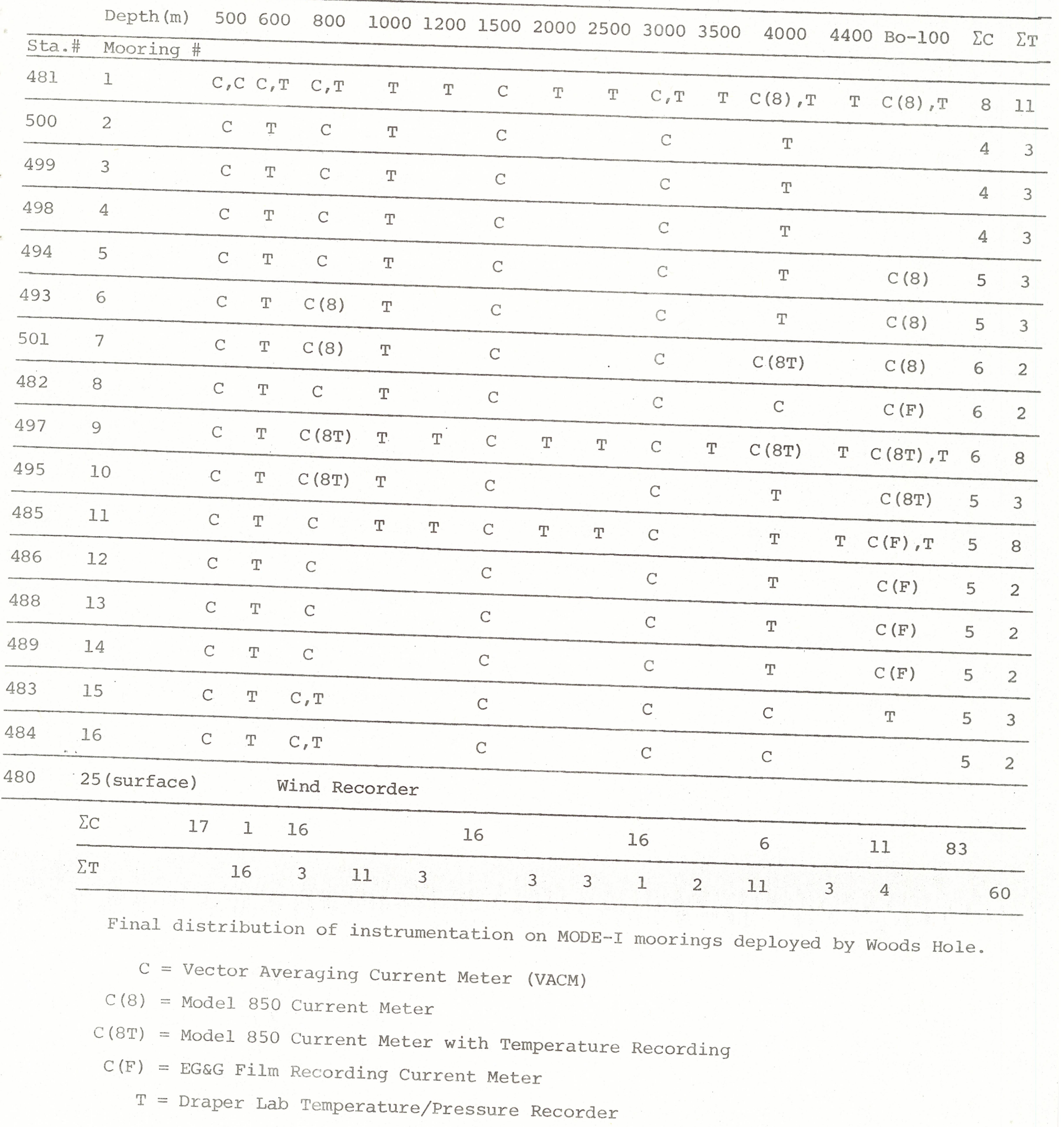


was assumed that it had somehow wrapped around the release. Since this problem had never occurred before it was assumed to be a fluke and the mooring was reset with a new anchor with no modifications. However, on Leg II Station 496 (MODE mooring \#9) was aborted in an almost identical manner and had to be reset. This time, and on all subsequent moorings, a five-meter piece of one-half inch chain was inserted below the release to prevent a recurrence.

On each deployment a brief survey of the bottom was made and a site picked out. The final adjustment was then made by cutting a Dacron shot for the lower section of the mooring, based on on-board computer runs. After setting a final run was made calculating depths of instruments including any last-minute changes. The nominal depths recorded were those for a zero current profile and are therefore slightly shallower than the nominal depths used in the design of the mooring where the design profile was used.

All moorings were set within two nautical miles of the preselected positions. No difficulties were encountered in this respect, even over the rough bottom of the eastern half of the site. Detailed drawings of each mooring as set are included in an appendix.

Hazards

On April 26 the CHAIN was towing a temperature-profiling fish on the trawl wire near station 500. Due to a navigation error, the fish was fouled in the mooring at a depth of about 750 meters. Attempts were made to release the mooring but failed, although the transponder was operating. (It was later determined that the wrong release code had been radioed to the ship.) After about four hours, the wire came free. The extent of damage to the mooring was unknown, although no debris came to the surface. It was decided to leave the mooring in place. Upon recovery in June, very little damage was found. The mooring wire was stripped of its jacket for about eight meters at a depth of about 600 meters. 
Various ships in the MODE operation had been using the central surface mooring (Station 480) as a reference marker. On May 23, the CHAIN was doing profiling operations near this mooring in earlymorning darkness. As the ship approached the mooring at a distance of about 10 miles a very strong radar return was noticed from the mooring position. Upon closer approach, a ship could be seen at the mooring location, apparently hove to, with running lights off and deck lights on. When the CHAIN got to within about five miles, the unknown vessel put out her deck lights, turned on running lights, and steamed away. The buoy was no longer on station. The vessel did not respond to radio calls and could not be overtaken by the CHAIN. The surface buoy had either been stolen or the unknown vessel had fouled the mooring and stopped to clear away the gear. ${ }^{14}$ Since the mooring was well lit we assume it was stolen. No further trace of Station 480 was ever found.

\section{Recovery Operations}

Leg VI of CHAIN Cruise 112 left from Bermuda for recovery of the set by the University of Rhode Island were recovered before proceeding north for other work. No trace was found of Station 480, the apparentlystolen surface mooring. All moorings came aboard in good order with only minor difficulties.

\section{Mooring Performance}

Analysis of pressure-recorder records after recovery indicated two shortcomings in the performance of the intermediate moorings used in the MODE-I array. The first was a large error in the mean depth of instruments, as compared with the nominal depths specified in the designs. This was apparently due to a combination of difficulties in measuring the Dacron in the lab accurately, uncertainties in prediction of the stretch of the Dacron, and not taking into account the length of connection hardware, such as shackles, when computing nominal depths. At 
the top, where this effect is greatest, this error averaged eightythree meters for all moorings and ranged from forty-four meters to 112 meters. All errors put the instruments shallower than intended. The second problem was larger variations than expected in the depths of instruments. These variations ranged up to 127 meters at the top of some moorings, and averaged 26 meters. In all cases these variations were due to the occurrence of higher current profiles than anticipated. When the measured profiles were fed into our computer program, the predicted depth variations matched well with the measured values. 16 


\section{Post-MODE}

After the completion of the MODE-I array a series of sitemaintenance moorings was deployed to continue monitoring of the MODE area until the commencement of the moored arrays for POLYMODE, the follow-on program to MODE. The original MODE East and MODE Center sites were used. All the moorings were intermediates and, with the one exception noted below, all followed essentially the same design criteria as used in MODE-I.

\section{Site-Maintenance Moorings}

The first pair of moorings, Stations 502 and 503, were deployed on CHAIN 112, Leg VI during the recovery of the MODE-I array. Each carried three current meters and no other instrumentation. On KNORR Cruise 36, December, 1973, these moorings were recovered. ${ }^{17}$ At the same time a pair of replacement moorings was deployed.

The next set of site-maintenance moorings were stations 521 and 522. Each had three current meters and nine temperature/pressure recorders. They were recovered in April, 1975 on KNORR 39. ${ }^{18}$

The final set of moorings for the MODE program was deployed on KNORR 39 and recovered in July, 1974 on CHAIN 116. ${ }^{19}$ Stations 538 and 540 carried three current meters and nine temperature/pressure recorders each.

\section{All-Wire Mooring}

In response to the problems uncovered during analysis of the pressure data from MODE-I, and in anticipation of mooring needs in the up-Coming POLYMODE program, an effort was made to design an intermediate mooring on which the instruments could be deployed with greater accuracy in their mean depths, and with less variation in the depths. Computer studies showed that the design of the compound intermediate mooring, with Dacron below 2,000 meters, would not meet the 
desired specifications, since there is a limit to the amount of buoyancy that can be put on a mooring, determined by the permissible working strain on the Dacron. After several other candidate mooring configurations had been examined by computer comparison, an all-wire mooring was designed which came closest to meeting the desired performance of ten meters static error and ten meters variation in the specified current profile at the top of the mooring.

In July, 1974 Station 538 was set in the all-wire configuration. One uncertainty was whether, when the anchor bottomed out, the gear would overshoot in depth before settling out causing a slack condition in the wire and possible kink formation. The possibility of putting in a short section of nylon above the back-up recovery section to absorb this overshoot was considered, but eventually decided against. Any synthetic sections, due to unpredictability in the stretch characteristics, would contribute to the static-depth error. For this mooring, set in a flat area (MODE Center) where the depth was accurately known beforehand, no adjustments had to be made in the field for the depth.

The mooring was carefully inspected during and after recovery. There was no evidence of kinking other than that which usually occurs during routine recovery operations.

Analysis of the pressure records from this mooring showed that the static error in depth was thirty-six meters. Since this mooring was designed the computer program used has been re-written to include wire stretch, more accurate instrument lengths, and the length of connection hardware. Using this new program it was found that these factors account for all but seven meters of the static-depth error. ${ }^{16}$.

The maximum dip of the top of the mooring was eight meters. This occurred in a current profile slightly worse than the design profile. It appears that this type of mooring is capable of meeting the desired performance specifications for future work in POLYMODE. 
Summary

During a period spanning almost three years the Buoy Project at the Woods Hole Oceanographic Institution successfully deployed a total of forty-four moorings in connection with the MODE program. In addition three moorings were aborted during launch without loss of equipment. Of those successfully set, nine were surface moorings and thirty-five were intermediates. All of the intermediates were recovered. One of the surface moorings was lost and one stolen.

Included on the moorings set were four wind recorders, 153 current meters, ninety-five temperature/pressure recorders, and twenty-six engineering instruments. Total instrumentation lost or stolen was two wind recorders, three current meters, and three tensiometers. Additional gear lost or stolen included two anchor releases, seventy-seven glass spheres, and two surface floats.

A minimum of two moorings was maintained at the site for the entire period from October, 1971 to July, 1974. The maximum number of moorings out at one time was seventeen, during the MODE-I experiment from March to June, 1973. A total of 4,588 mooring days at sea resulted (not including the mooring stolen) for an average deployment time of 109 days.

\section{Acknowledgments}

A great many people contributed to the work done by the Operations Group of the Buoy Project during MODE. We could not have carried out our share of this program without the help and cooperation of the ships' crews and officers, the Institution's shop personnel, and, of course, the scientists, engineers, and data processors of the Buoy Project. Most of all, I would like to thank the members of the Operations Group themselves for the patience, energy, and ingenuity they have displayed during MODE.

Work described in this report was supported by the Office of Naval Research under Contract N00014-74-C-0262 NR 083-004, and the National Science Foundation, Office for the International Decade of Ocean Exploration, under Grant GX 29054. 


\section{References}

1. Heinmiller, Robert $\mathrm{H}$. and Robert G. Walden, Details of Woods Hole Moorings, WHOI Ref. 73-71 (unpublished manuscript).

2. Heinmiller, Robert H., Jr. and Henri O. Berteaux, Back-Up Recovery of Deep Sea Moorings, M.T.S. Jour., V. 7, No. 3.

3. Moller, Donald A., Cruise Report ATLANTIS II 63, WHOI Ref. 74-43 (unpublished manuscript) .

4. Heinmiller, R. H., Cruise Report CHAIN 101, WHOI Ref. 72-48 (unpublished manuscript).

5. Moller, Donald A., Cruise Report CHAIN 103, WHOI Ref. 74-41 (unpublished manuscript).

6. Gifford, James E., Cruise Report KNORR 26, WHOI Ref. 74-104 (unpublished manuscript).

7. Gifford, James E., Cruise Report CHAIN 107, WHOI Ref. 73-4 (unpublished manuscript).

8. Heinmiller, R., Cruise Report CHAIN 112, Legs I and II, WHOI Ref. 73-51 (unpublished manuscript).

9. The MODE-I Scientific Council, MODE-I The Program and the Plan, 1973.

10. Turner, Harry J., Jr., and Bryce Prindle, The Vertical Distribution of Fishbites on Deep-Sea Mooring Lines In the Vicinity of Bermuda, WHOI Ref. 67-58 (unpublished manuscript).

11. Stimson, Paul B., and Bryce Prindle, Armoring of Synthetic-Fiber Deep-Sea Mooring Lines Against Fishbite, WHOI Ref. 72-75 (unpublished manuscript).

12. Schmitz, William J., Jr., Personal communication, October, 1972.

13. Katz, Eli, Third MODE Leg of R/V CHAIN, MODE Hot-Line News, No. 31 , 11 May 1973.

14. Wunsch, Carl, Fourth MODE Leg of R/V CHAIN, MODE Hot-Line News, No. 33,8 June 1973. 
15. Heinmiller, R. H., Cruise Report CHAIN 112, Leg VI, WHOI Ref. 73-50 (unpublished manuscript).

16. Clay, Peter R., personal communication, March, 1975.

17. Moller, Donald A., Cruise Report KNORR 34 and KNORR 36, WHOI Ref. 74-94 (unpublished manuscript).

18. Tupper, George H., Cruise Report KNORR 39, WHOI Ref. 74-42 (unpublished manuscript).

19. Heinmiller, R. H., Cruise Report CHAIN 116, WHOI Ref. 74-77 (unpublished manuscript). 


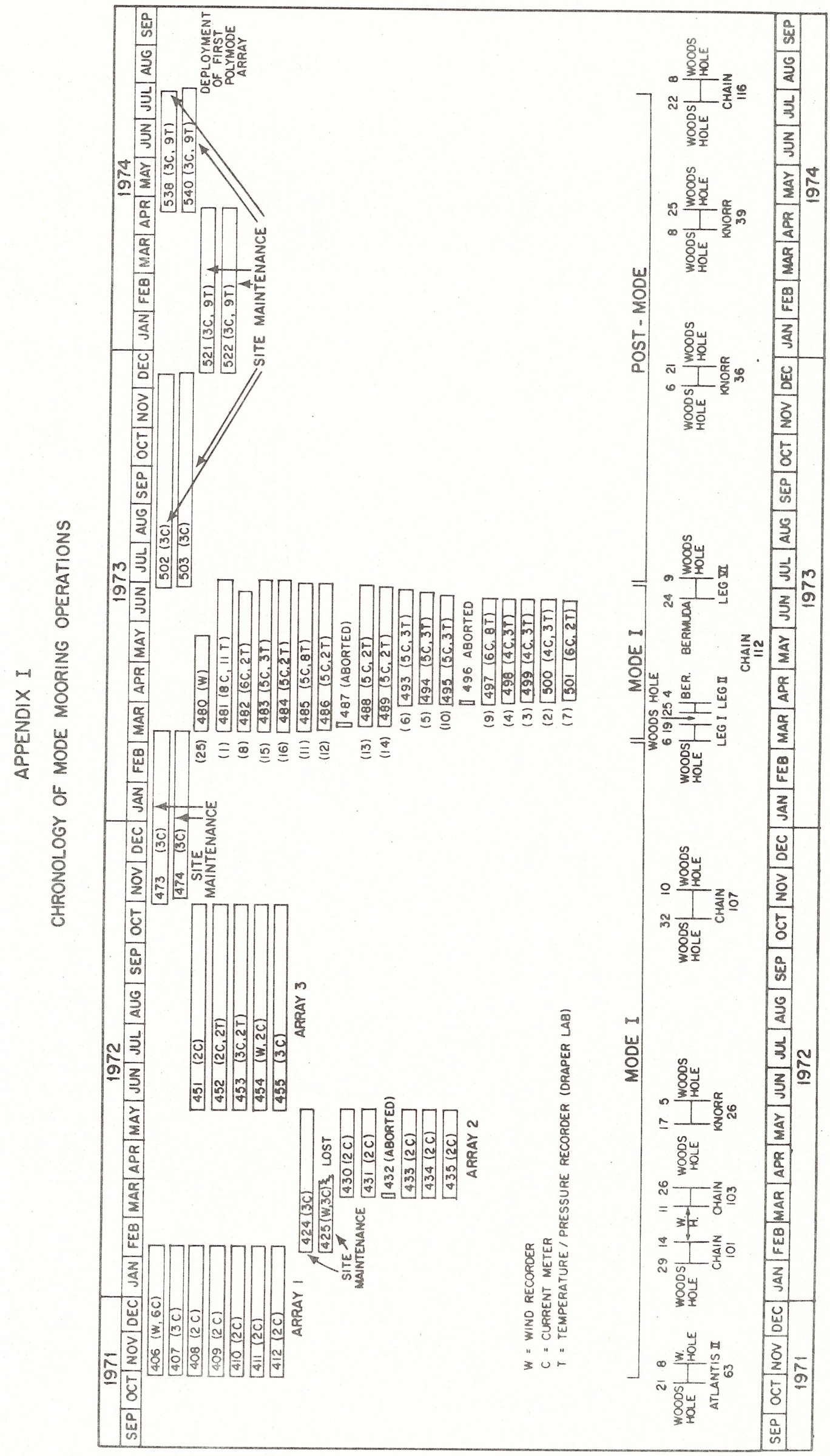




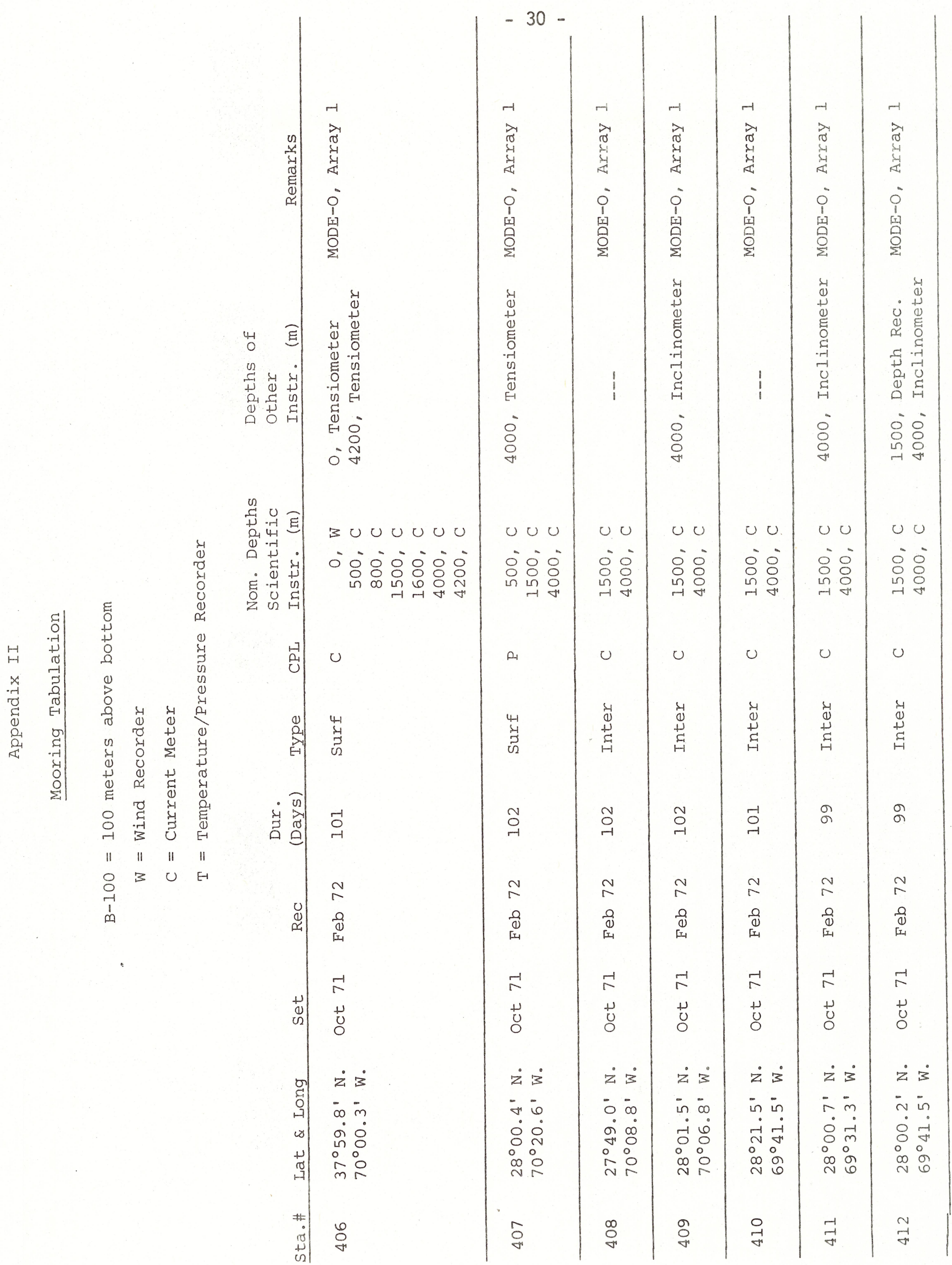




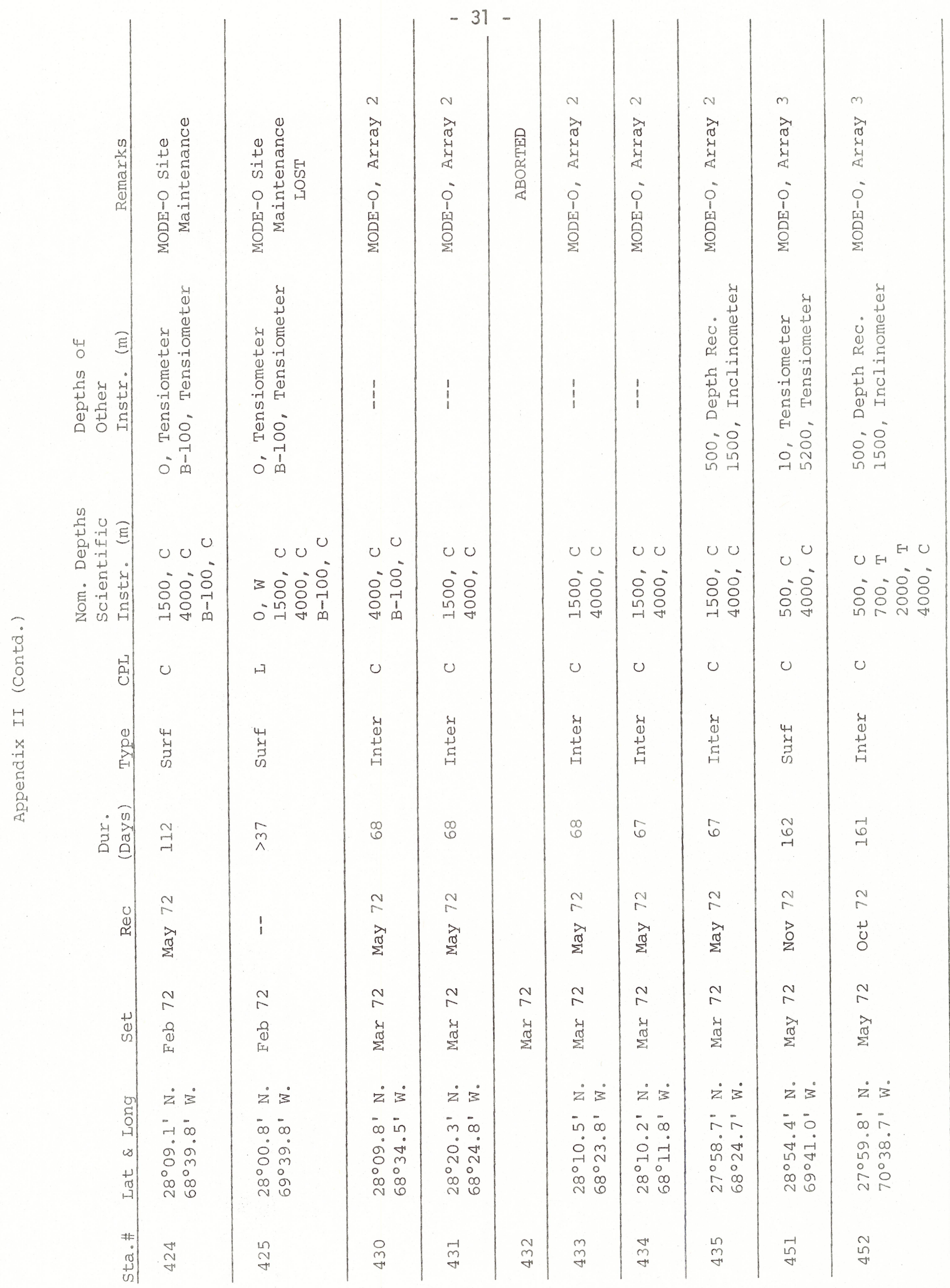




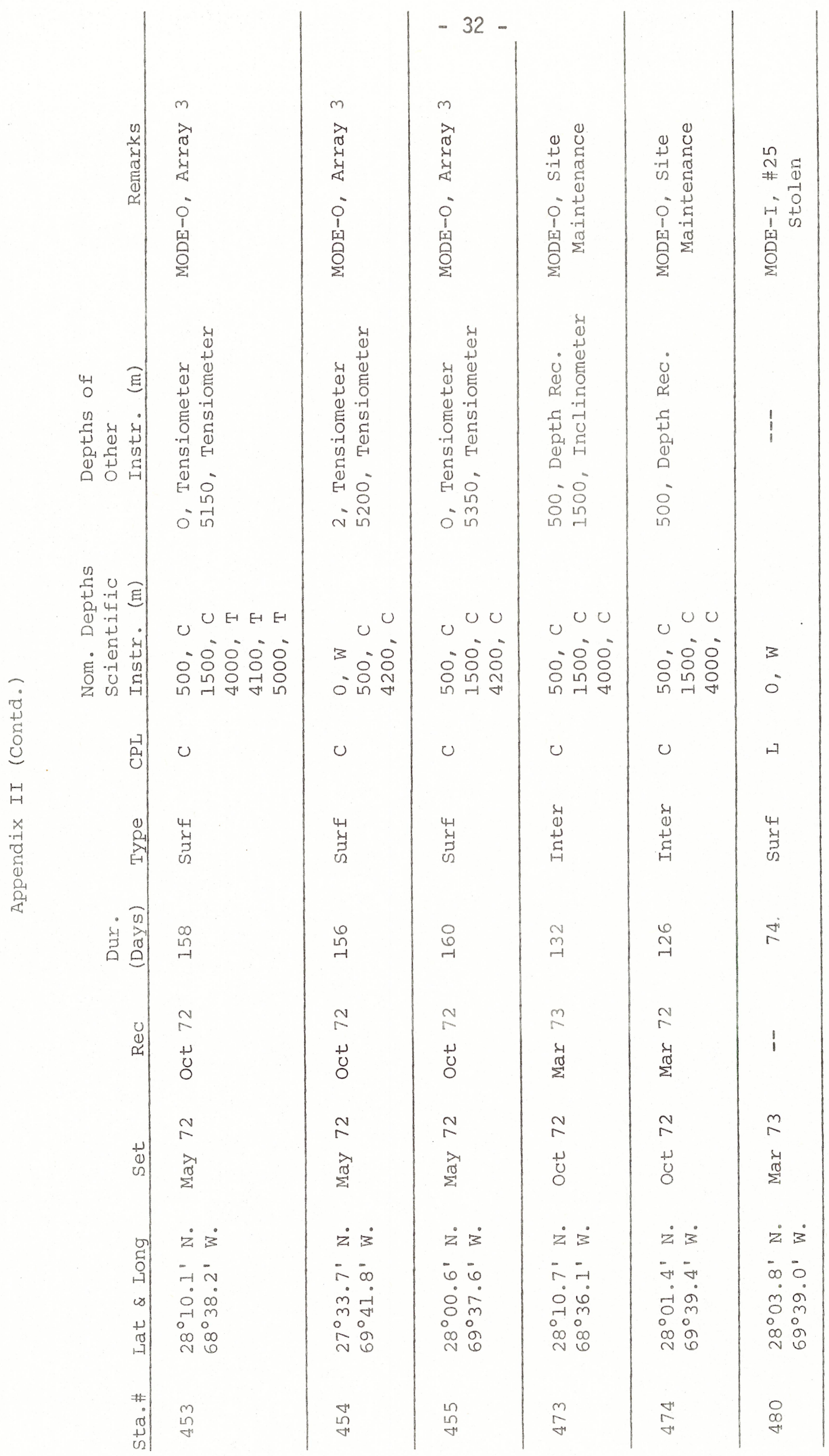




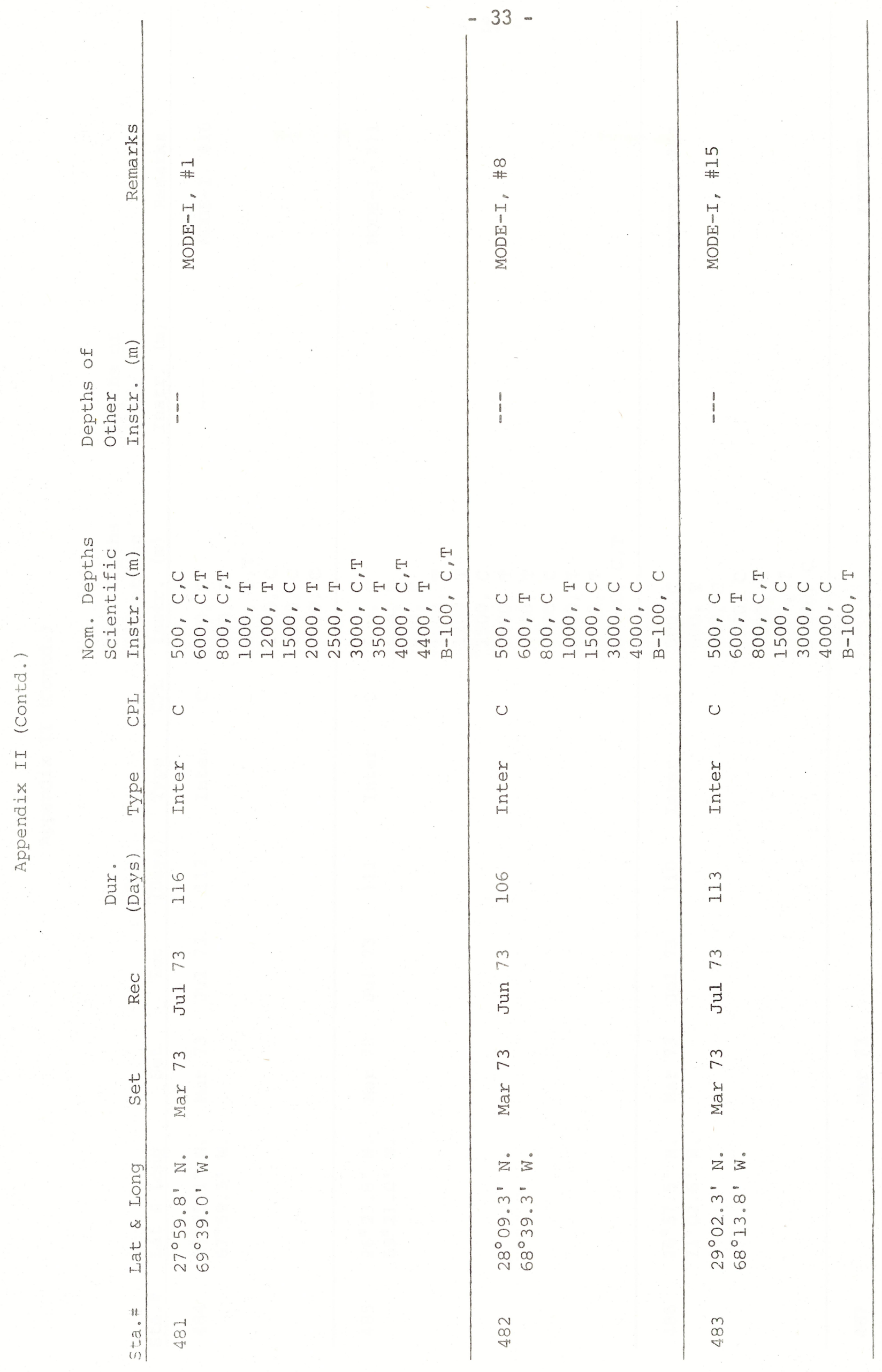




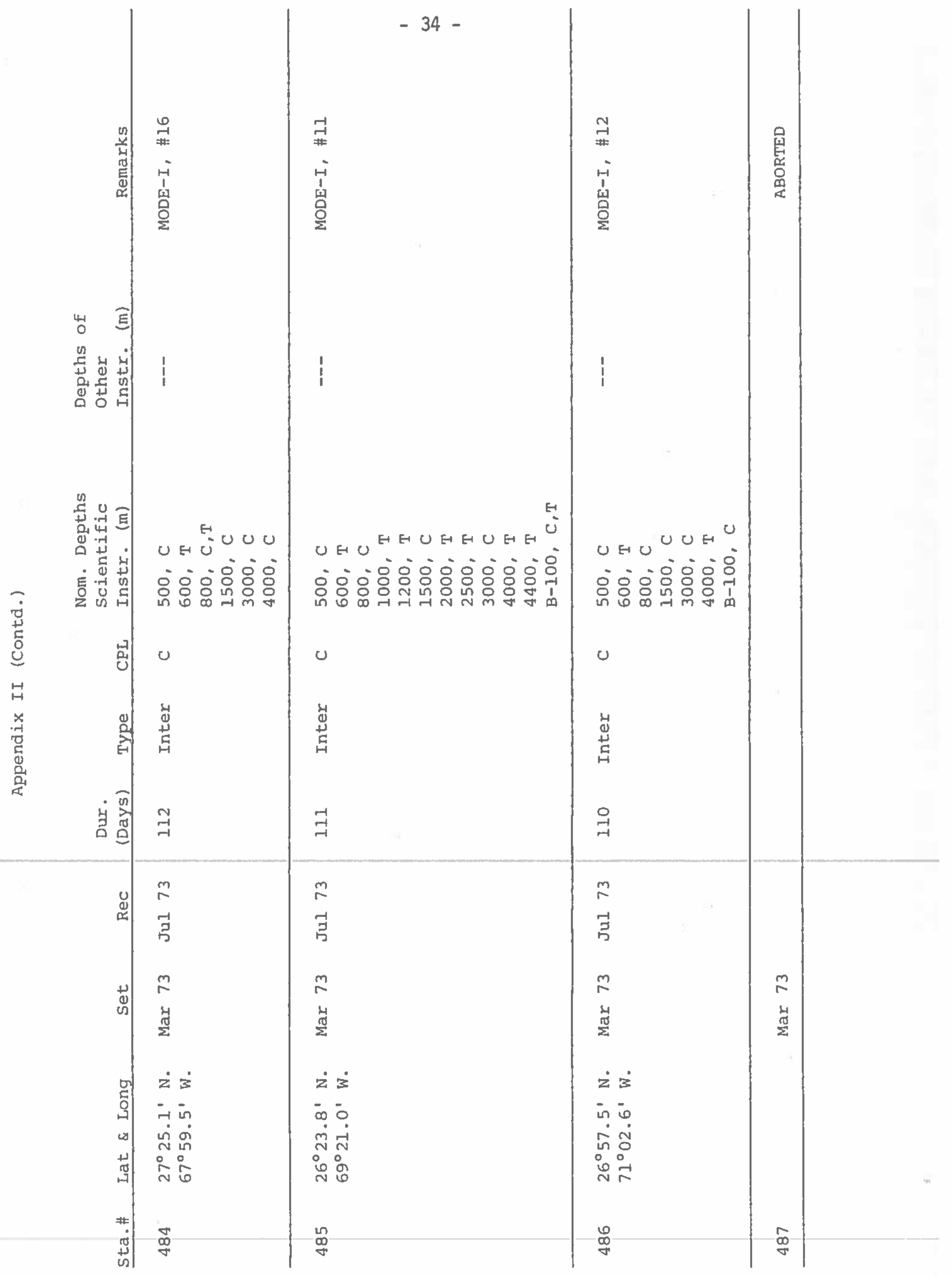




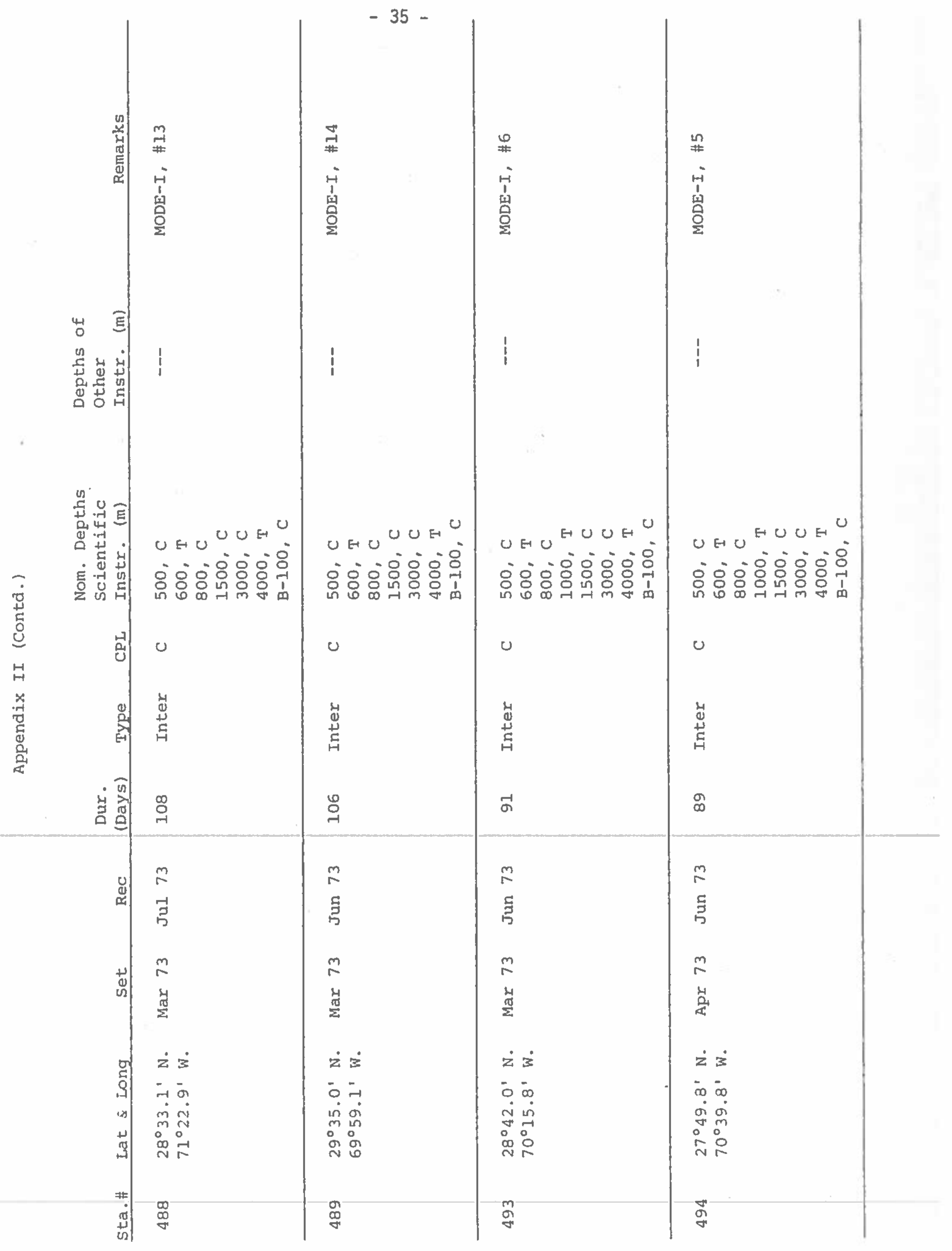




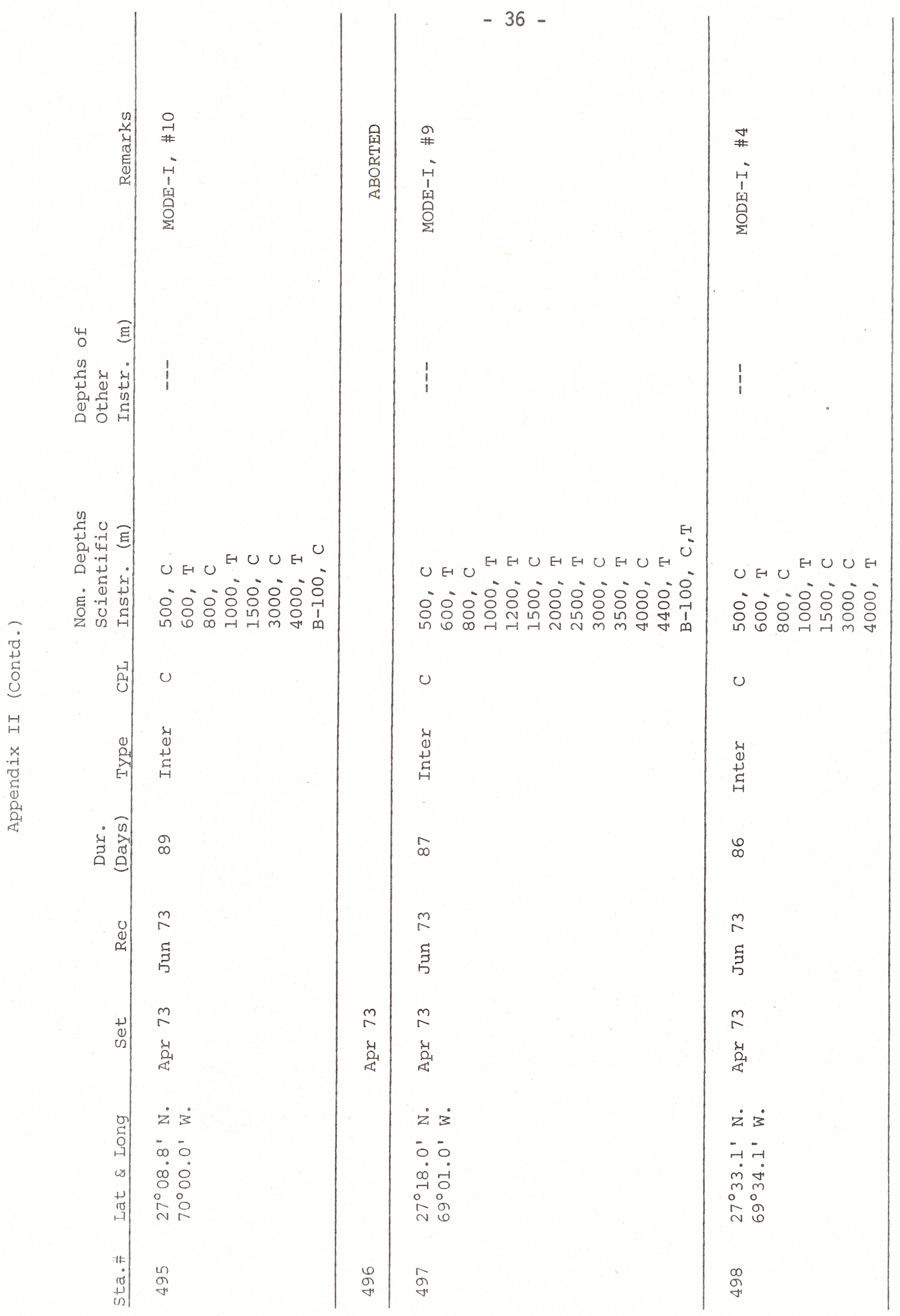




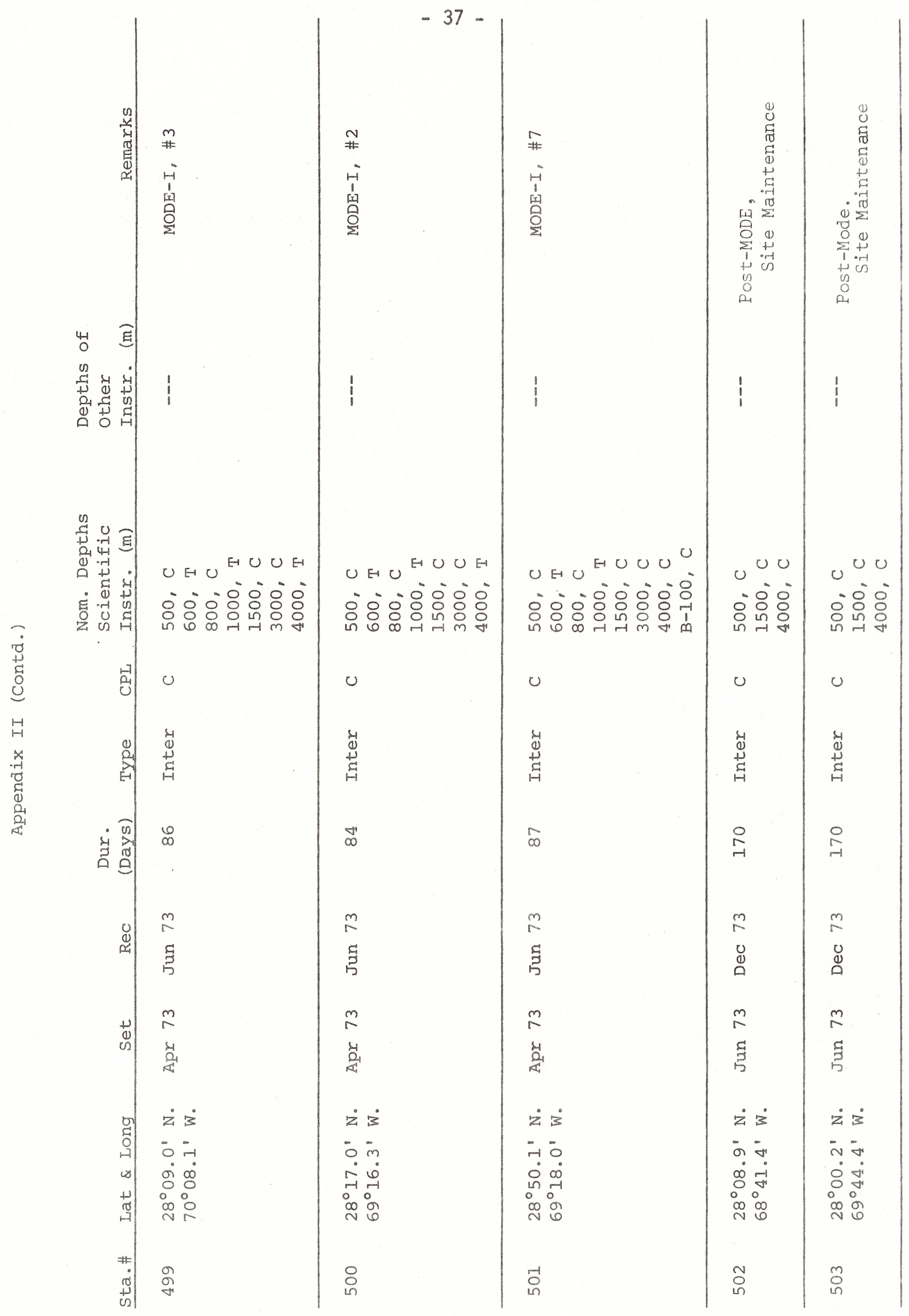




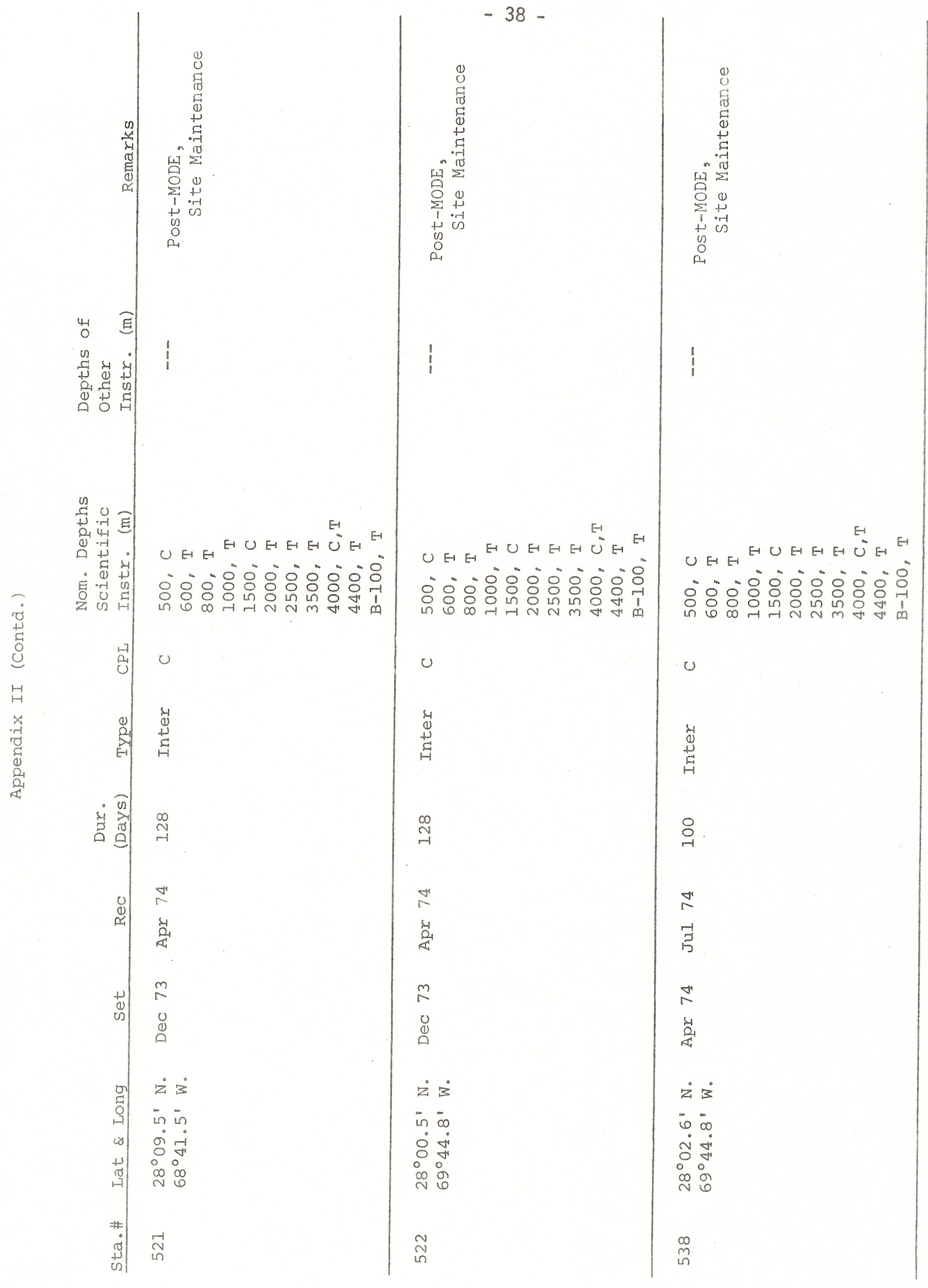




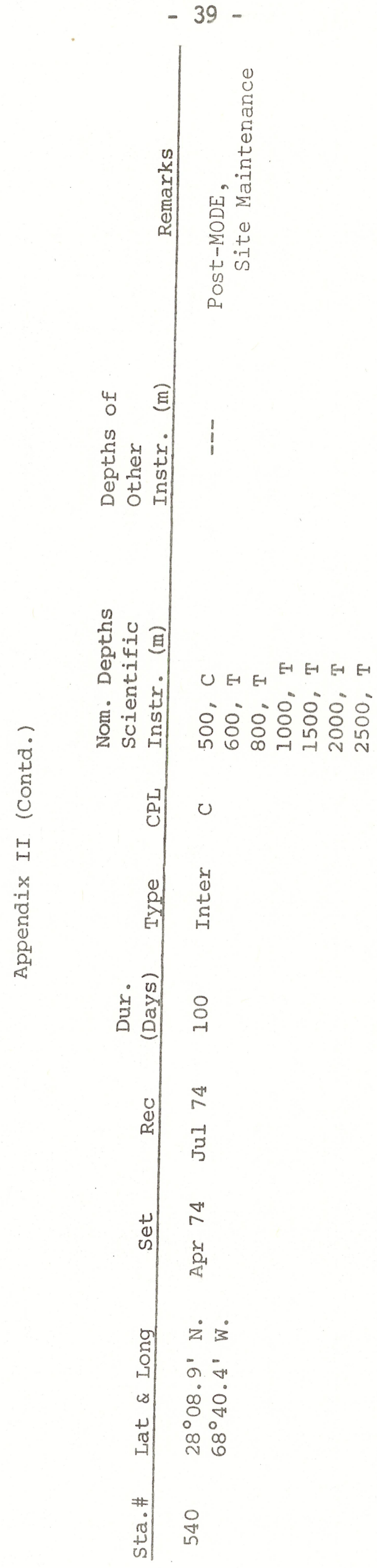


Appendix III

Mooring Drawings

$\begin{array}{llll}\text { Stations } & 406 & 452 & 490 \\ 407 & 453 & 493 \\ 408 & 454 & 494 \\ 409 & 455 & 495 \\ 410 & 473 & 496 \\ 411 & 474 & 498 \\ 412 & 480 & 499 \\ 424 & 481 & 500 \\ 425 & 482 & 501 \\ 430 & 483 & 502 \\ 431 & 484 & 503 \\ 433 & 485 & 521 \\ 434 & 486 & 522 \\ 435 & 488 & 538 \\ 451 & 489 & 540\end{array}$




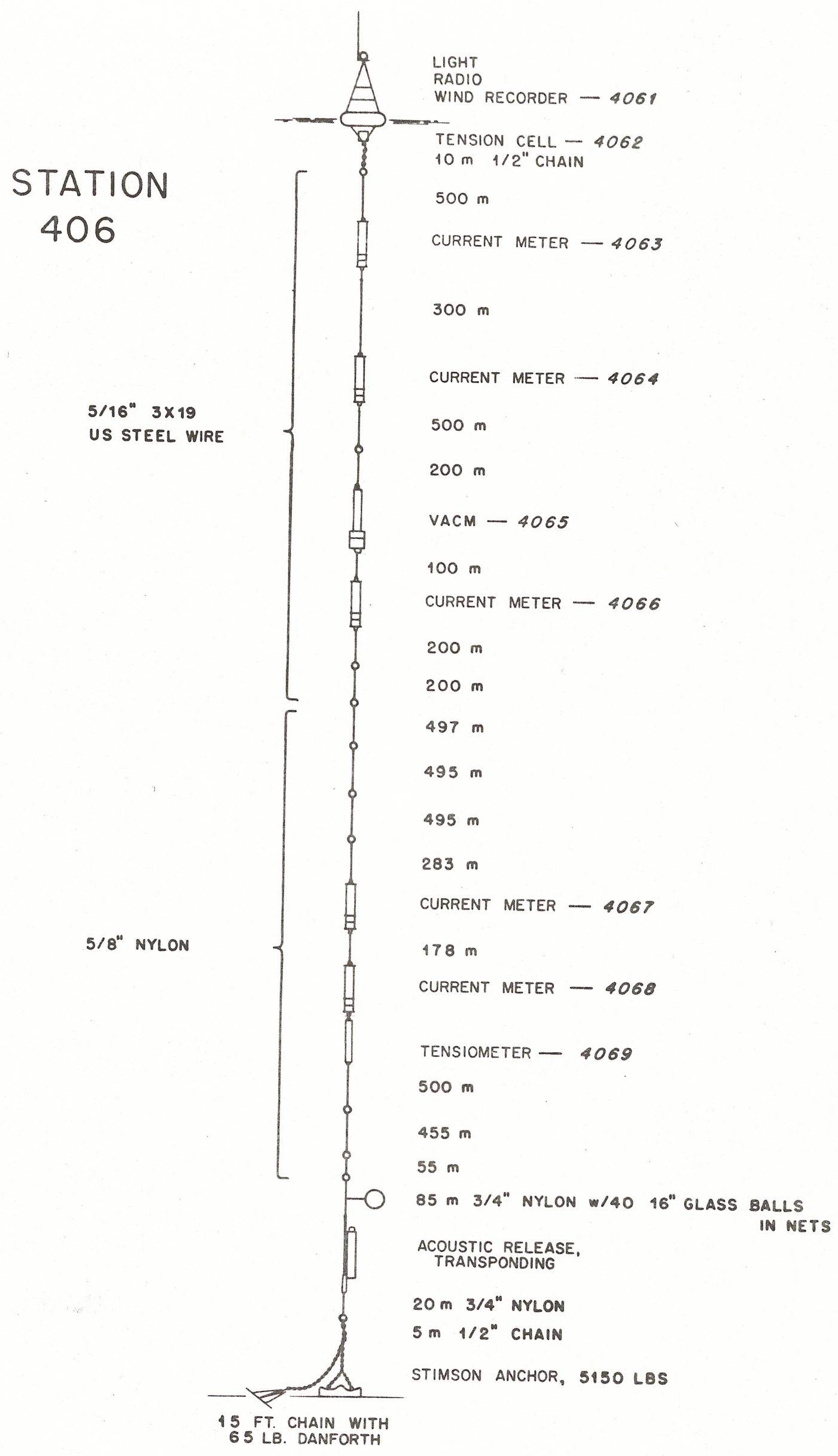




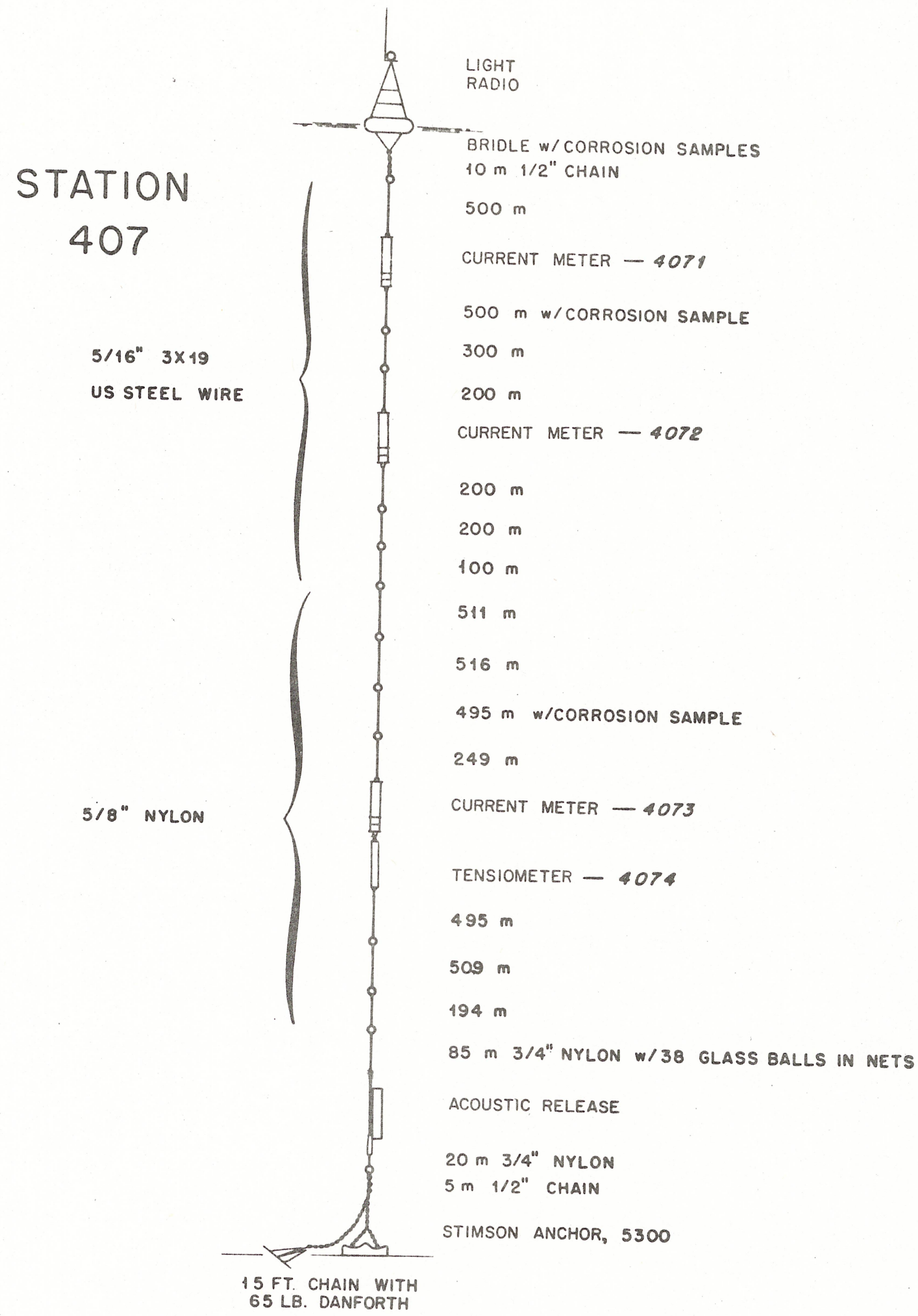




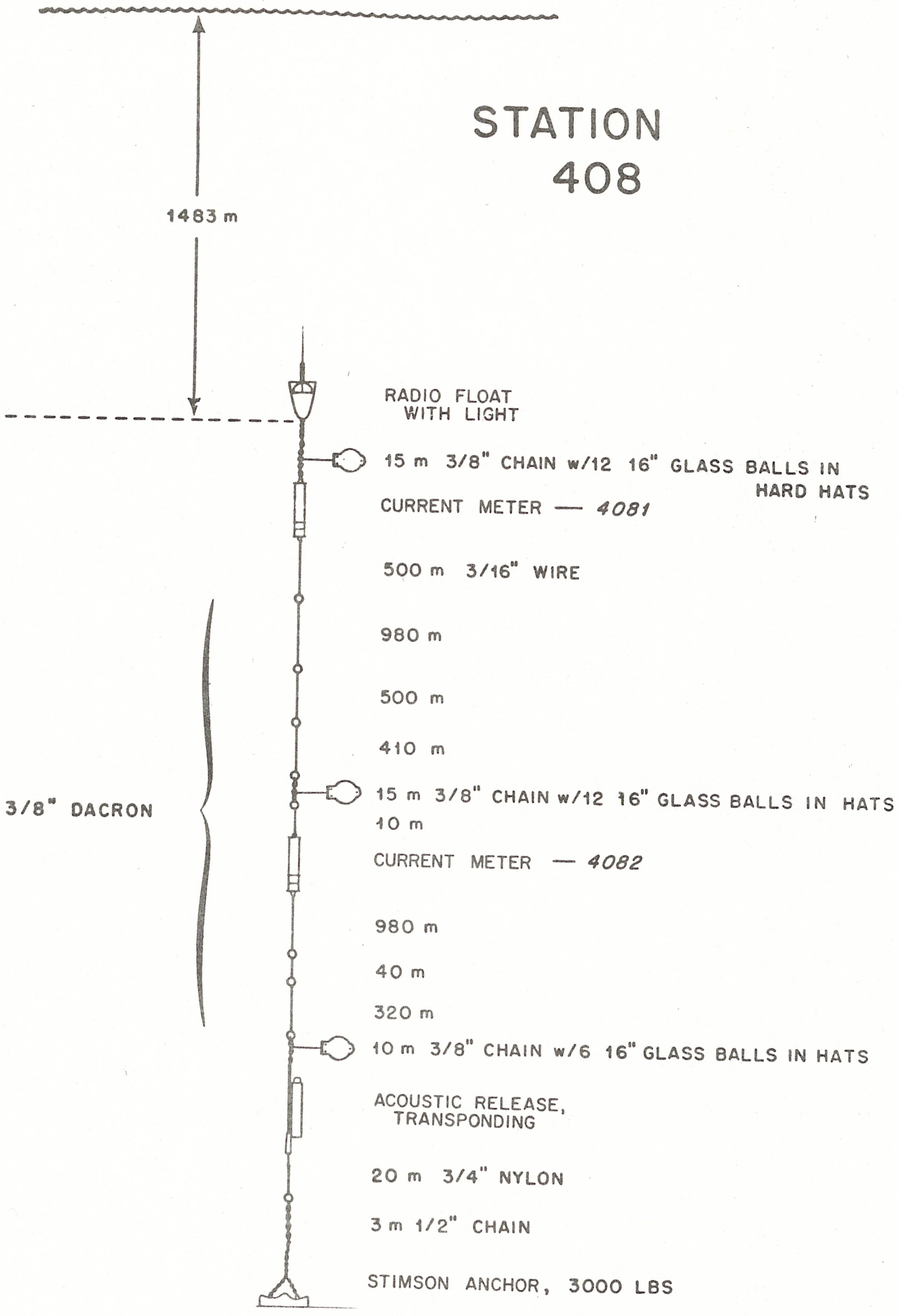




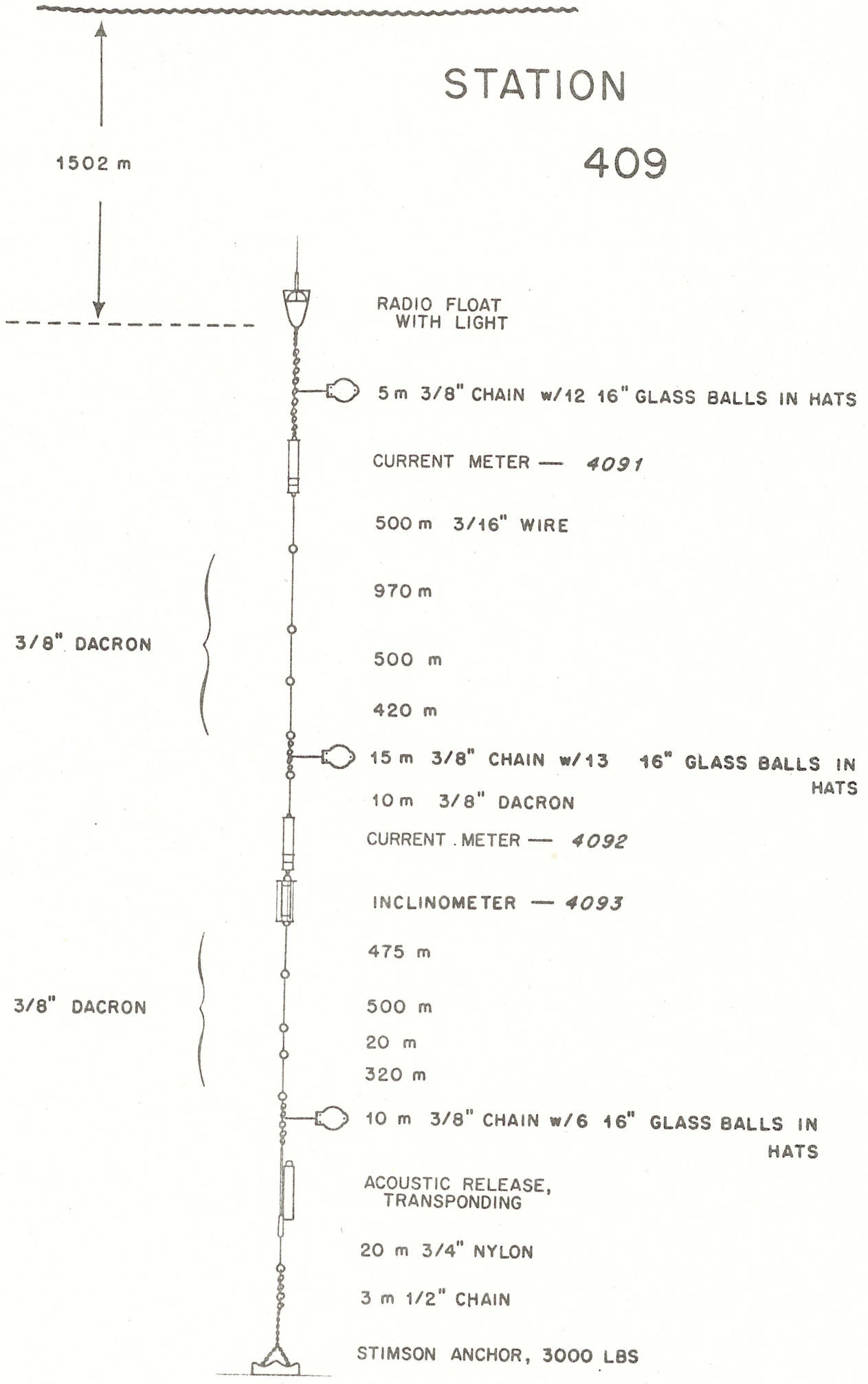




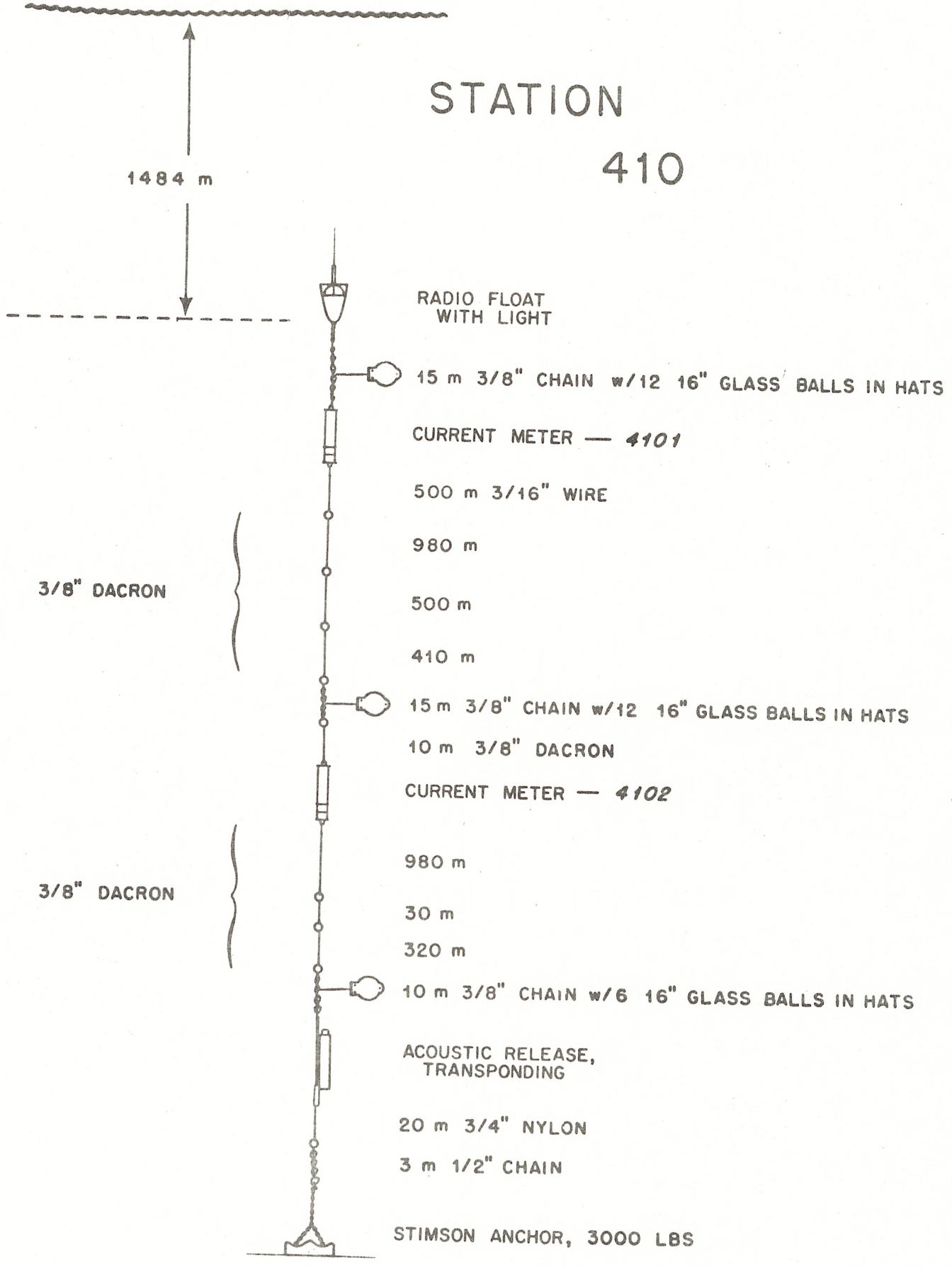




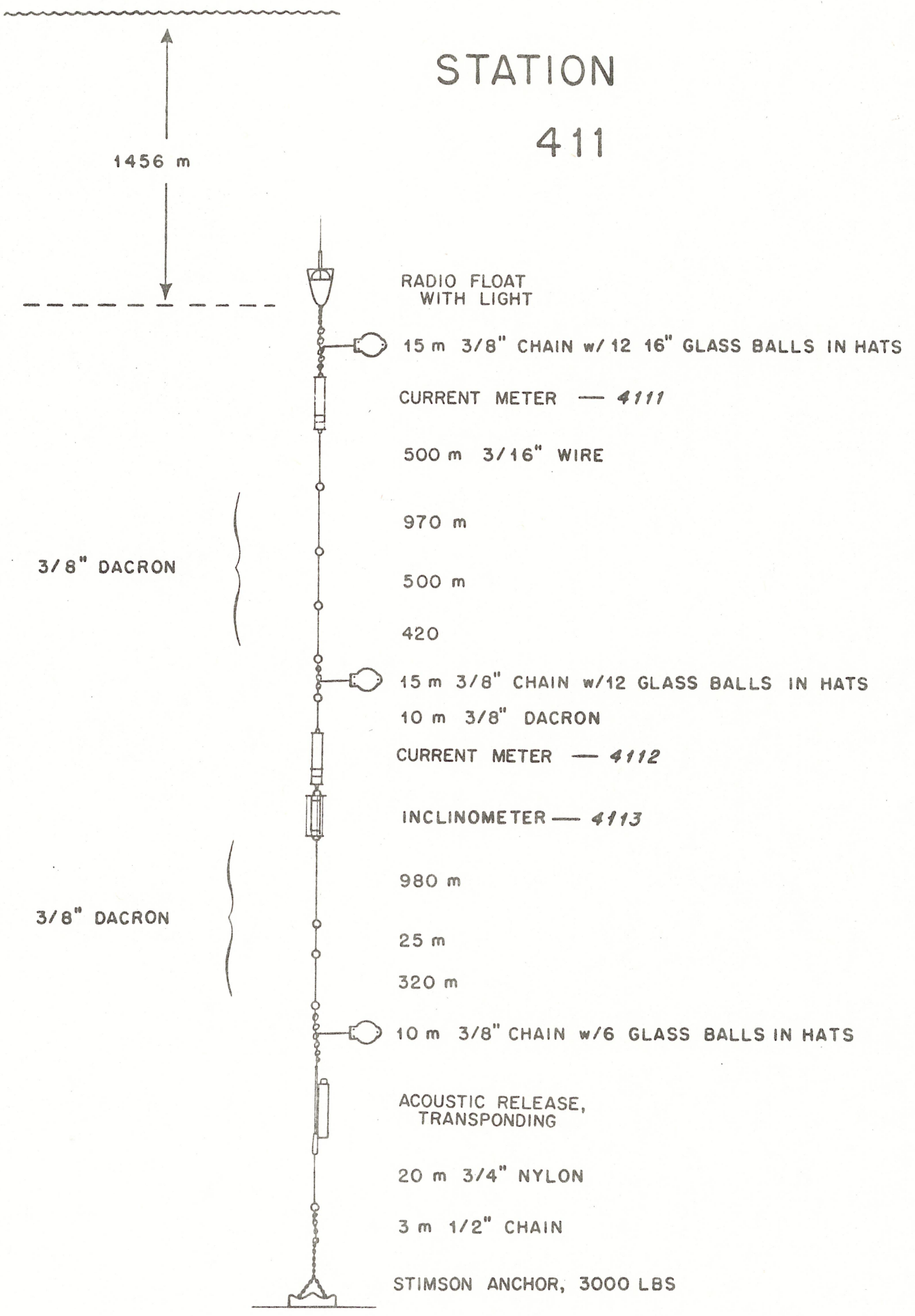




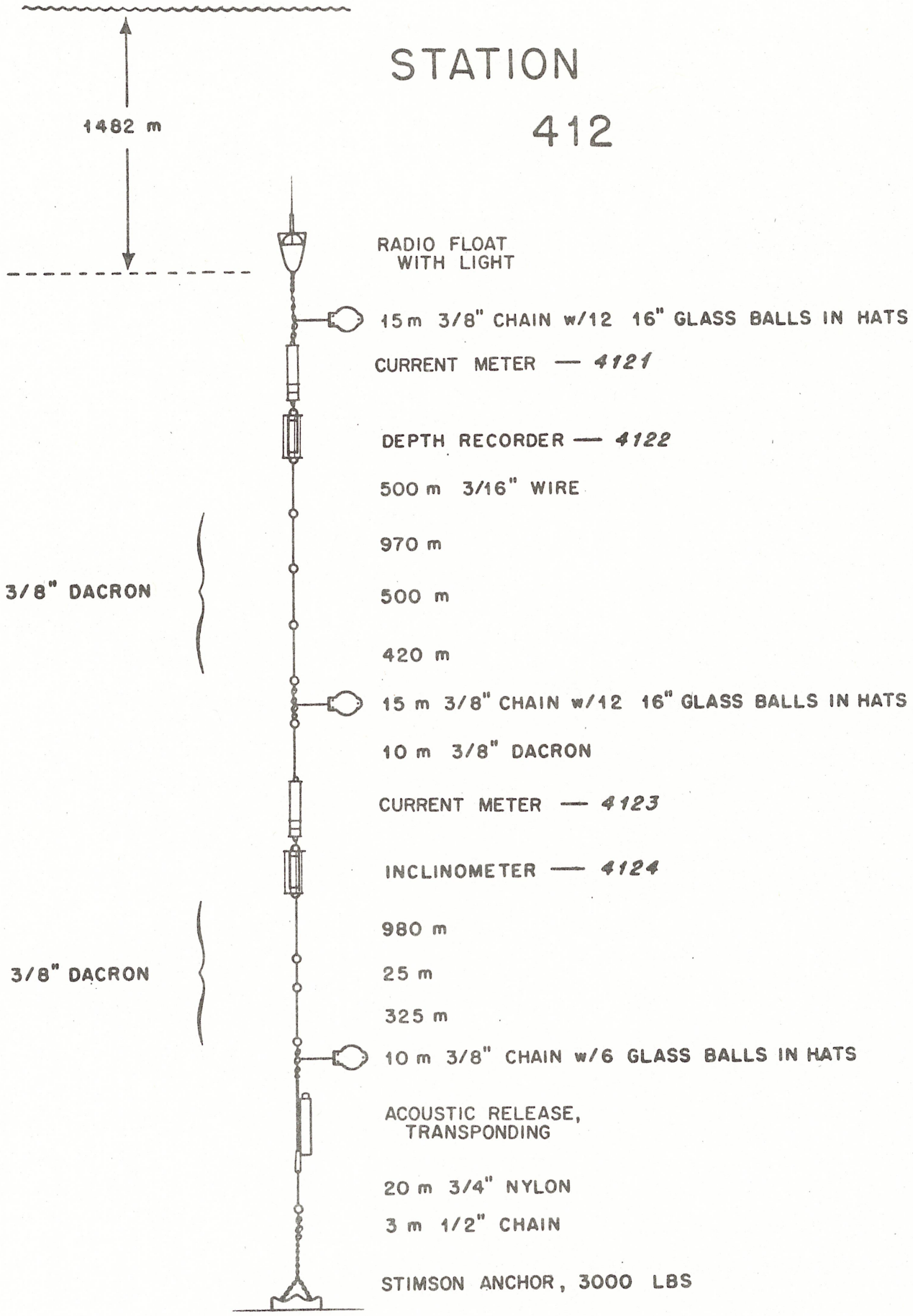




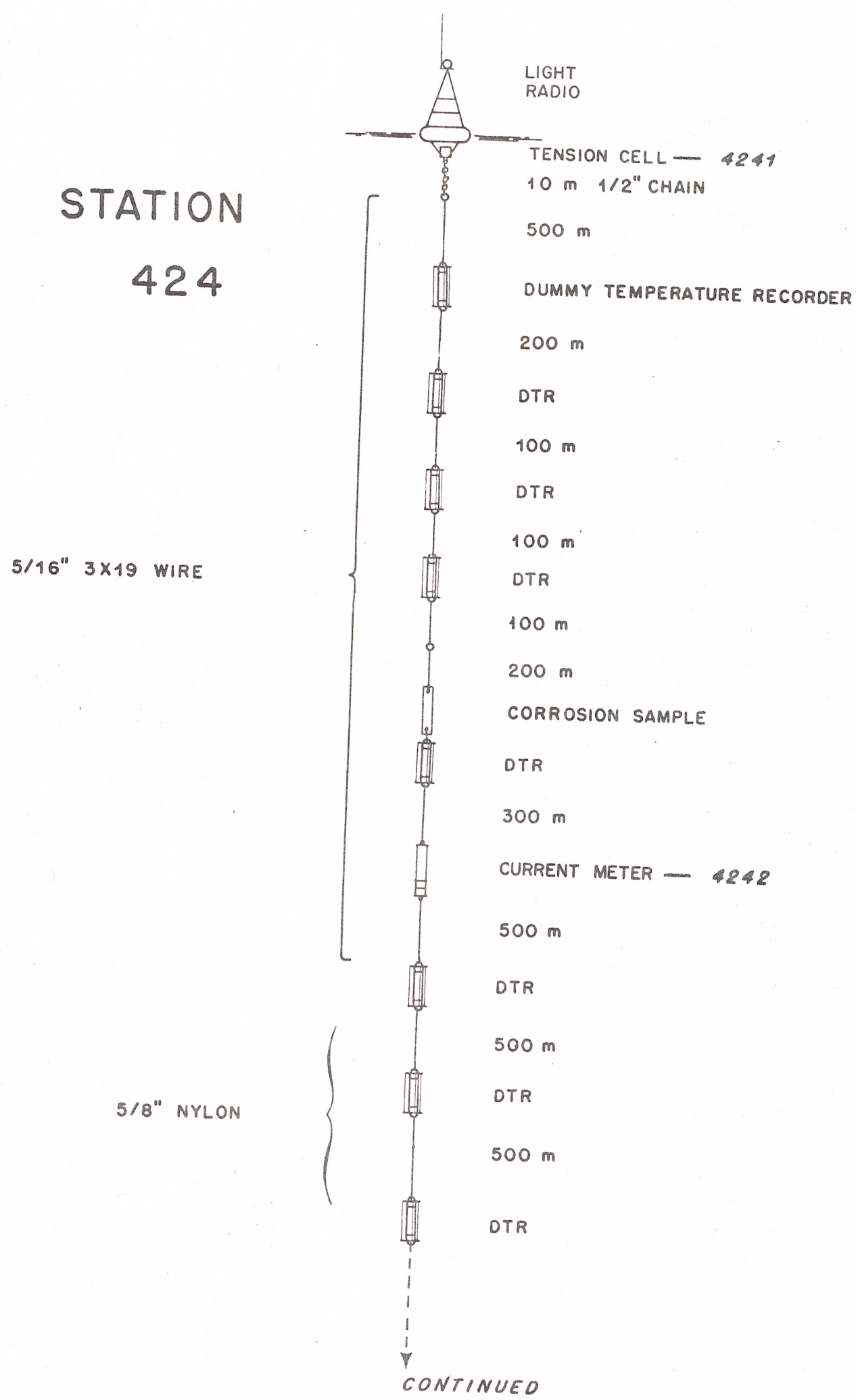


424 continueo

$5 / 8^{\circ 1}$ NYLON

$3 / 4^{\prime \prime}$ NYLON

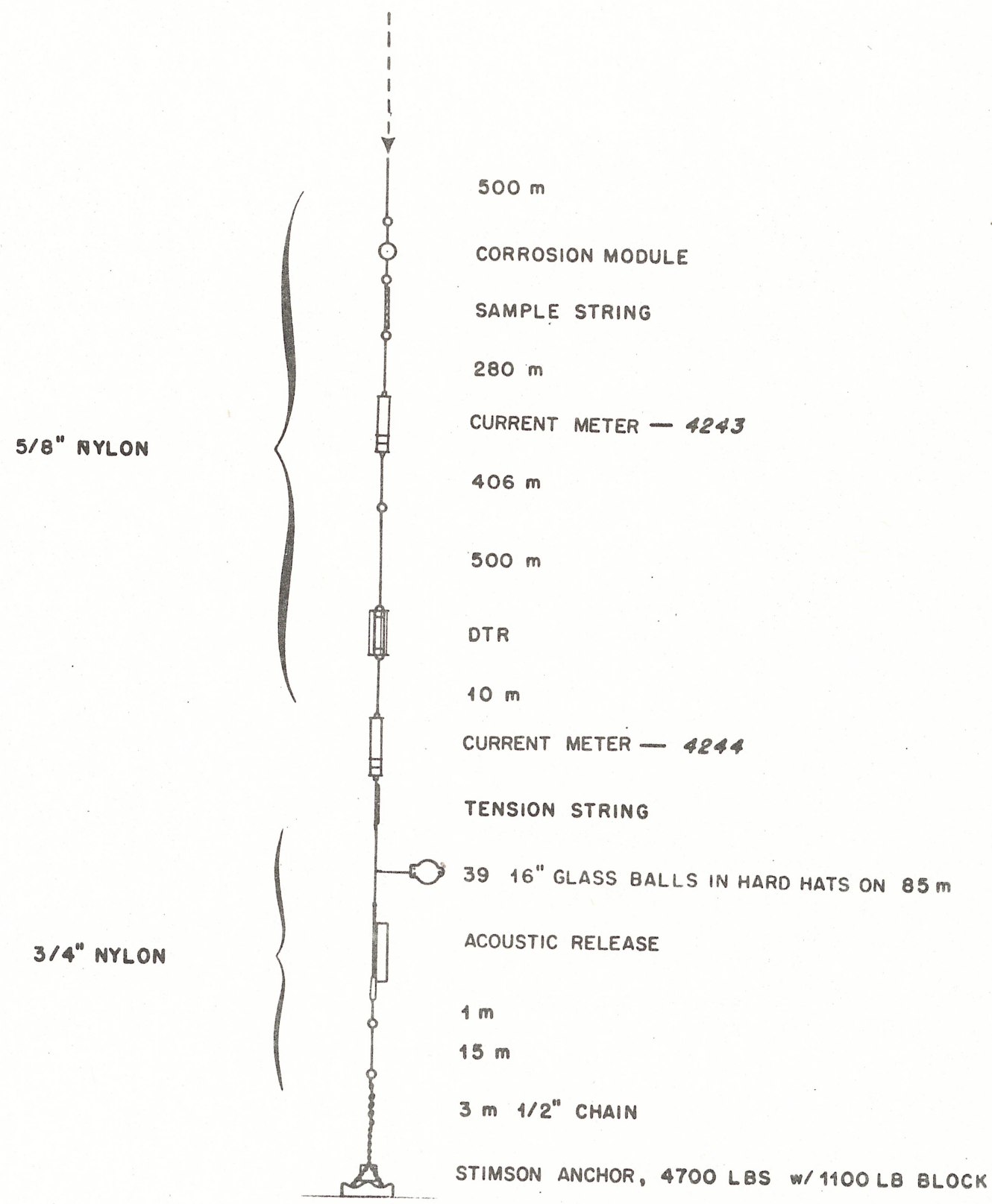


STATION

425

$5 / 16^{11}$ WIRE

$5 / 8^{\circ 0}$ NYLON

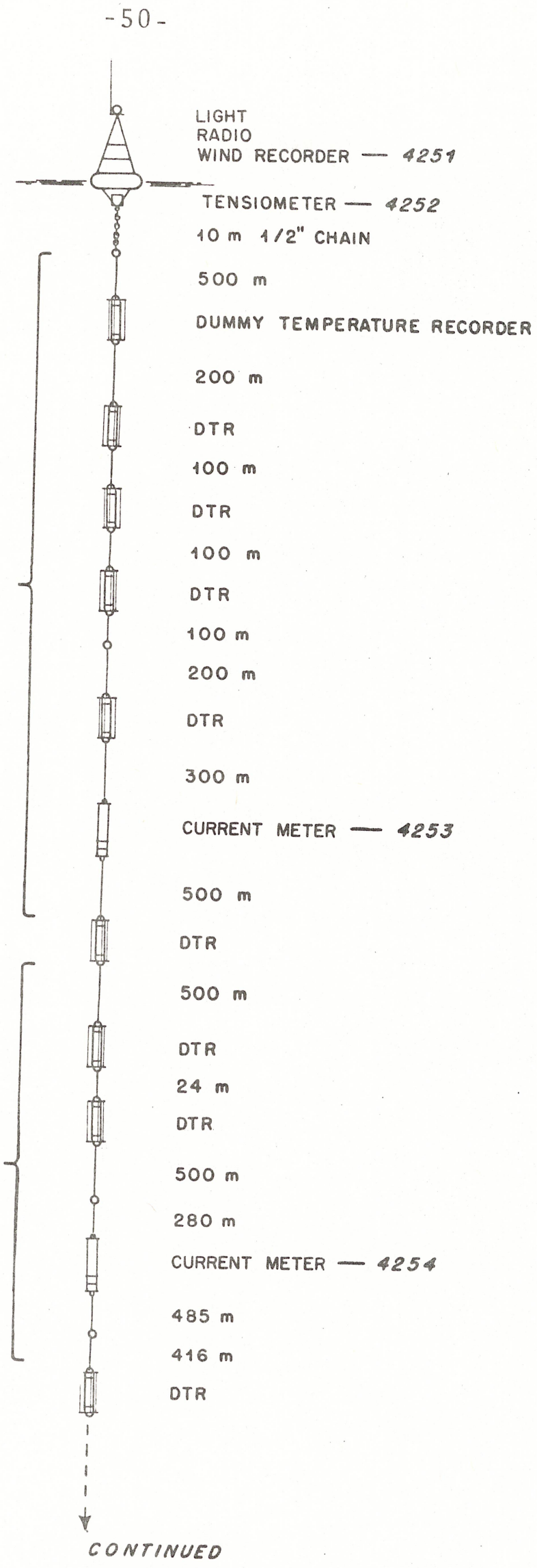




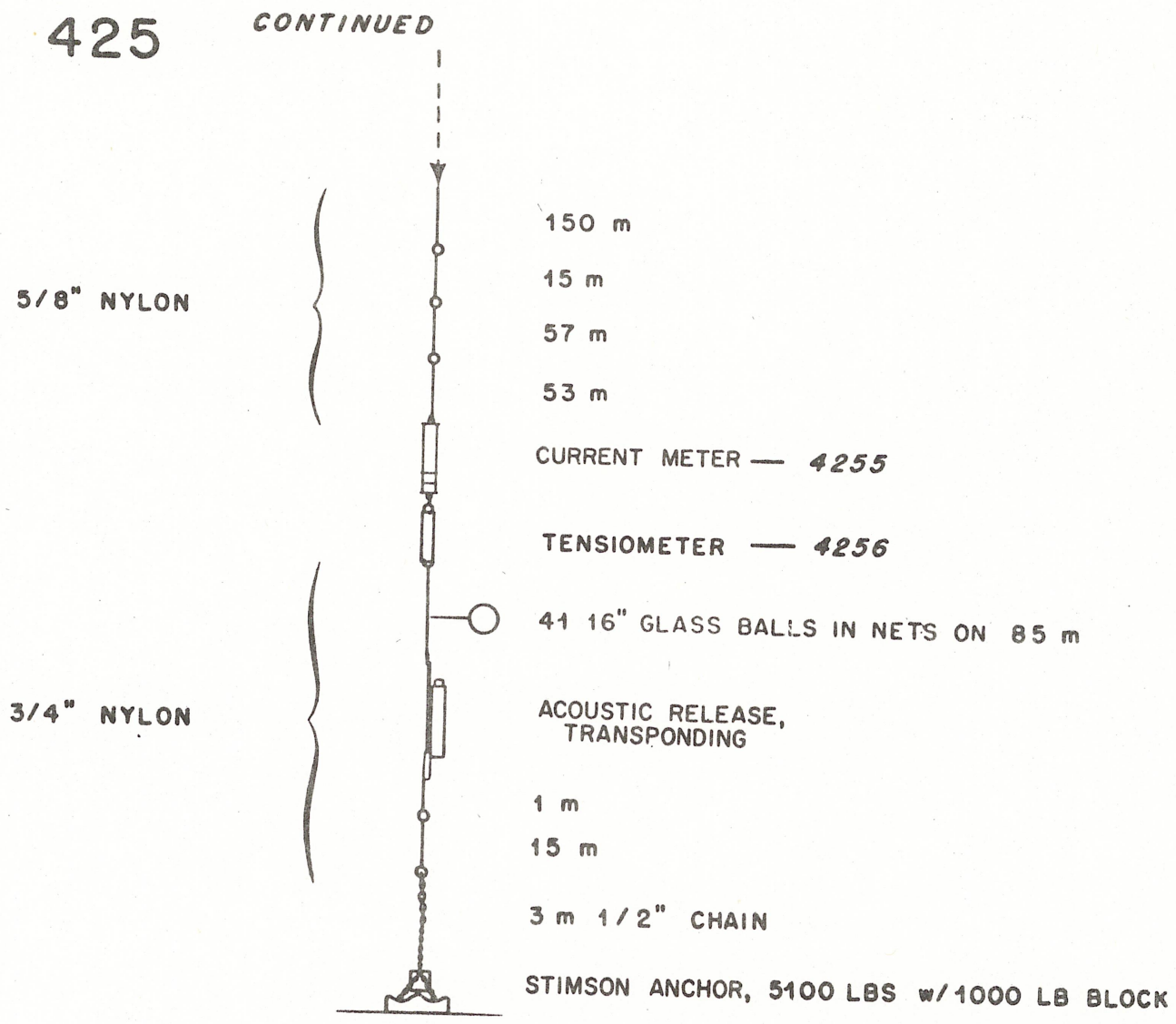




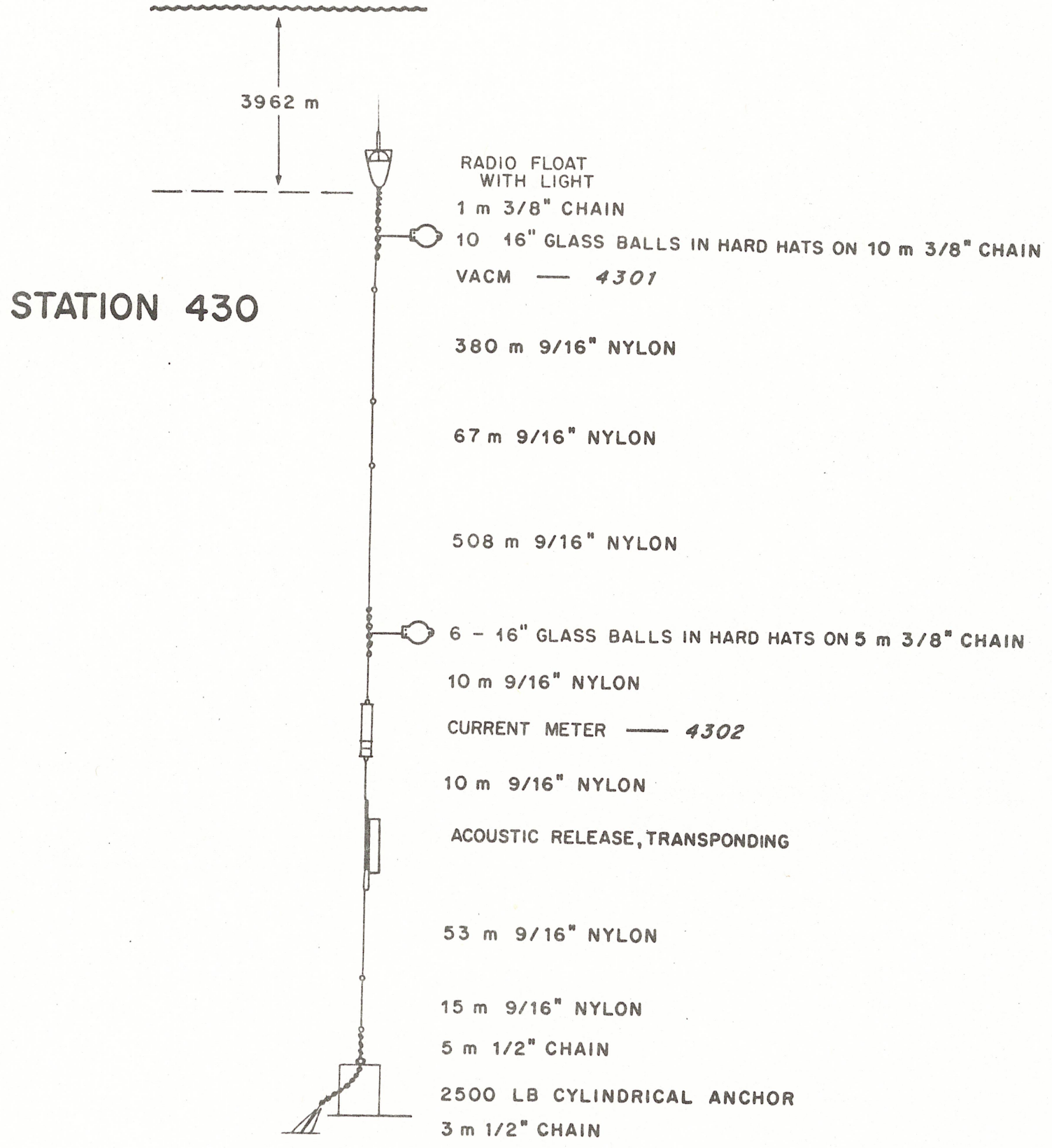




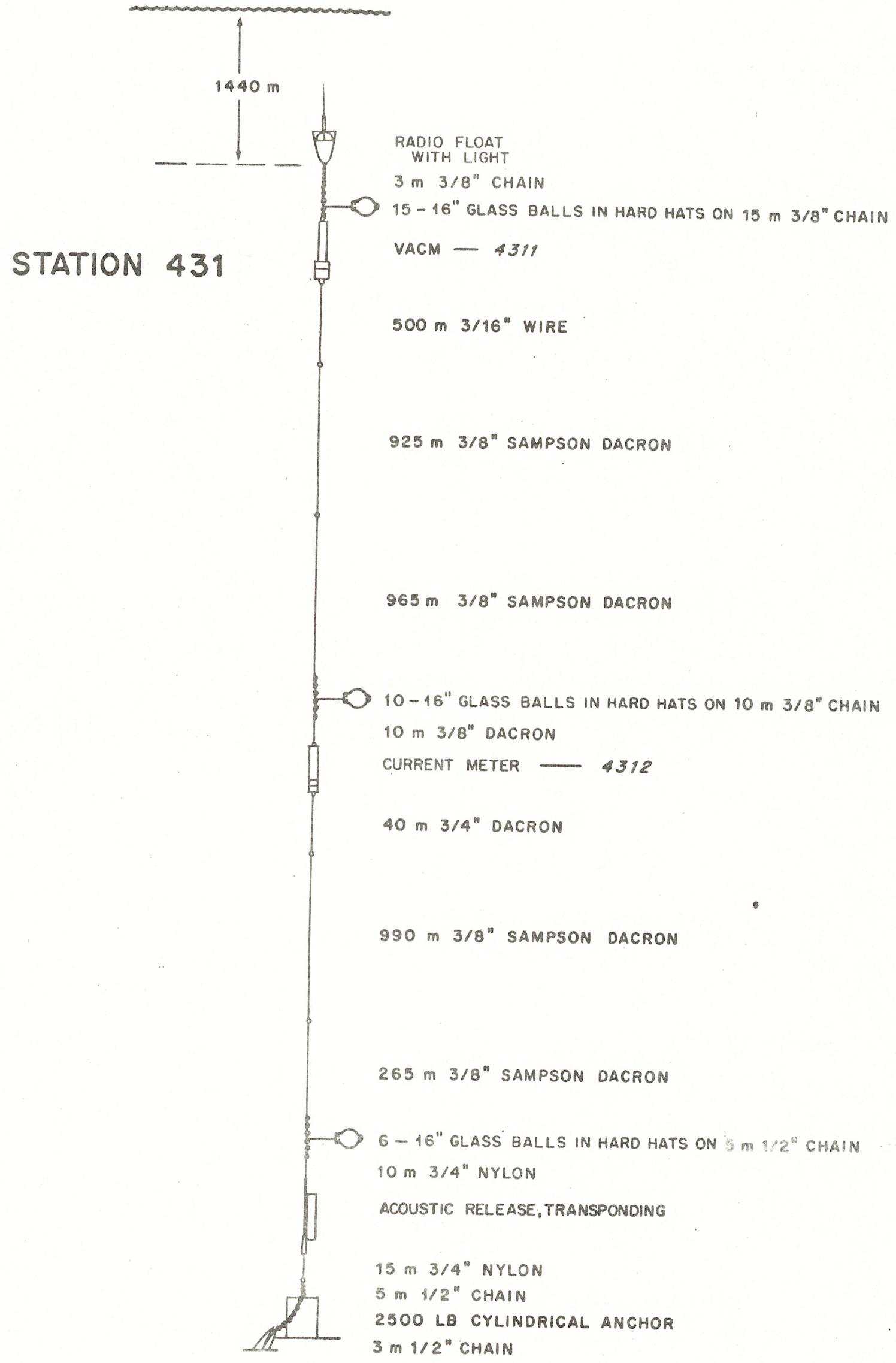




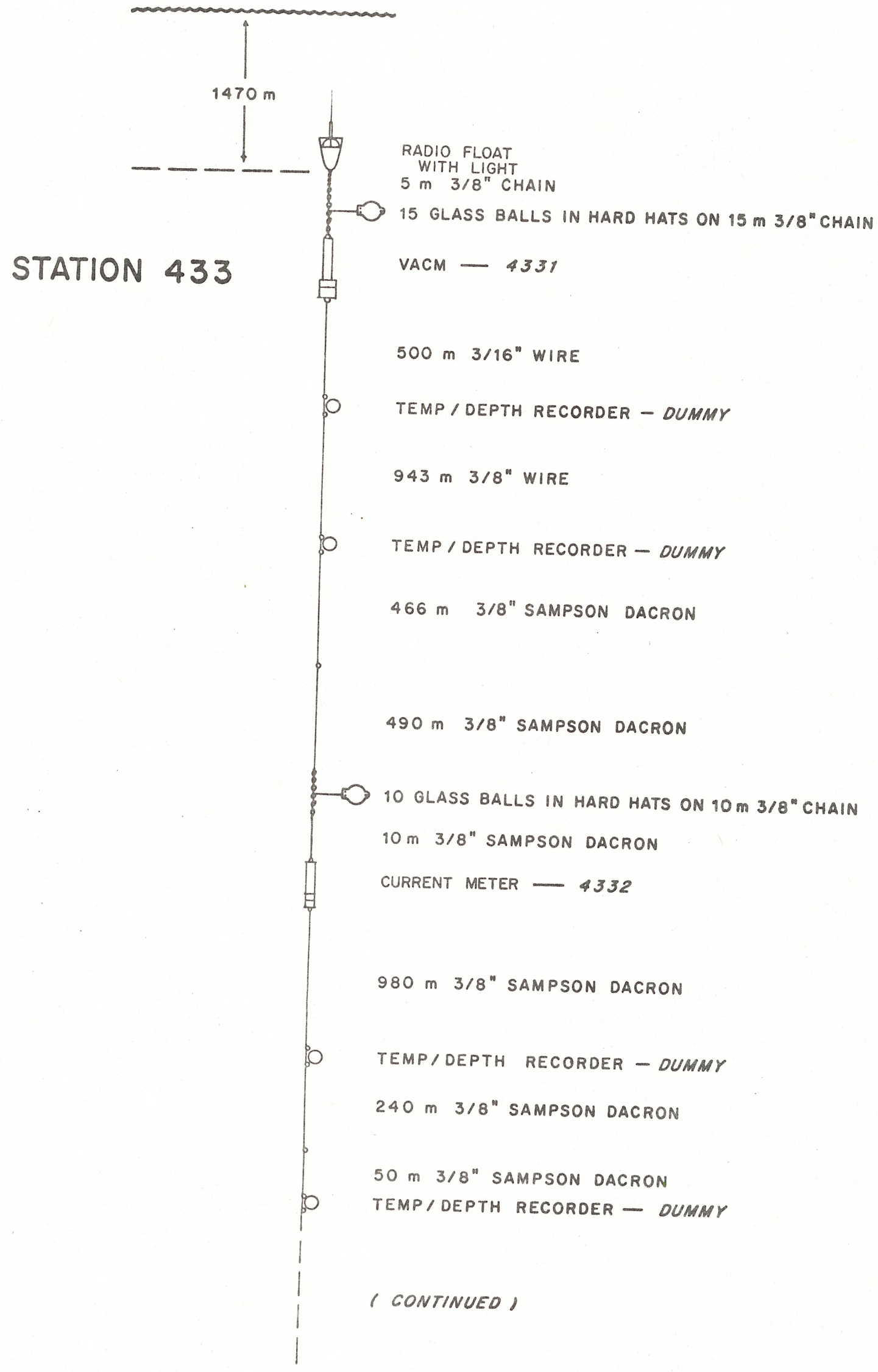




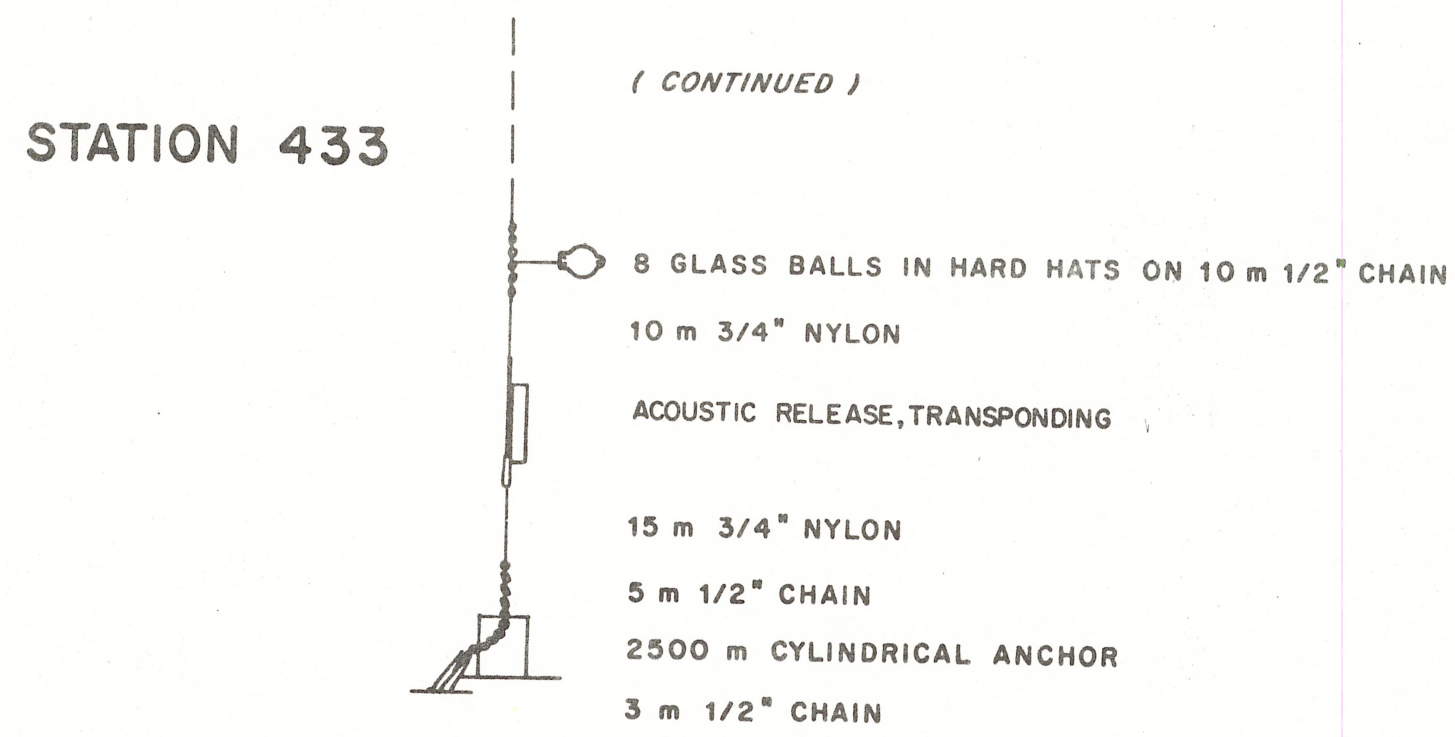




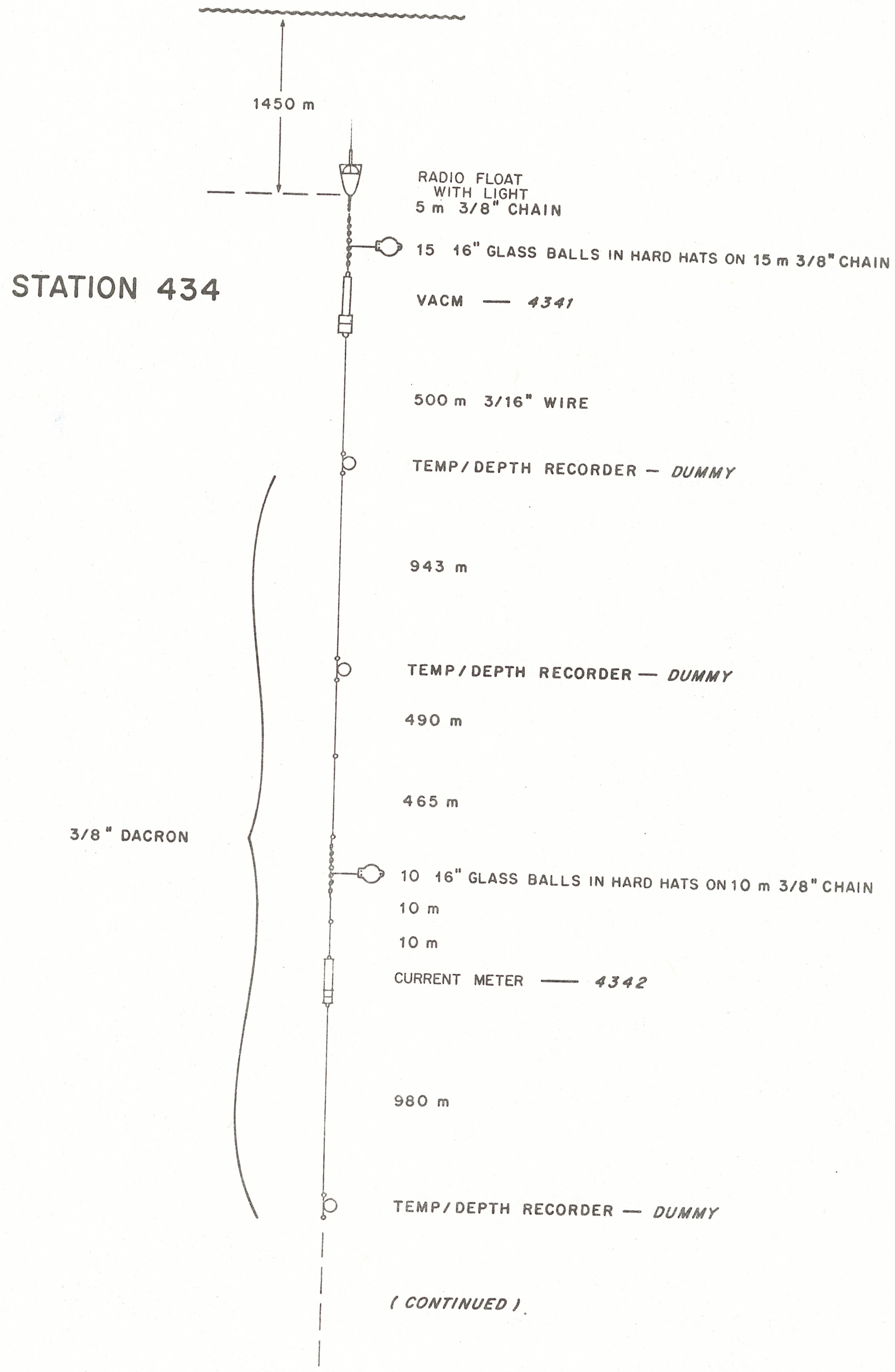




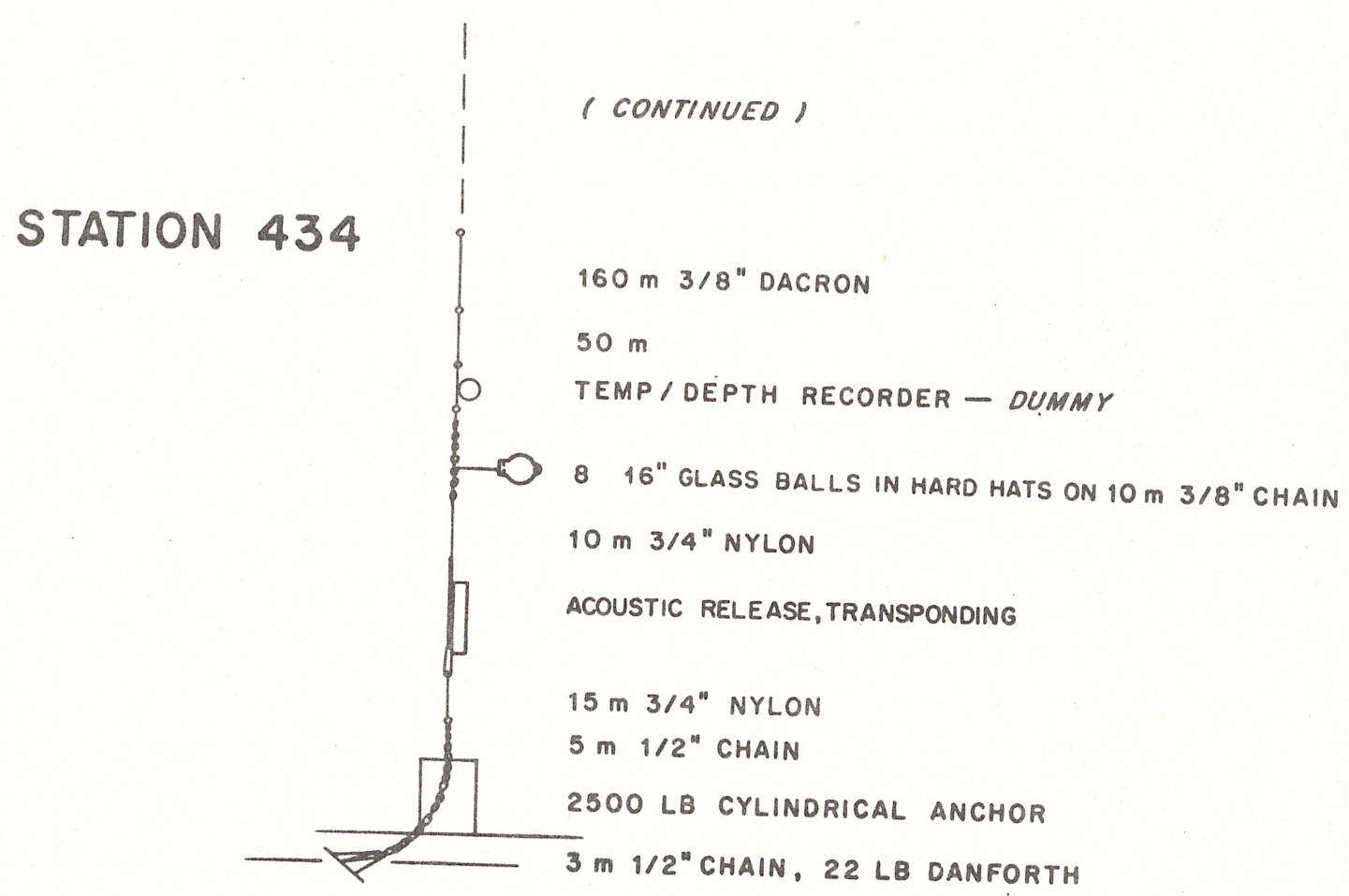




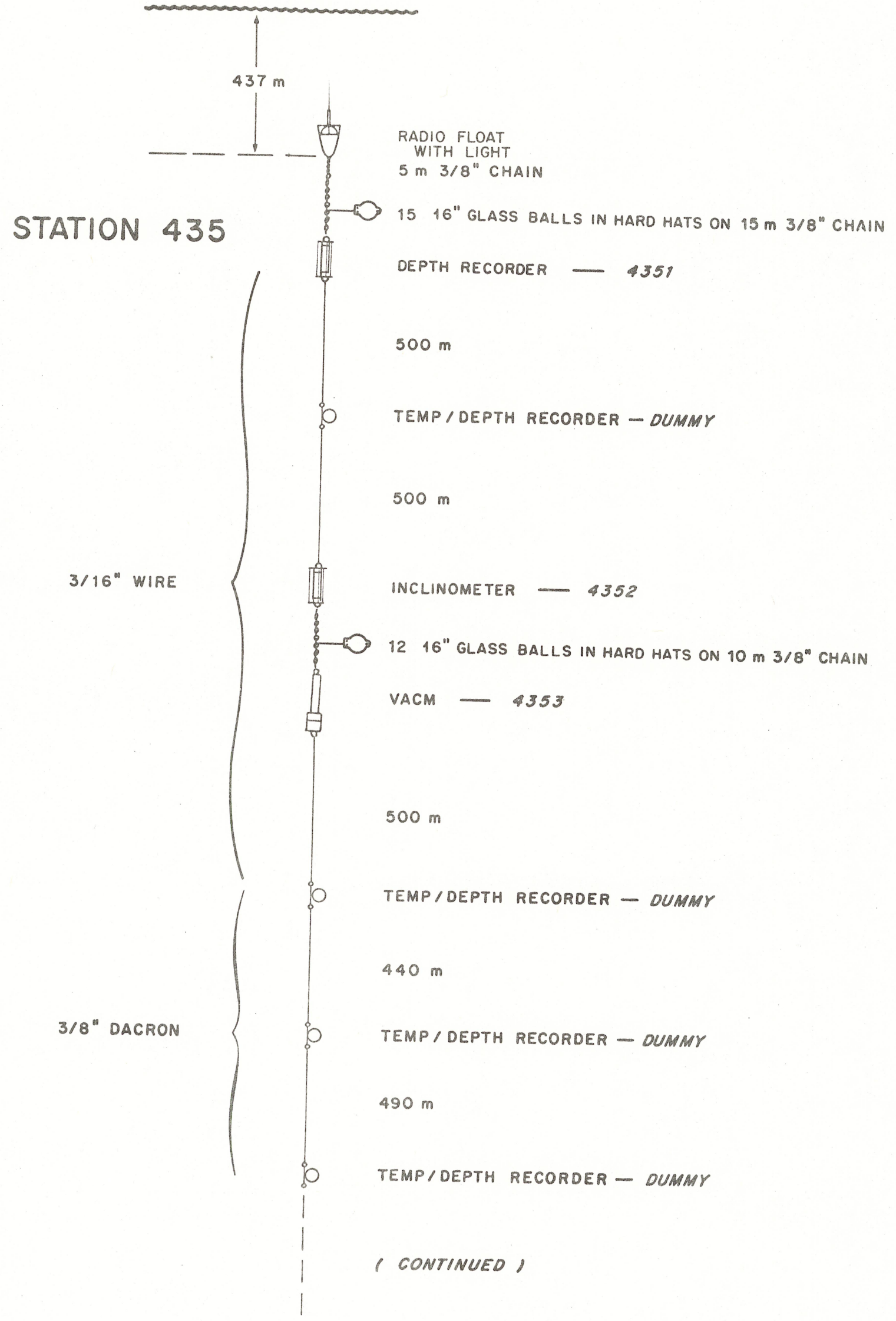




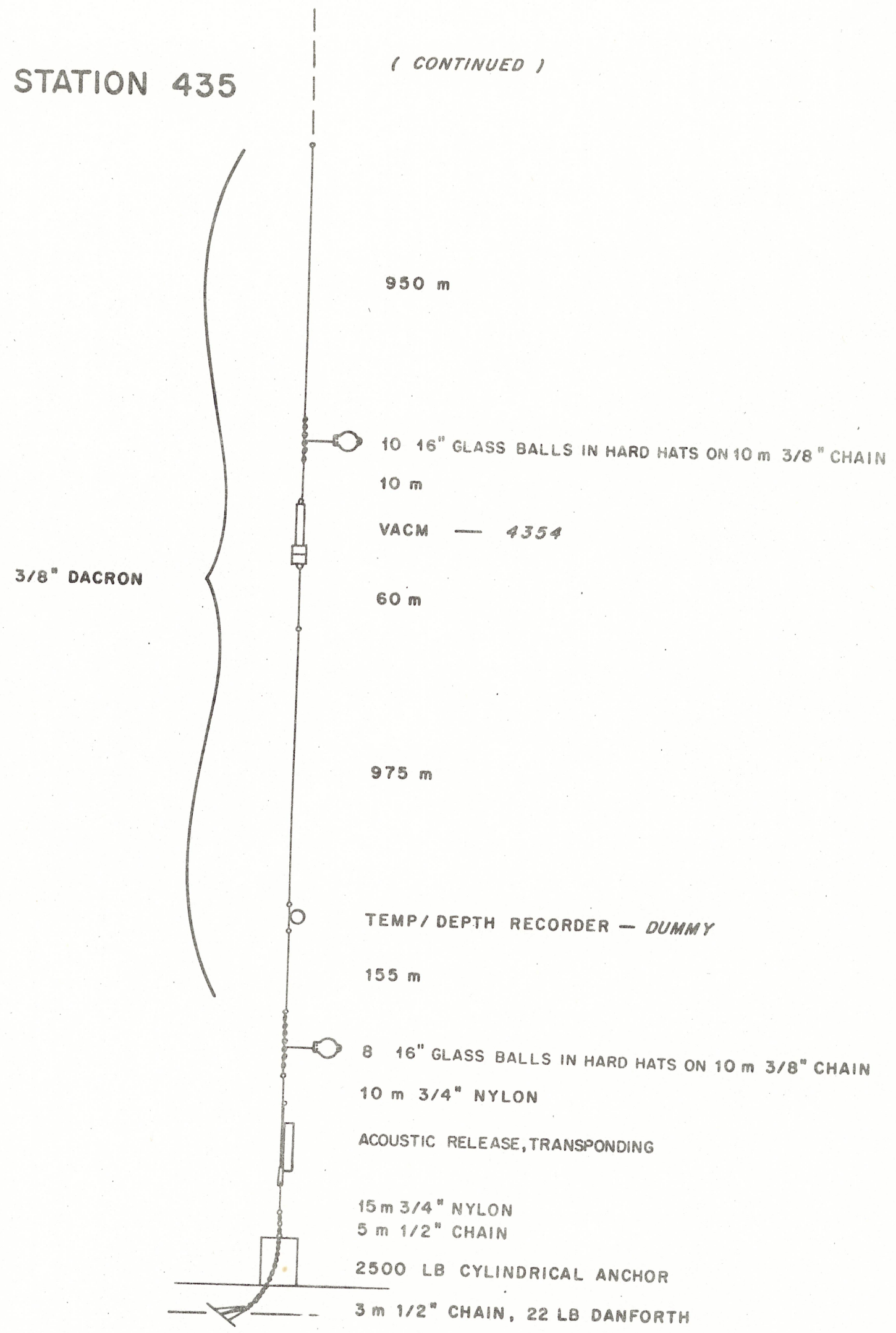




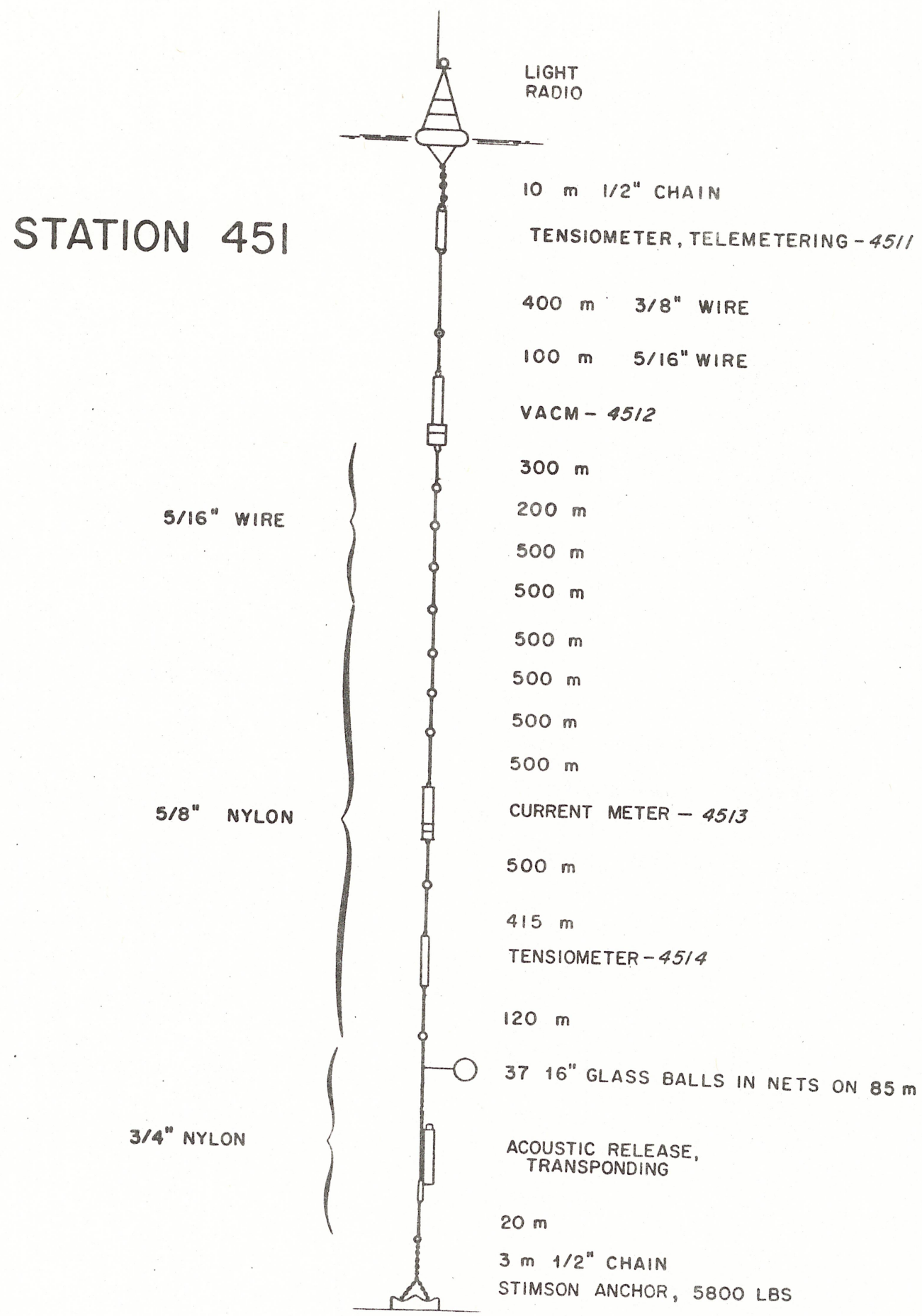




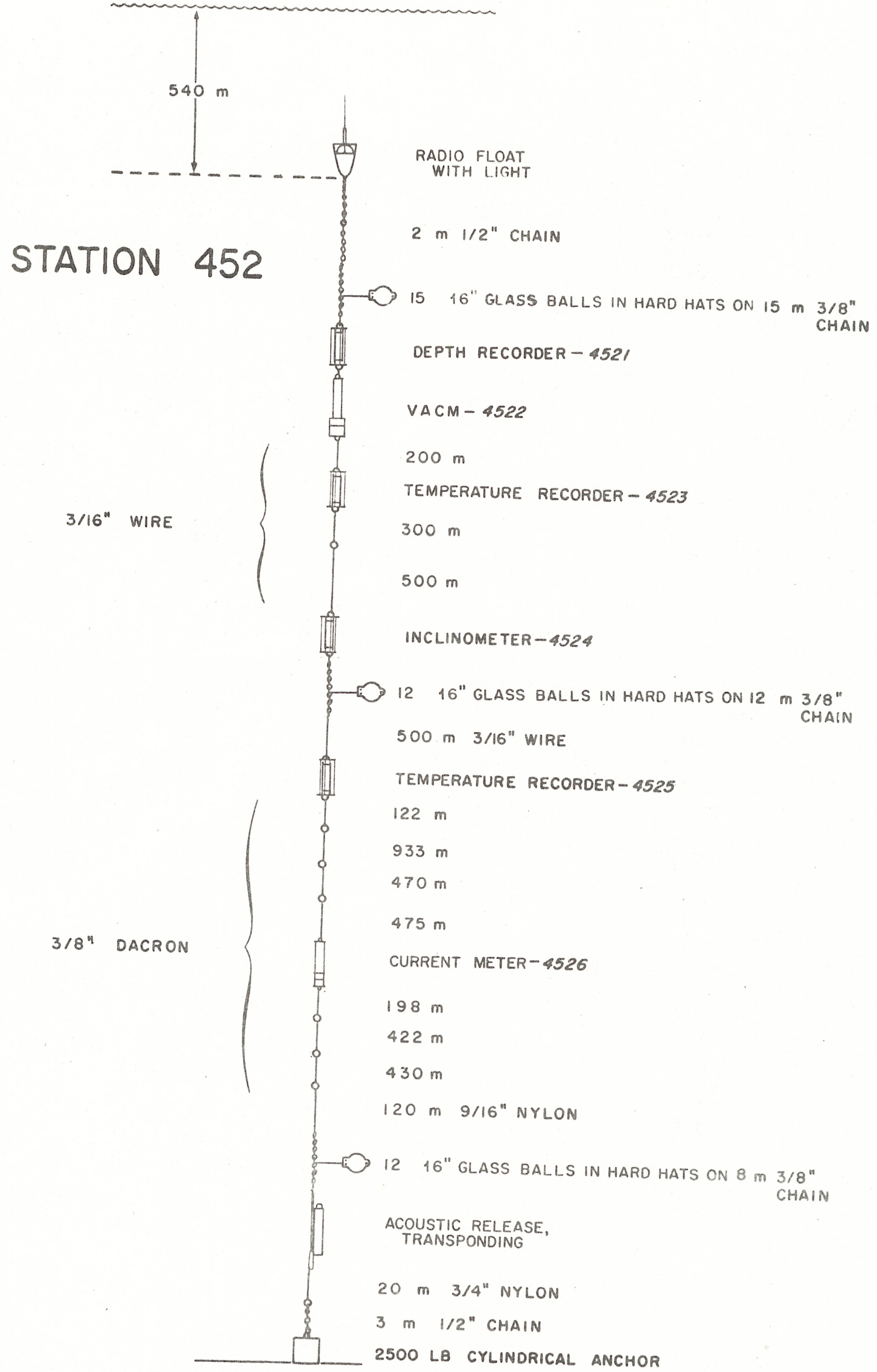




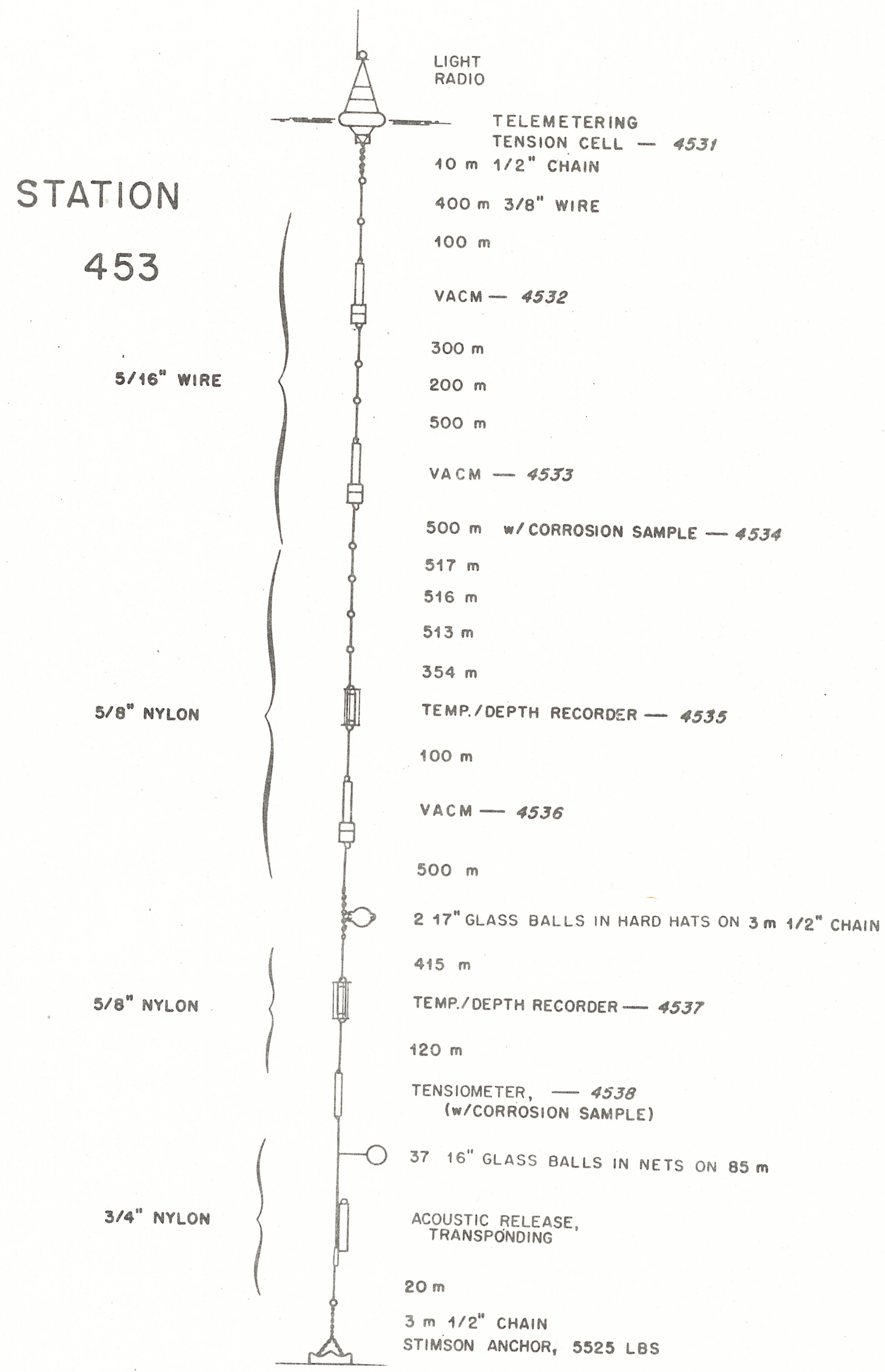


$-63-$

\section{STATION 454}

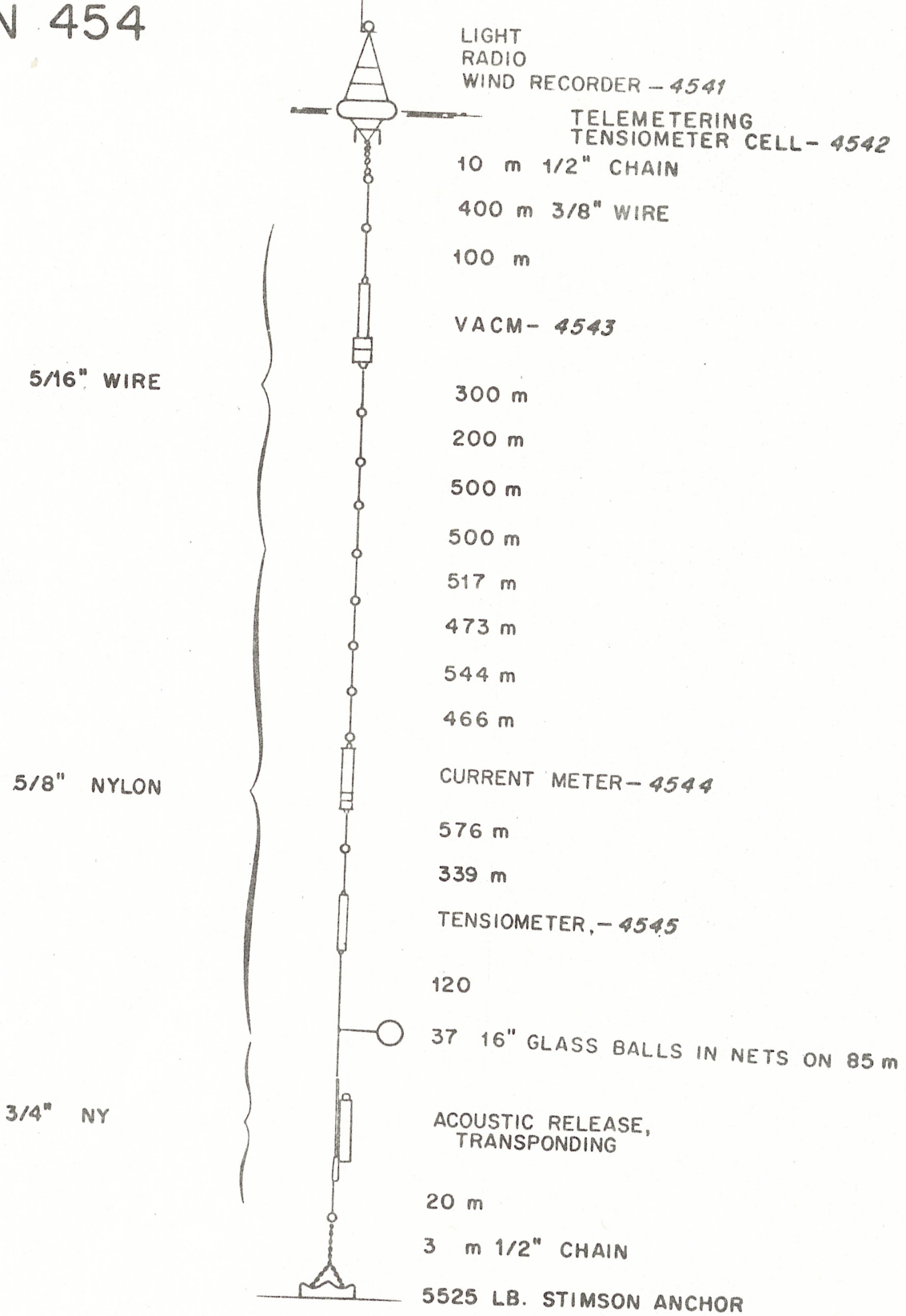




\section{STATION 455}

$5 / 16^{\circ 1}$ WIRE

5/8" NYLON

$3 / 4^{\prime \prime}$ NYLON

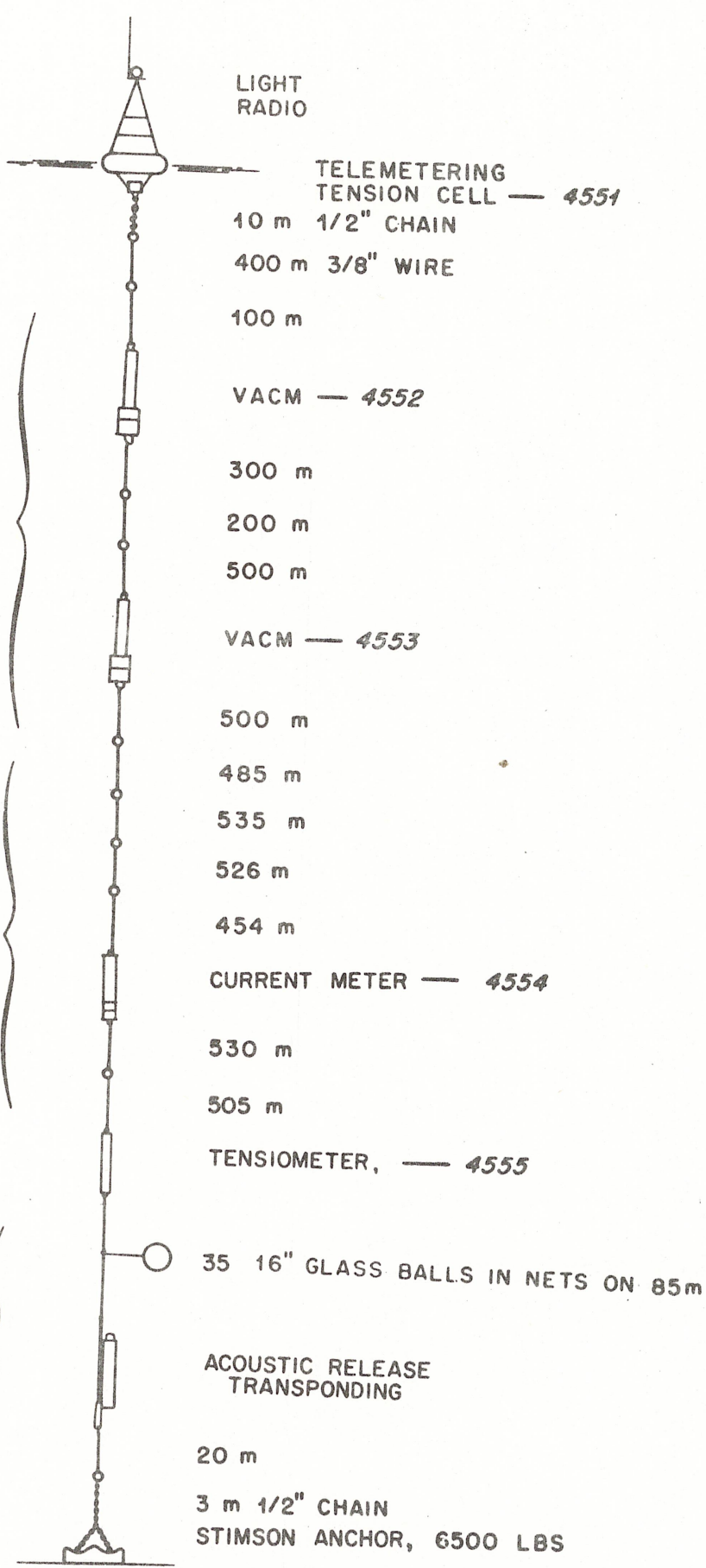


$-65-$

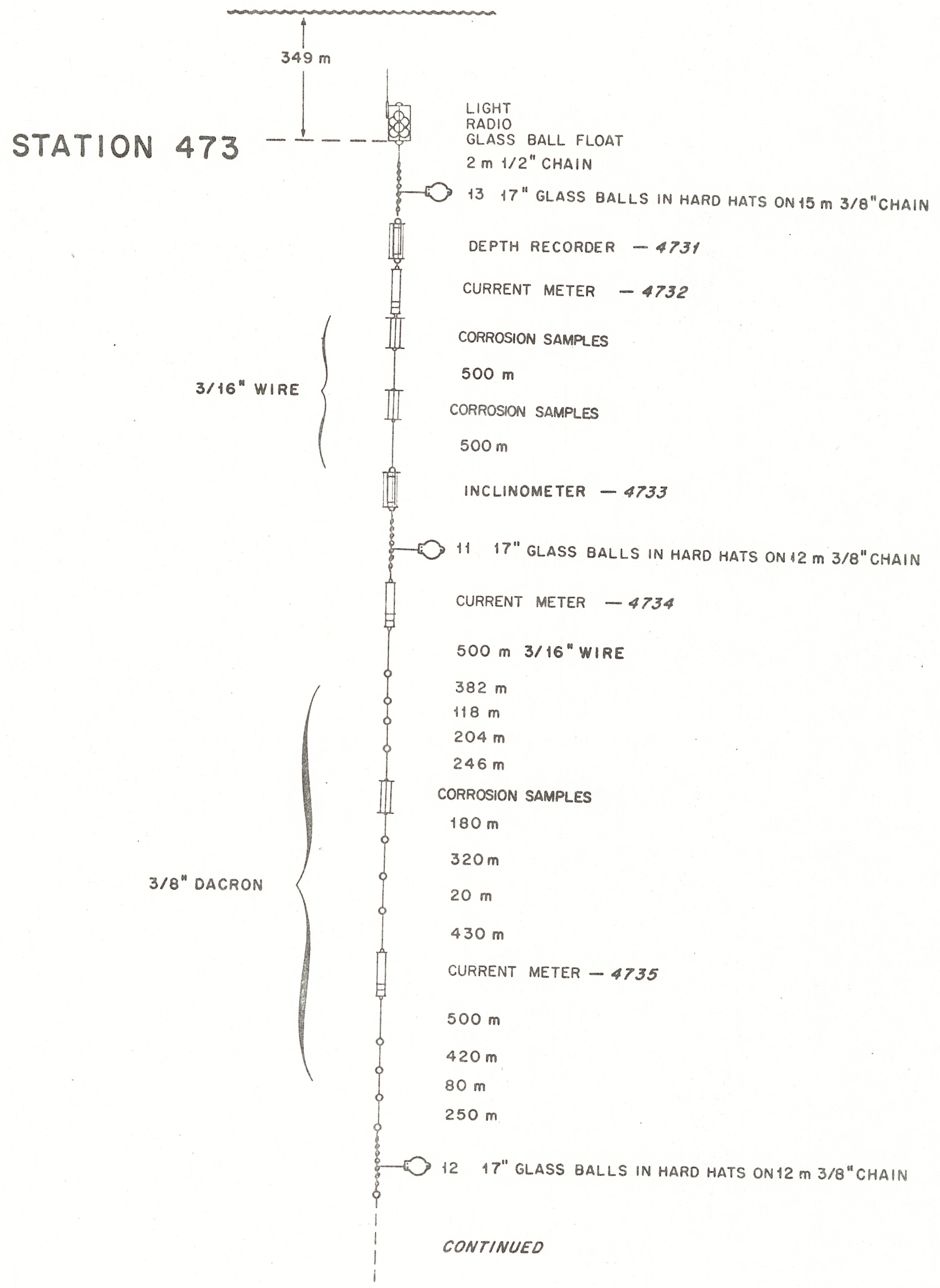




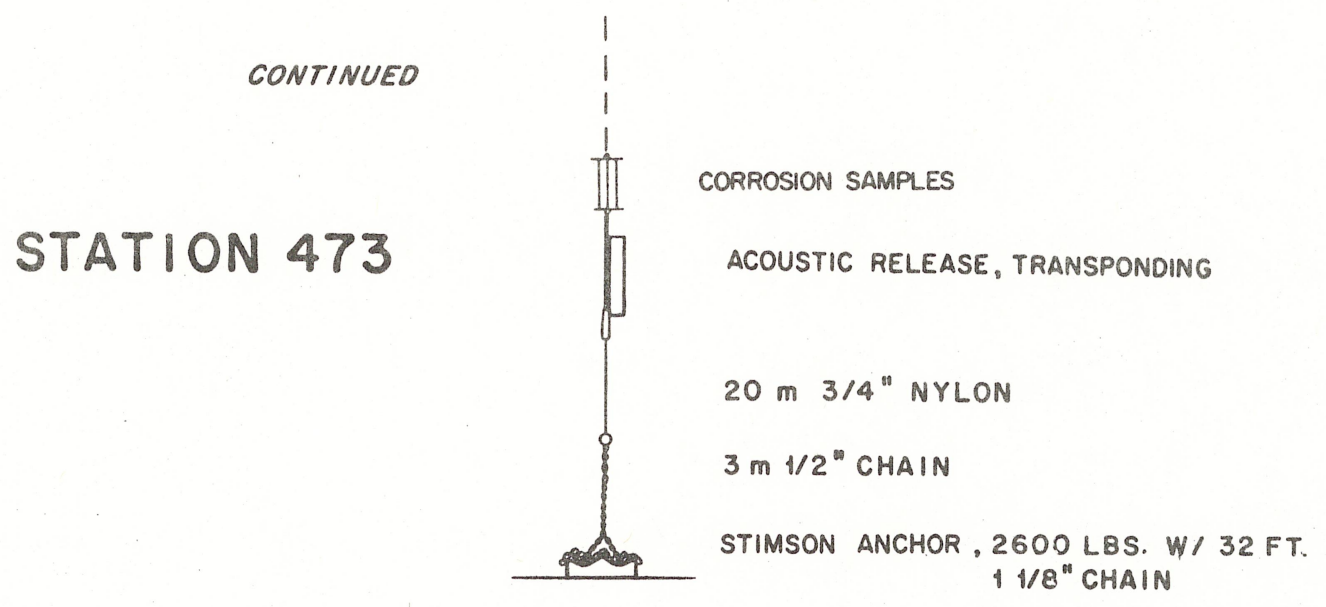




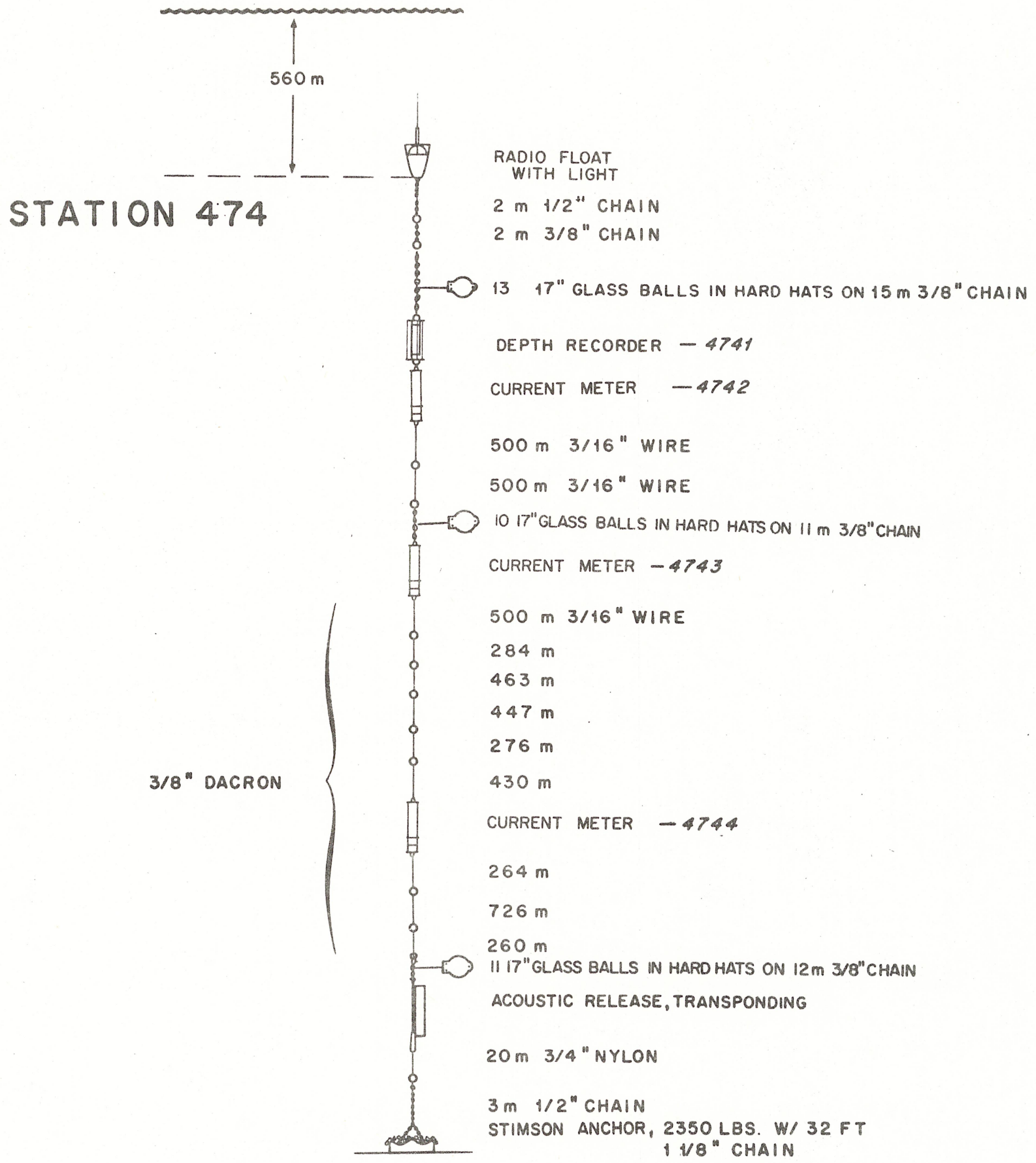


$-68-$

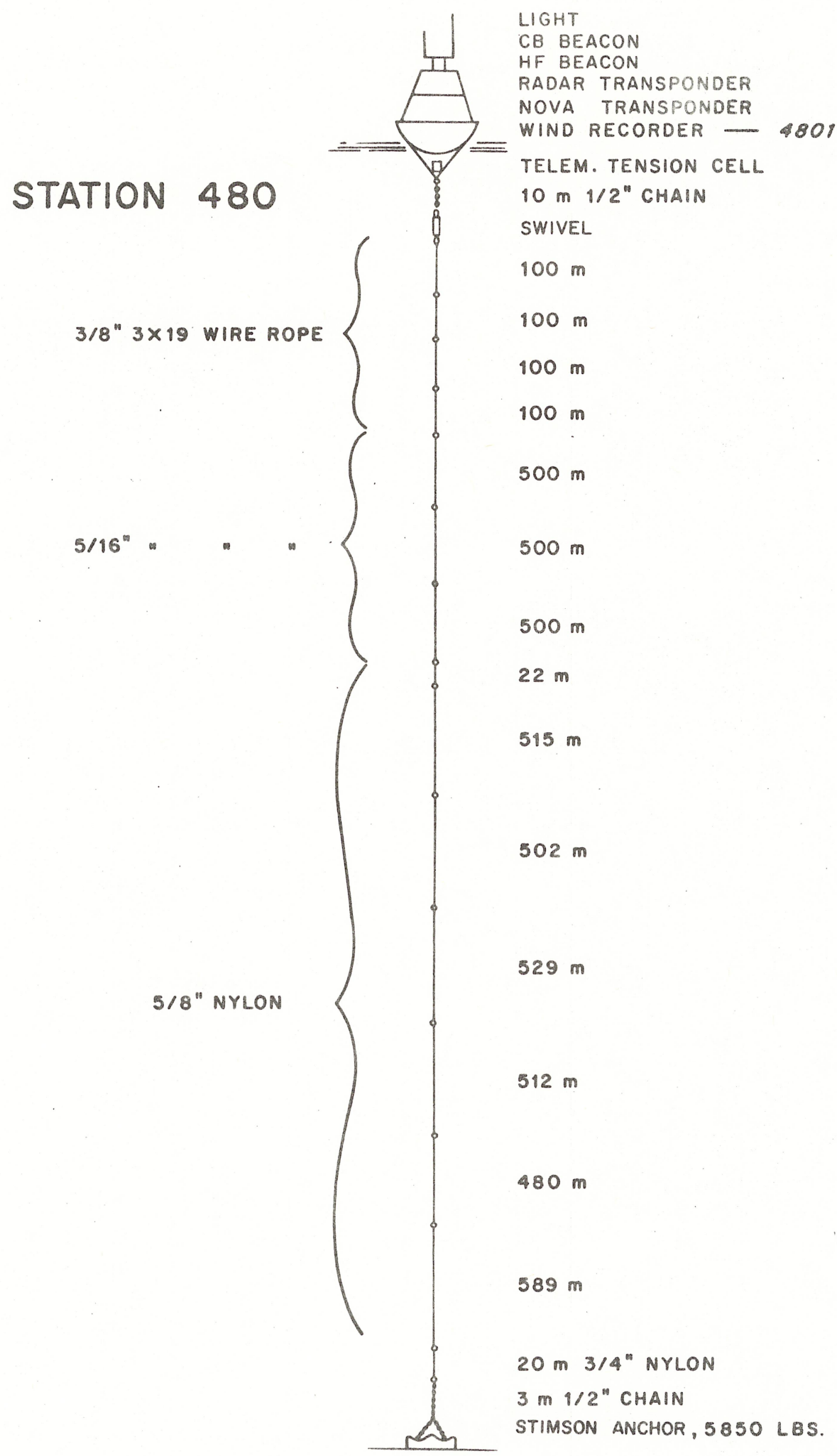




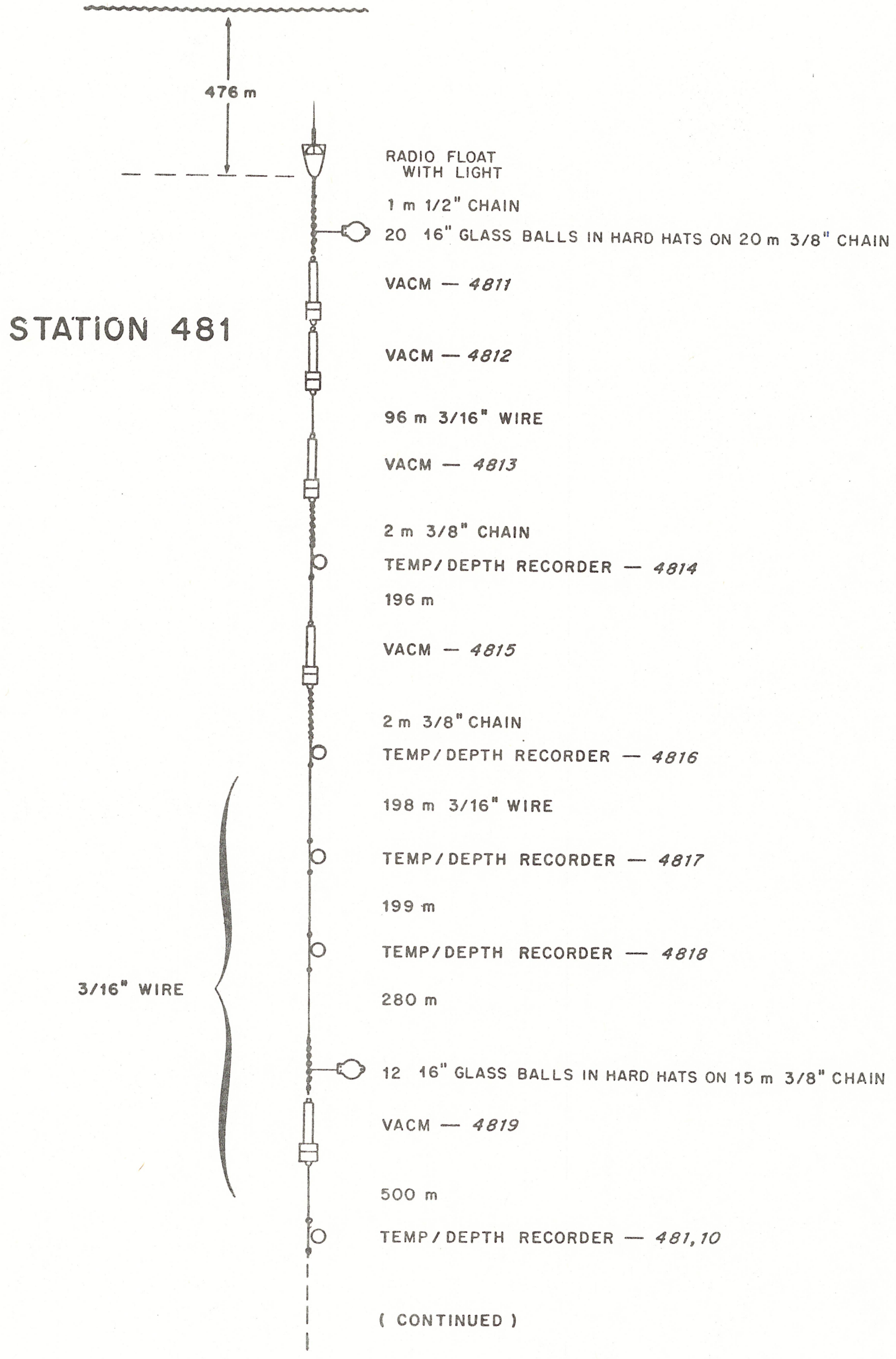




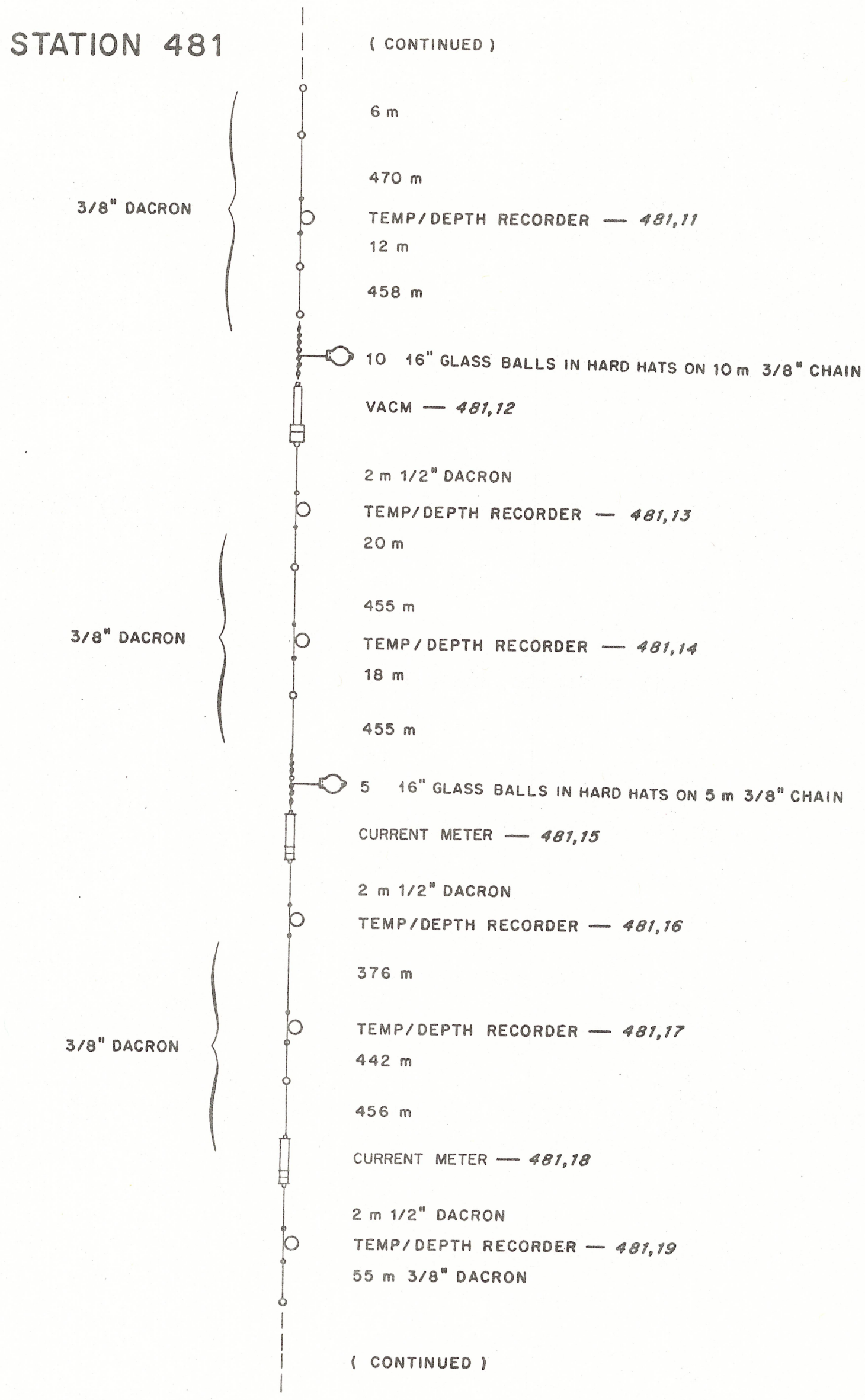




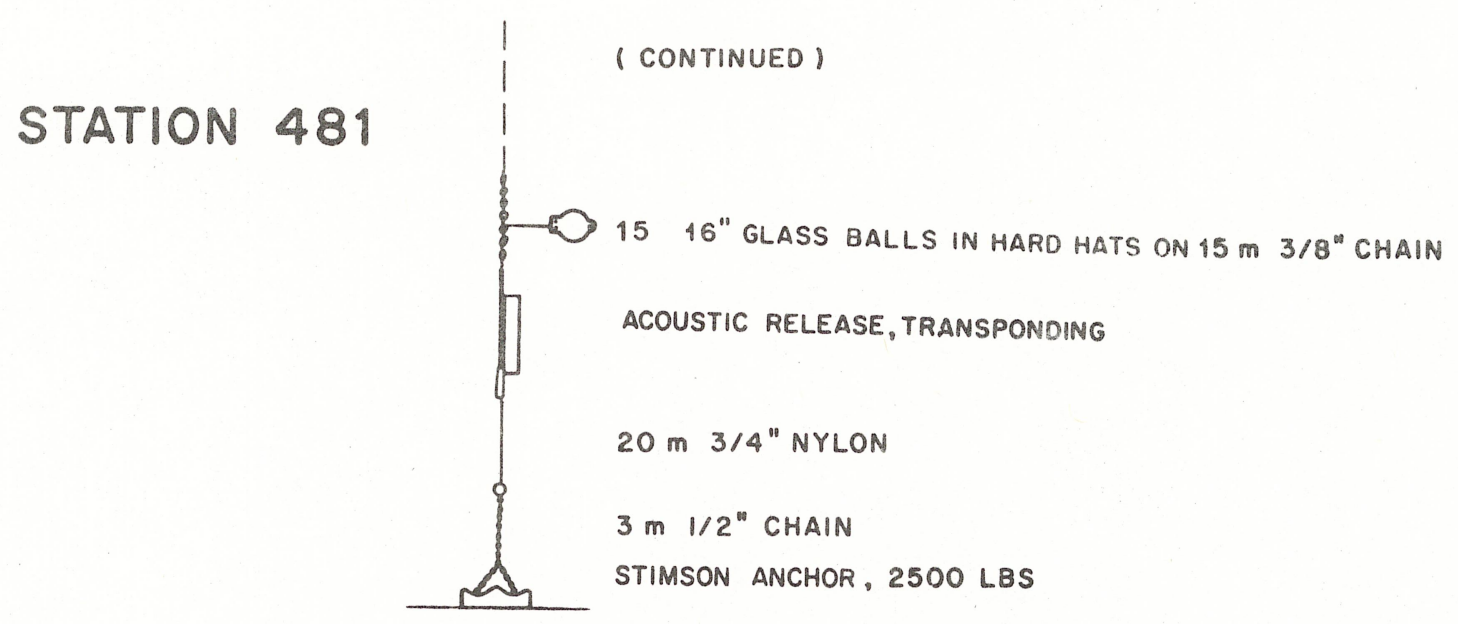




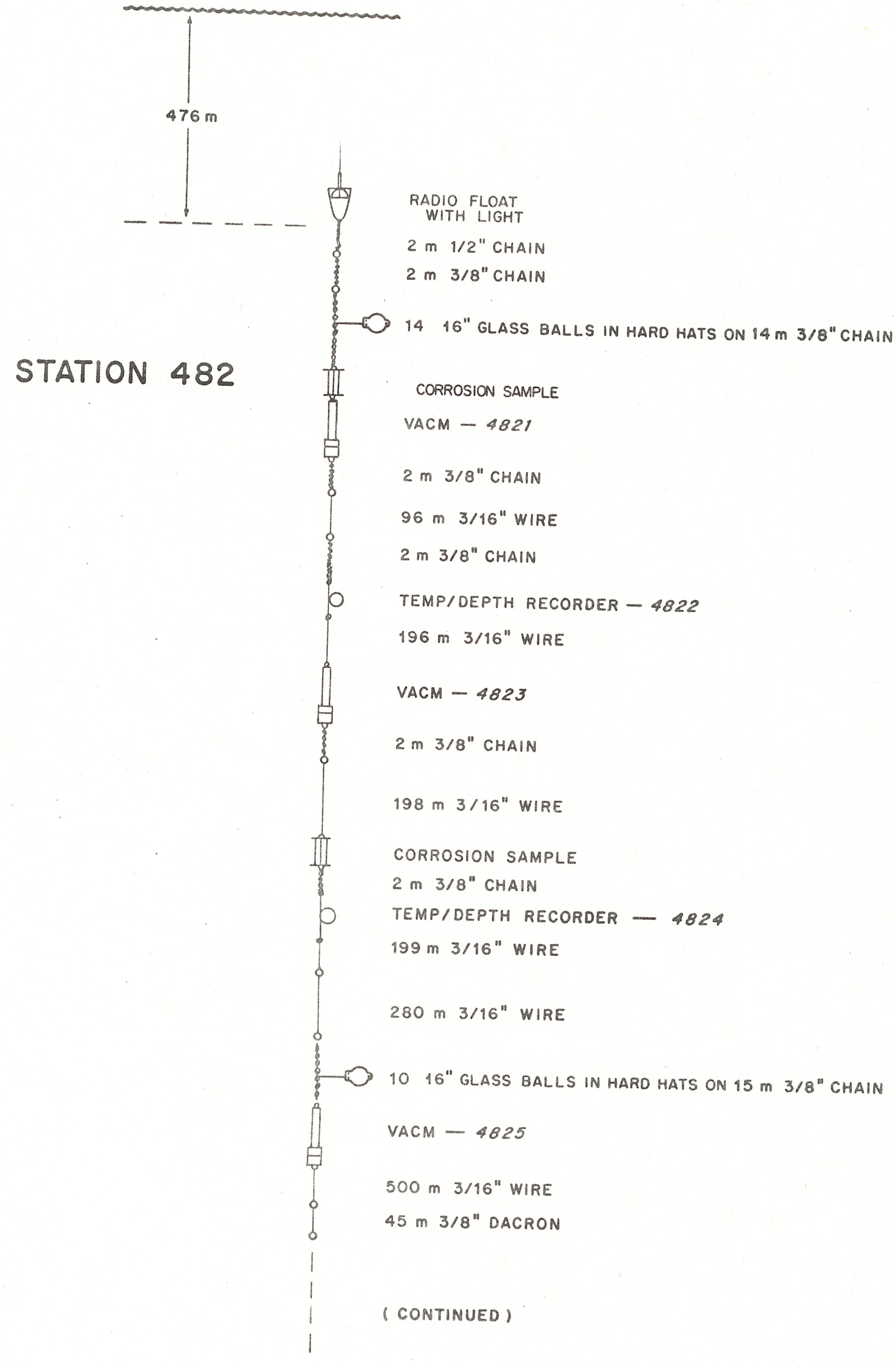




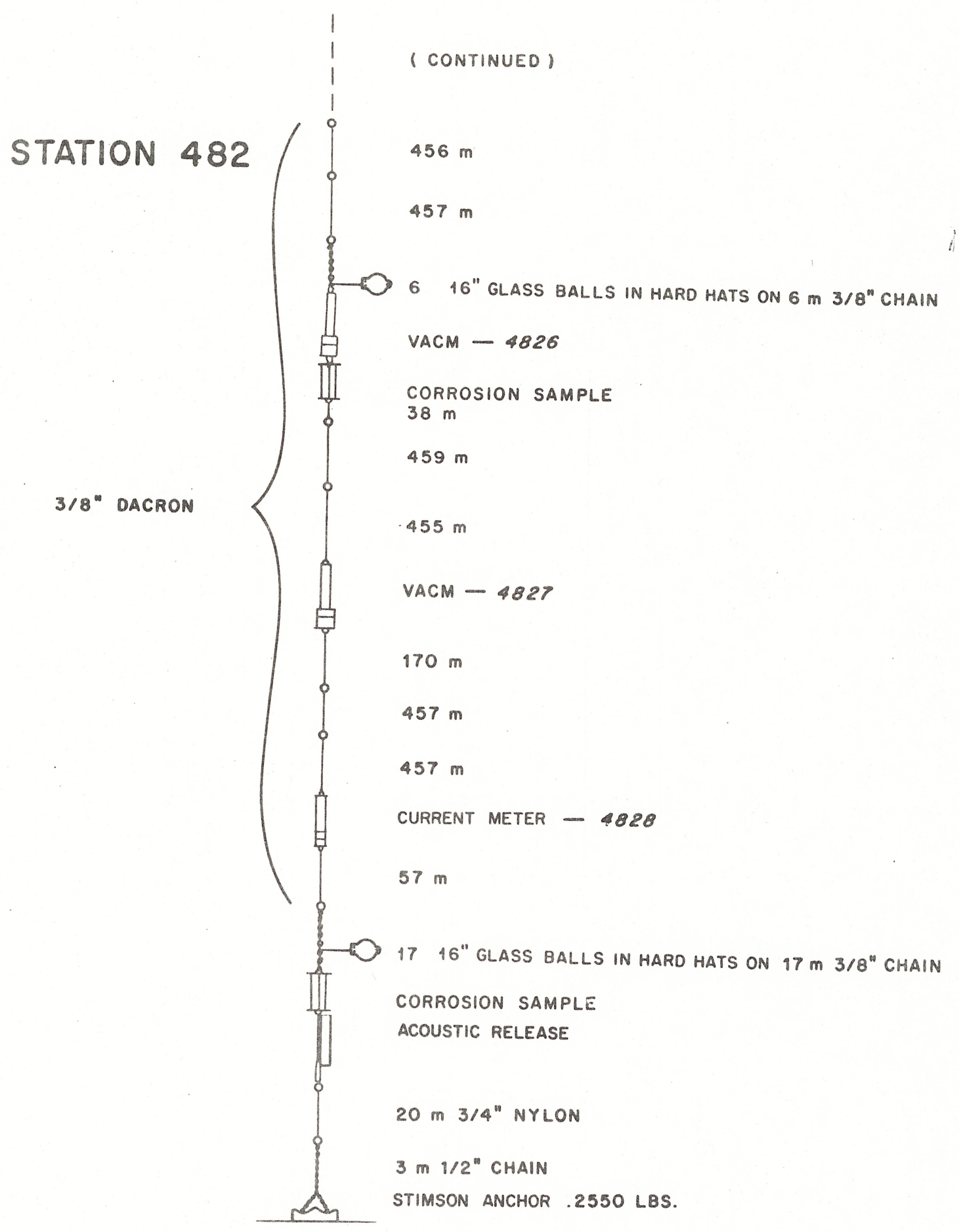




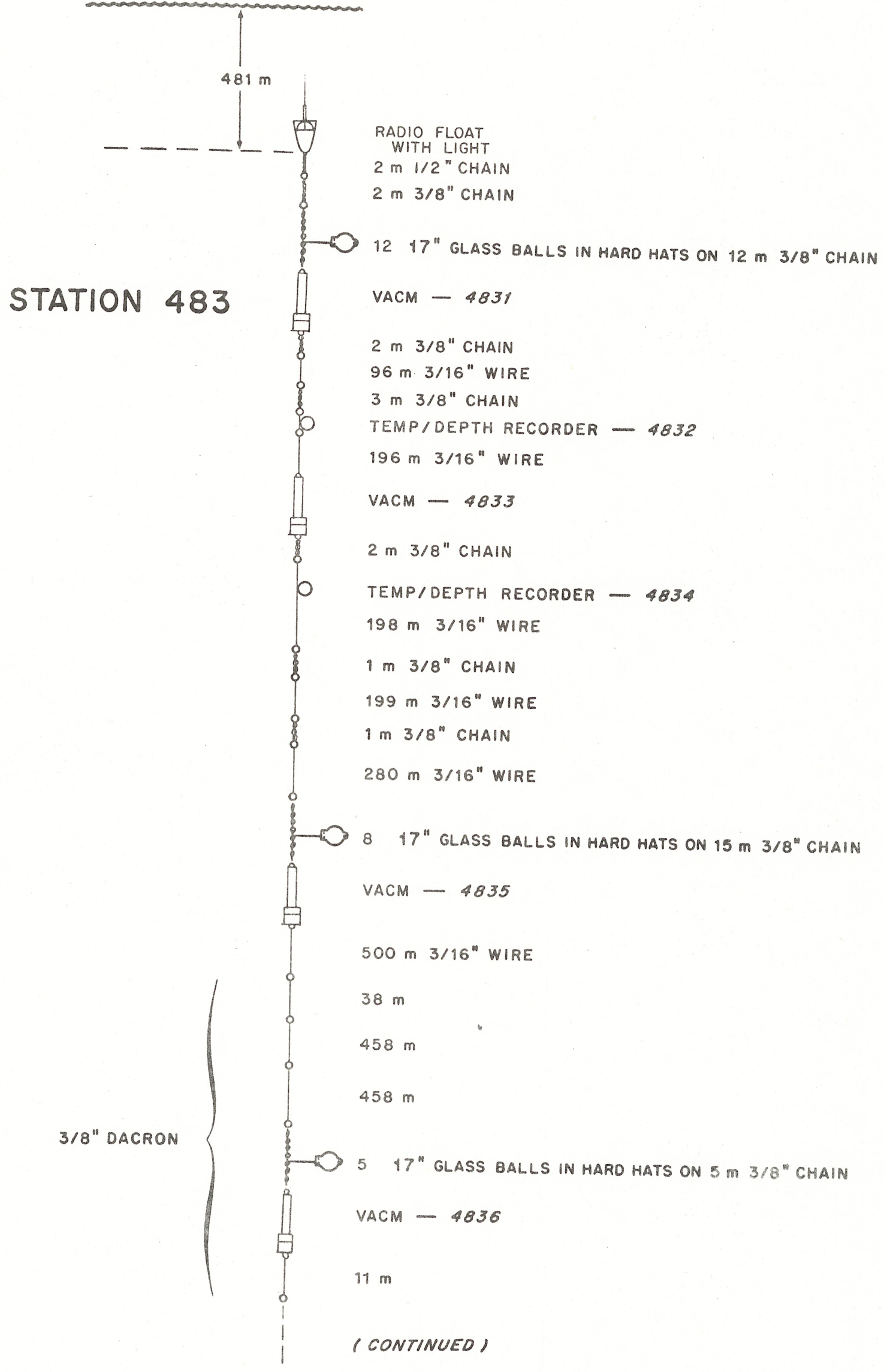




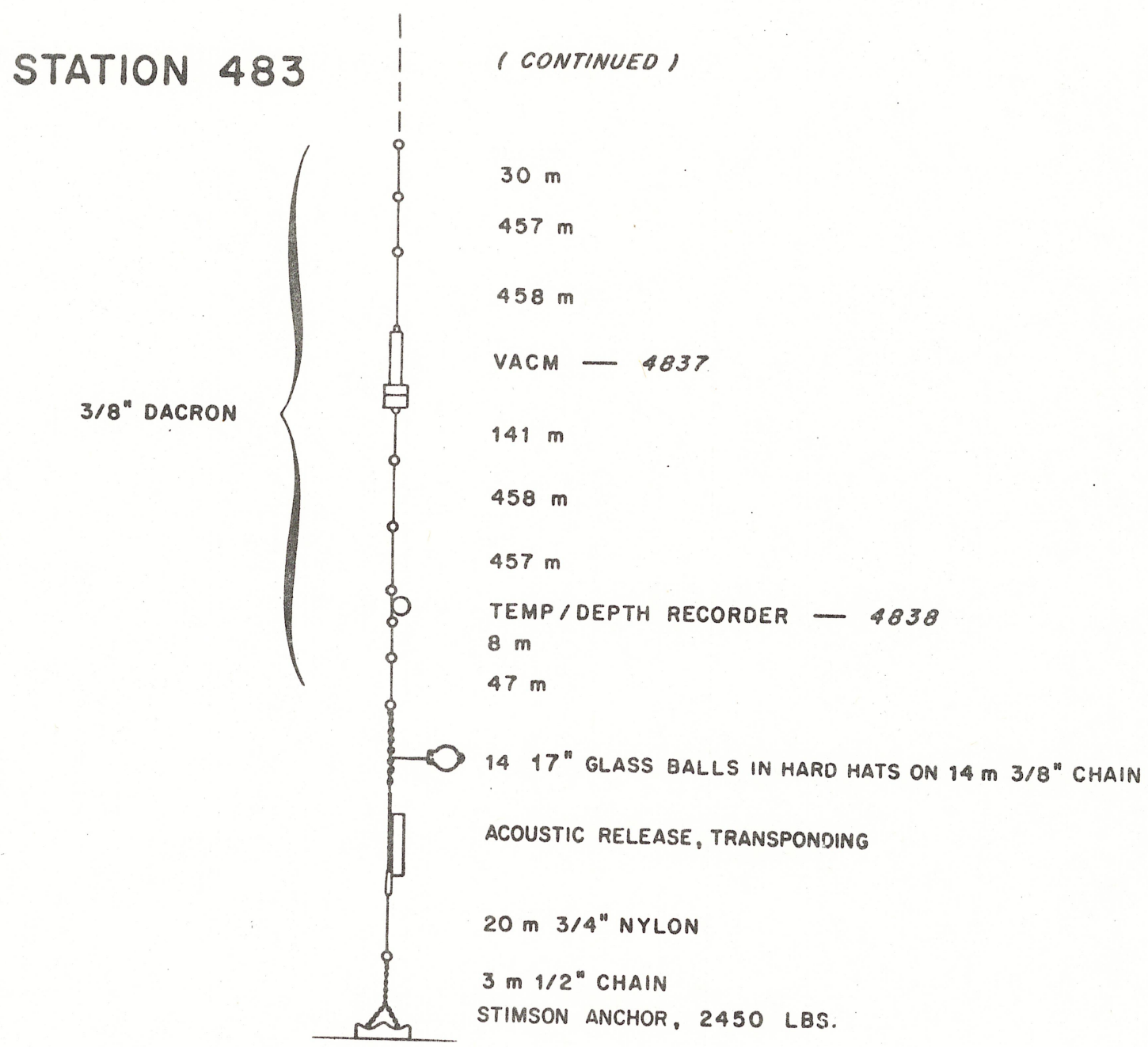




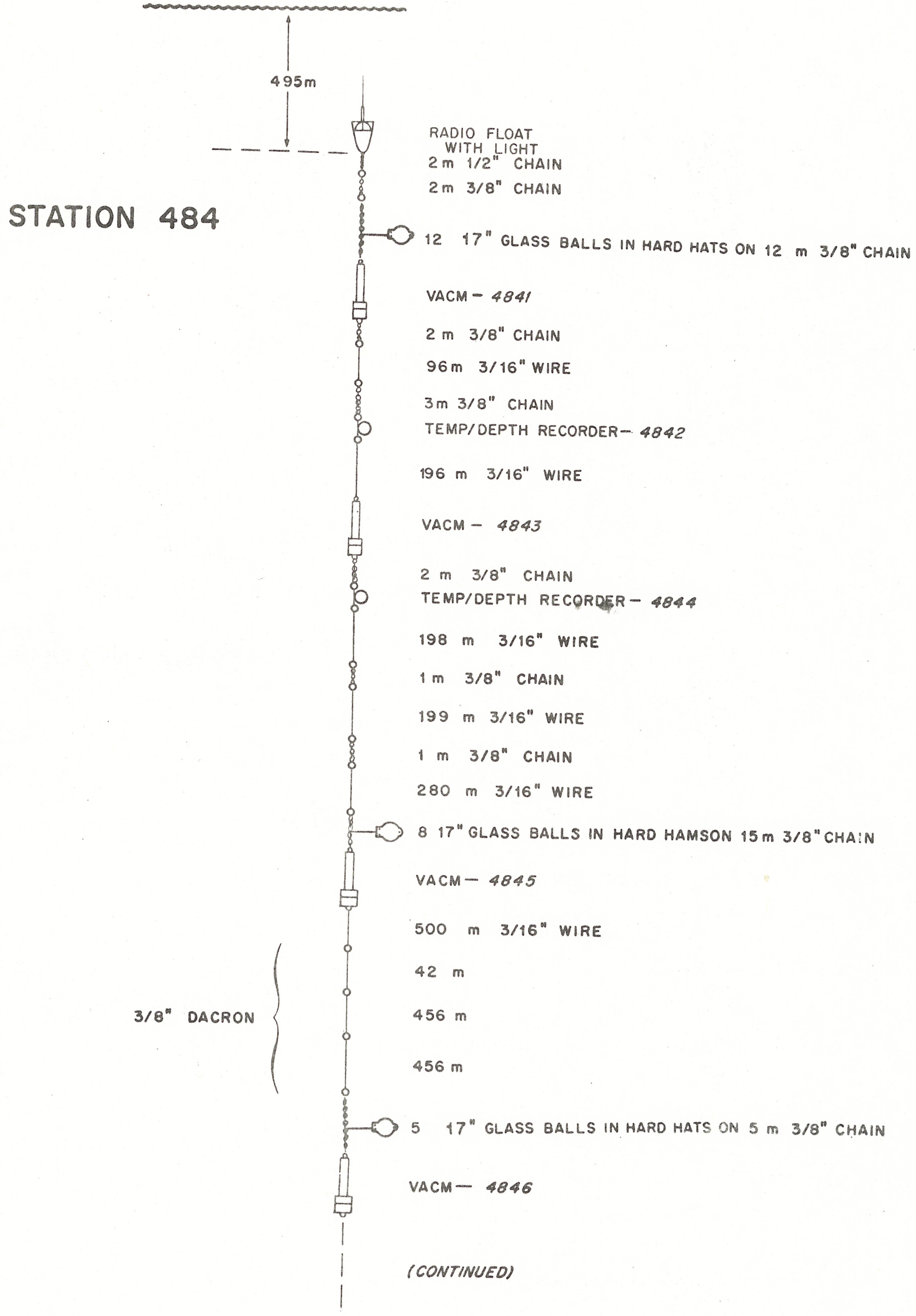


$-77-$

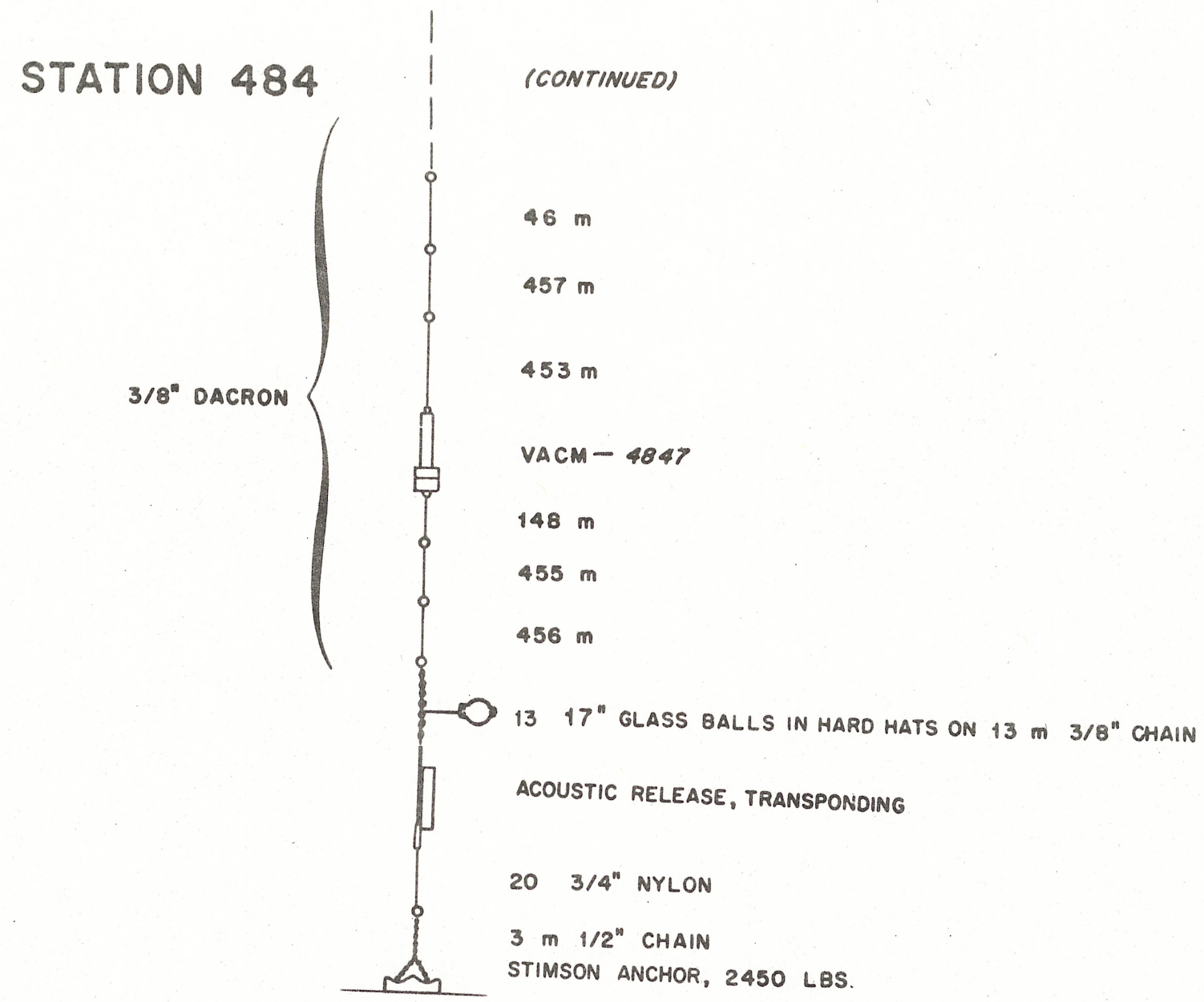



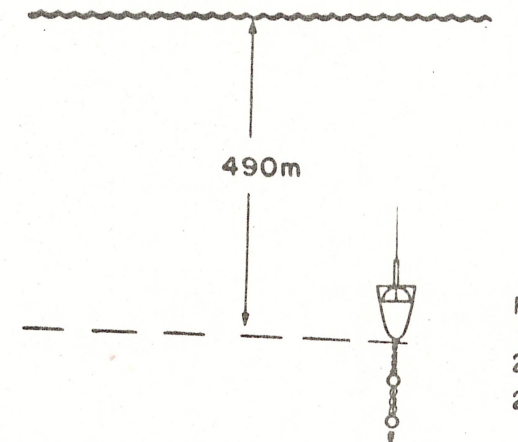

RADIO FLOAT

WITH LIGHT

2 m $1 / 2^{11}$ CHAIN

2 m 3/8" CHAIN

STATION 485

3/16" WIRE

3/8 DACRON

$1317 "$ GLASS BALLS IN HARO HATS ON $13 \mathrm{~m}$ 3/8" CHAIN

VACM - 4851

2 m 3/8" CHAIN

$96 \mathrm{~m} \mathrm{3/16"} \mathrm{WIRE}$

3 m 3/8" CHAIN

TEMP/DEPTH RECORDER - 4852

$196 \mathrm{~m} 3 / 16^{n}$ WIRE

VACM -4853

2 m 3/8" CHAIN

$198 m$

TEMP/DEPTH RECORDER - 4854

$199 \mathrm{~m}$

TEMP/DEPTH RECORDER - 4855

$280 \mathrm{~m}$

$817^{\prime \prime}$ GLASS BALLS IN HARO HATS ON' 15 m $3 / 8^{\circ}$ CMAIN

VACM - 4856

$500 \mathrm{~m}$

TEMP/DEPTH RECORDER - 4857

$10 \mathrm{~m}$

$16 \mathrm{~m}$

$457 \mathrm{~m}$

TEMP/DEPTH RECORDER - 4858

$8 \mathrm{~m}$

$458 \mathrm{~m}$

(CONTINUEO) 


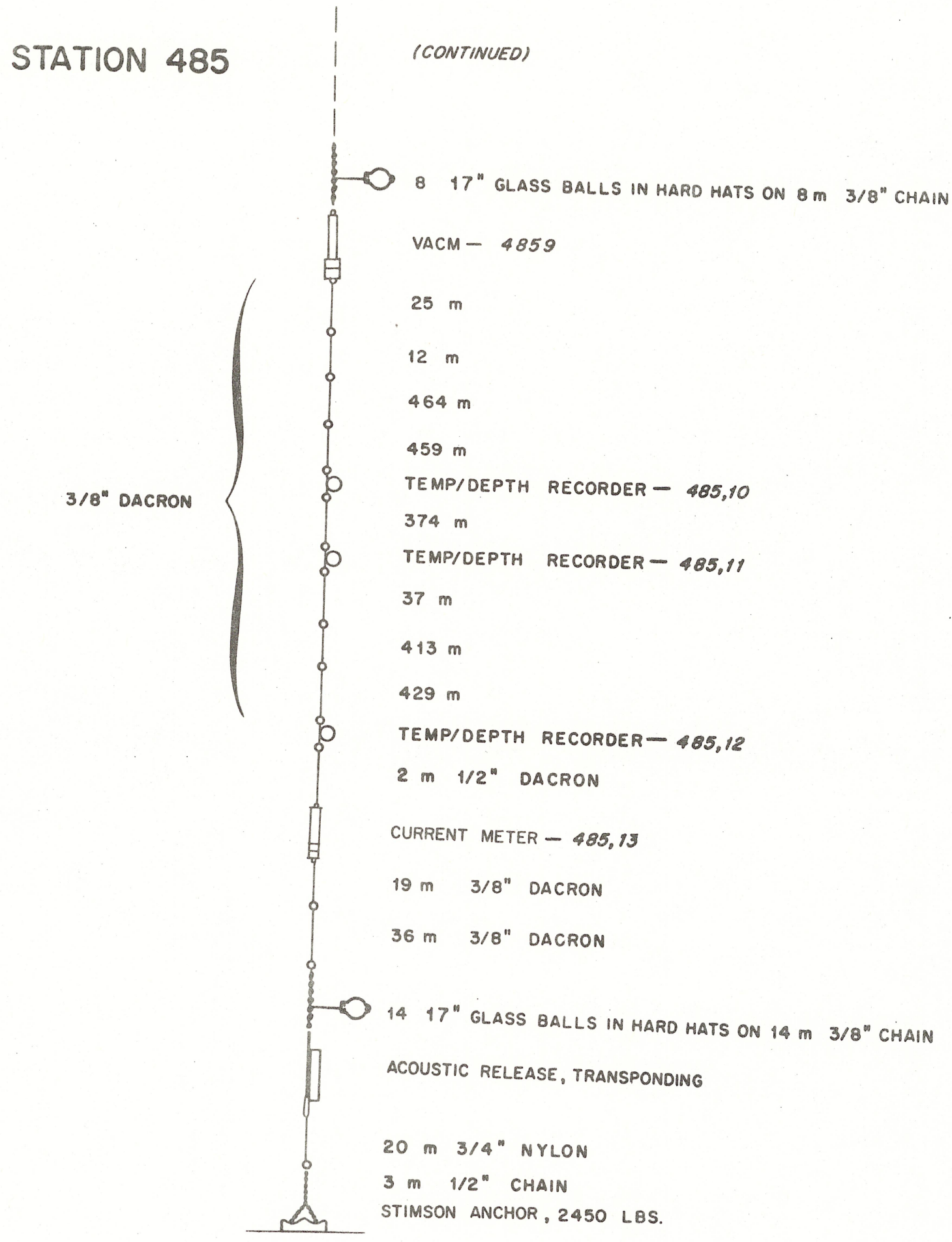




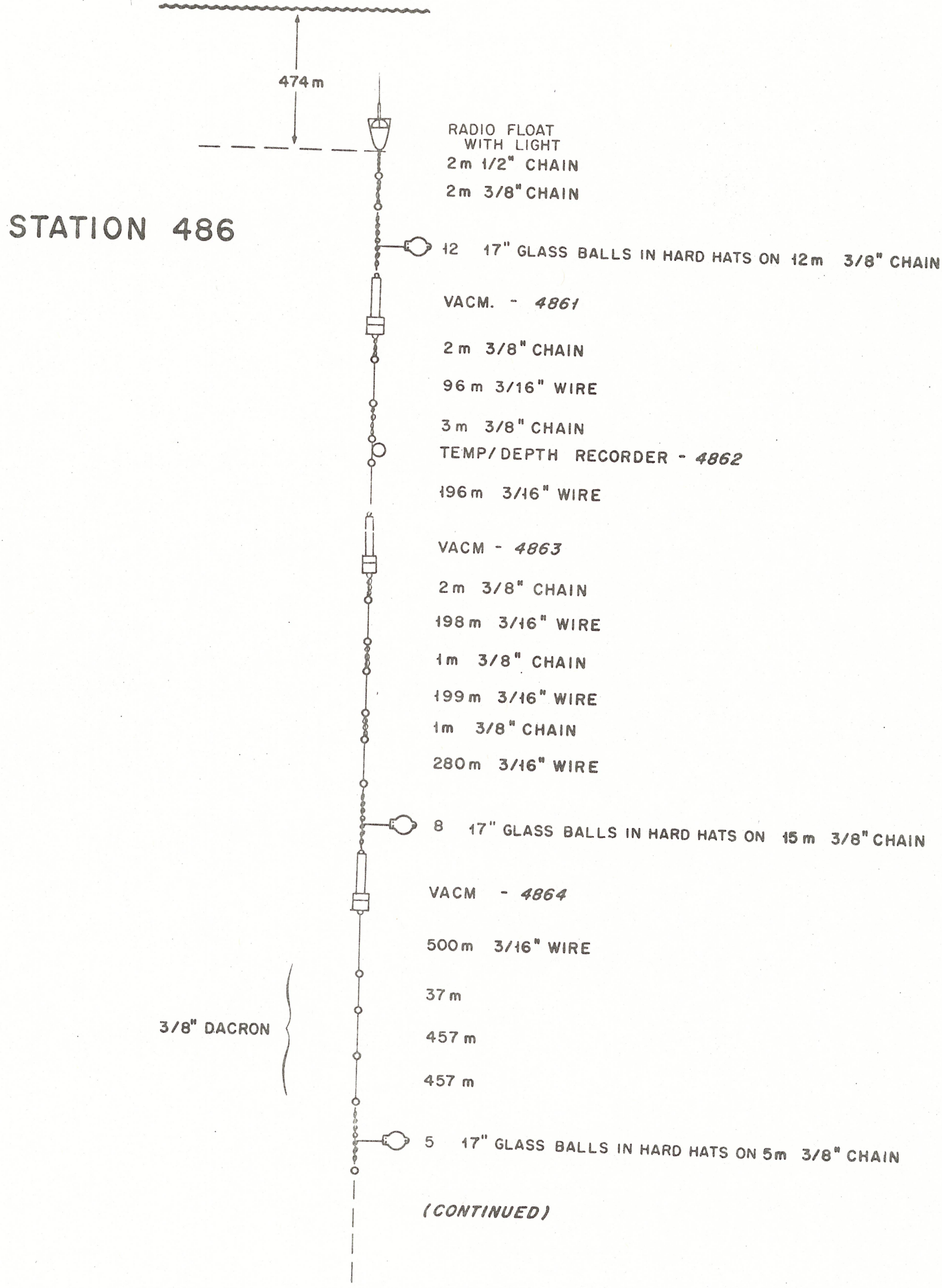




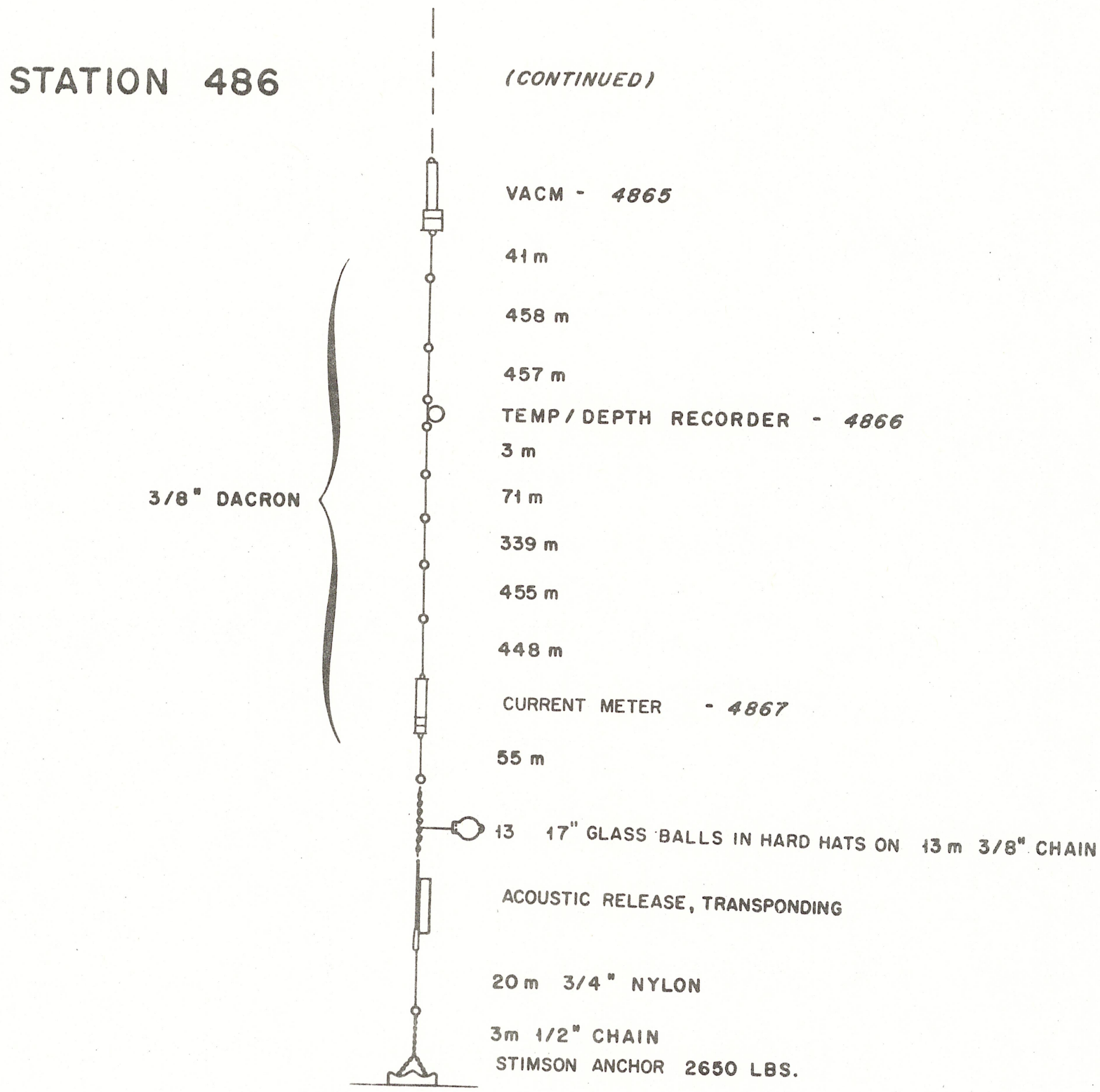


STATION 488

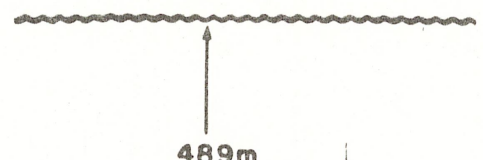

RADIO FLOAT

WITH LIGHT

$2 \mathrm{~m} 1 / 2$ " CHAIN

2 m 3/8" CHAIN

$1217 "$ GLASS BALLS IN HARD HATS ON $12 \mathrm{~m}$ 3/8" CHAIN

VACM - 4881

$2 m 3 / 8^{\prime \prime}$ CHAIN

$96 \mathrm{~m} 3 / 16^{\prime \prime}$ WIRE

$3 \mathrm{~m} \mathrm{3/8"} \mathrm{CHAIN}$

TEMP/DEPTH RECORDER - 4882

$196 \mathrm{~m} \mathrm{3/16"} \mathrm{WIRE}$

VACM - 4883

$2 \mathrm{~m} 3 / 8^{\prime \prime}$ CHAIN

$198 \mathrm{~m} \quad 3 / 16^{\mathrm{N}}$ WIRE

Im 3/8" CHAIN

$199 \mathrm{~m} 3 / 16^{\prime \prime}$ WIRE

Im 3/8" CHAIN

$280 \mathrm{~m} 3 / 46^{11}$ WIRE

$817 "$ GLASS BALLS IN HARD HATS ON $15 \mathrm{~m} 3 / 8^{\prime \prime}$ CHAIN

VACM - 4884

$500 \mathrm{~m} 3 / 46^{\mathrm{m}}$ WIRE

$458 \mathrm{~m}$

$458 m$

$35 \mathrm{~m}$

(CONTINUEO) 


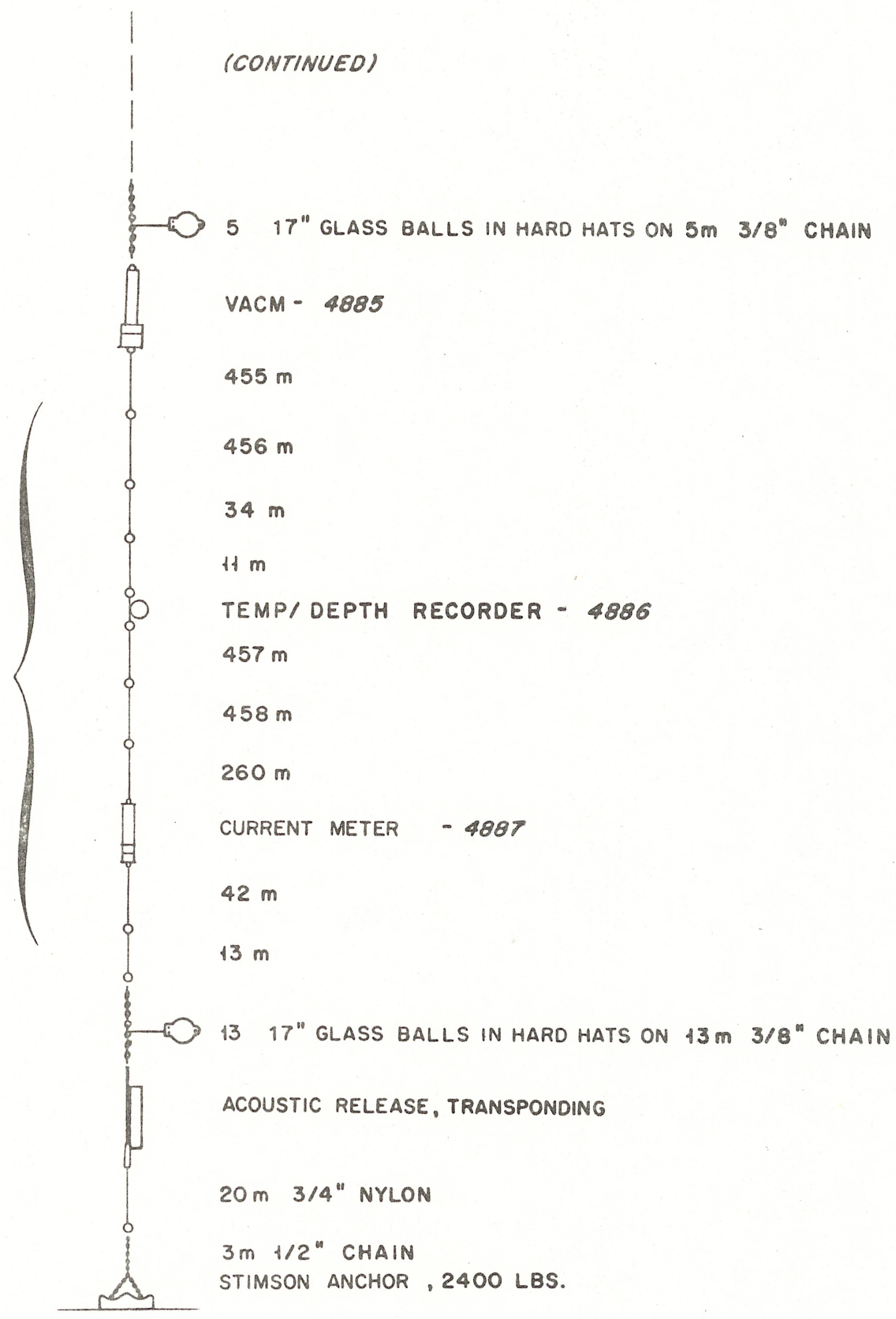




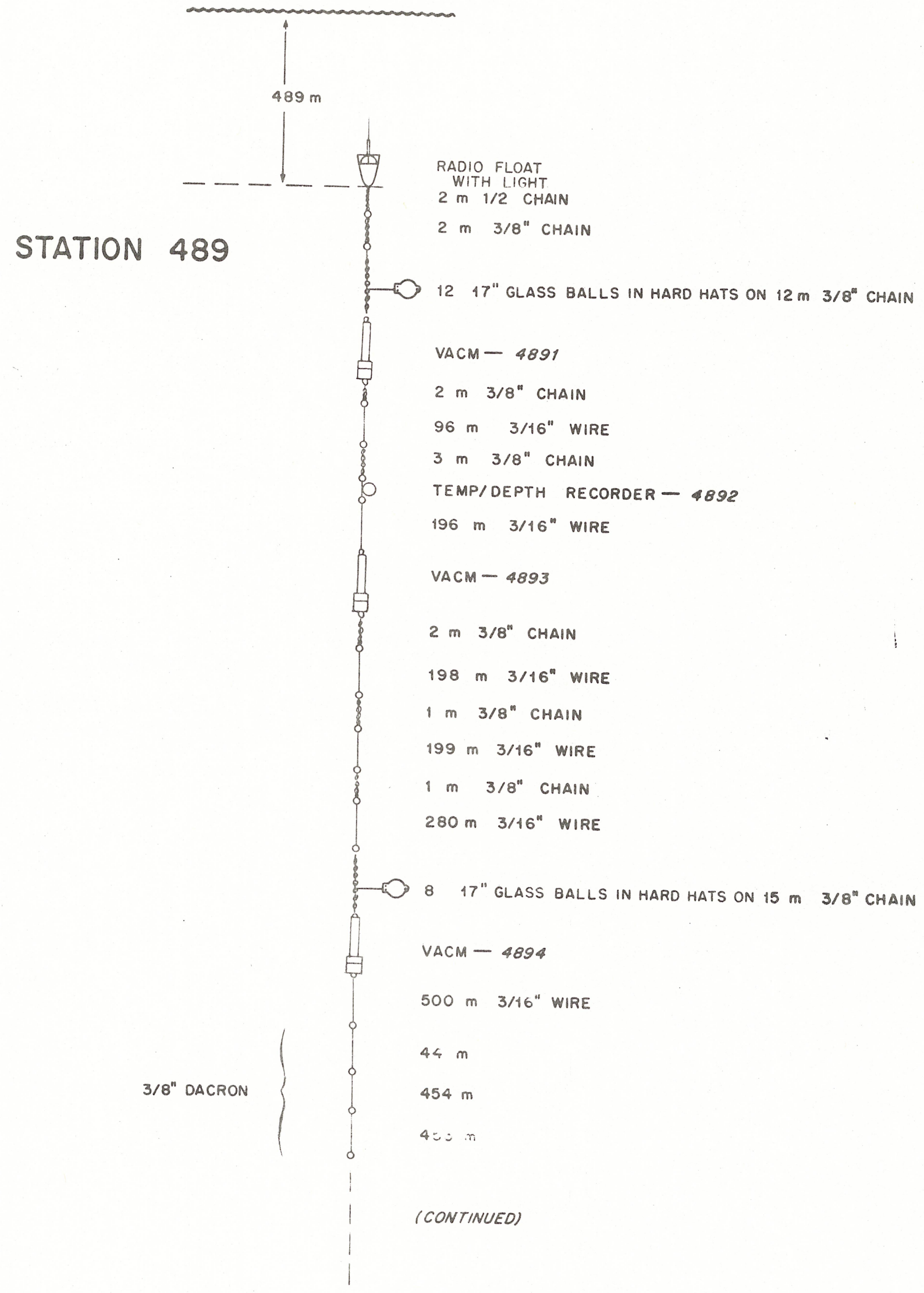


$-85-$

STATION 489

(CONTINUED)

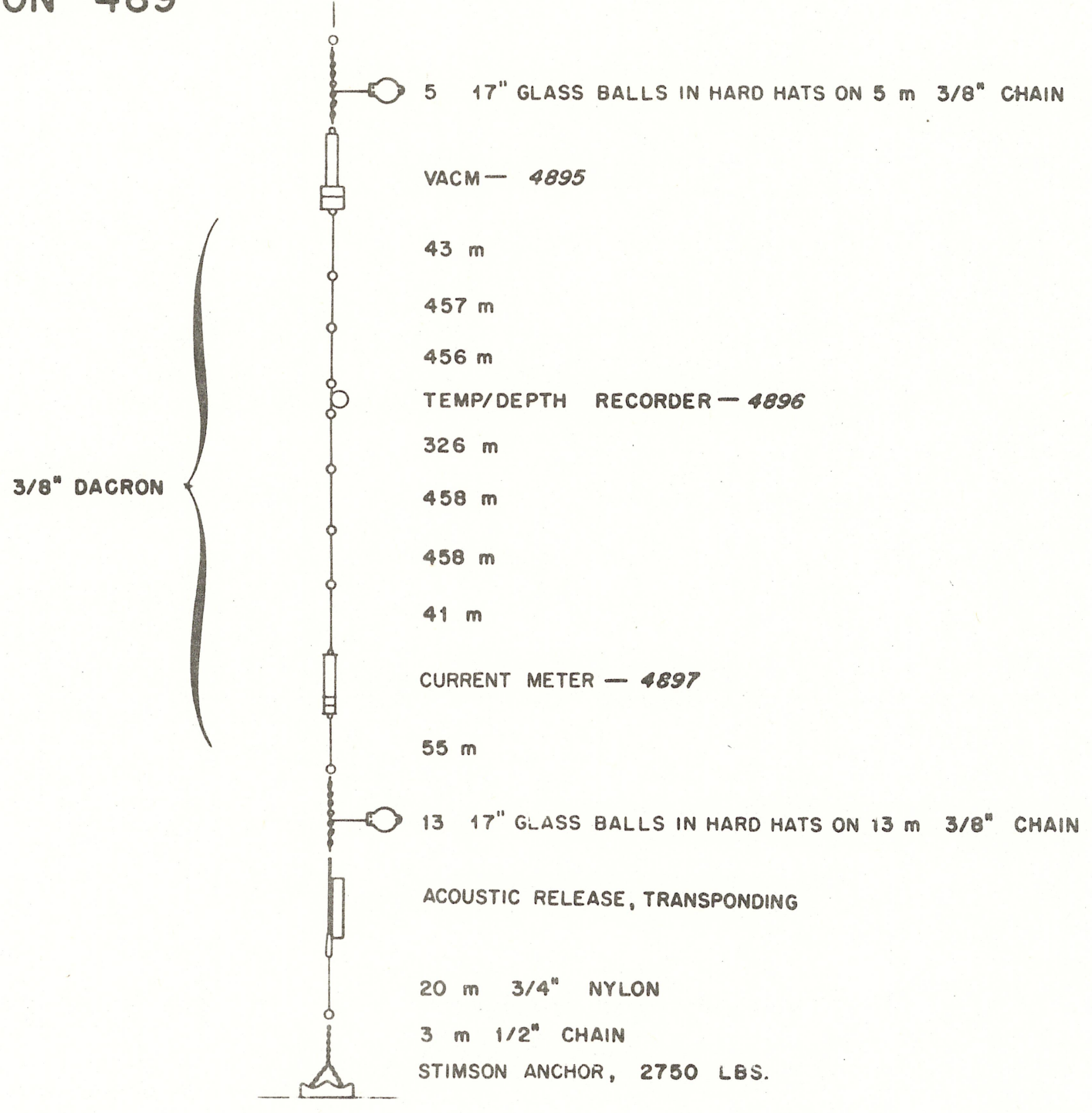




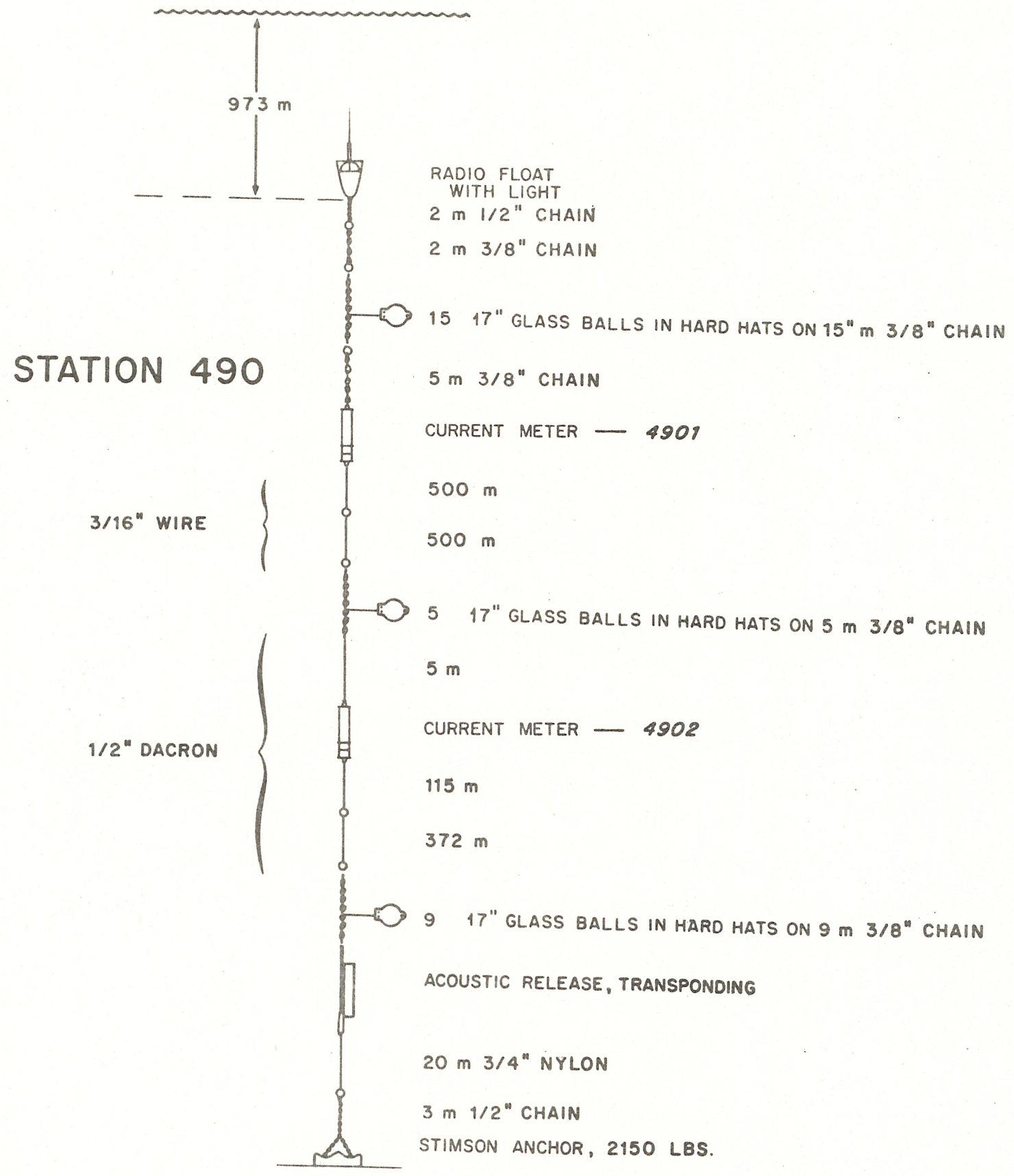




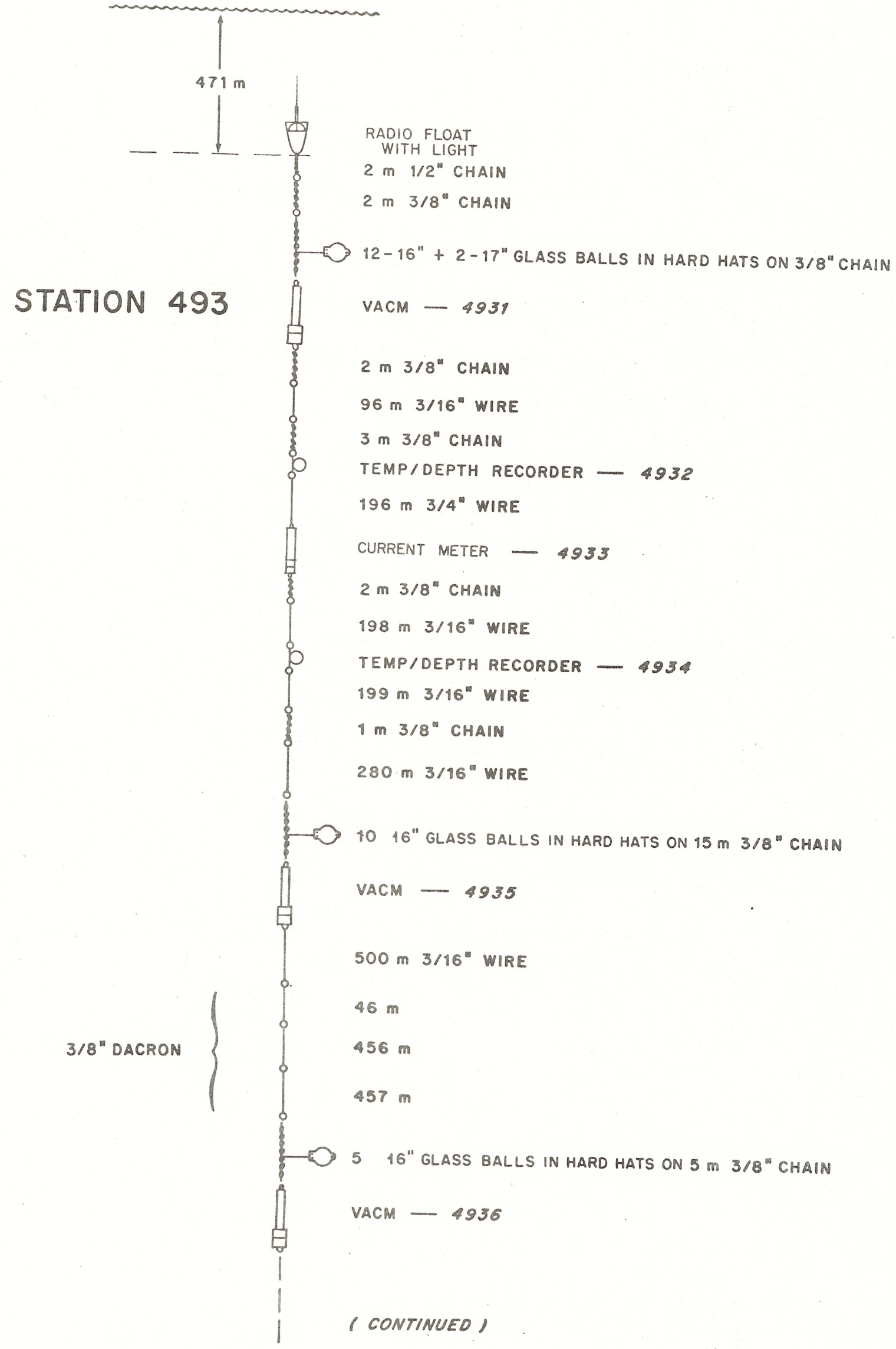




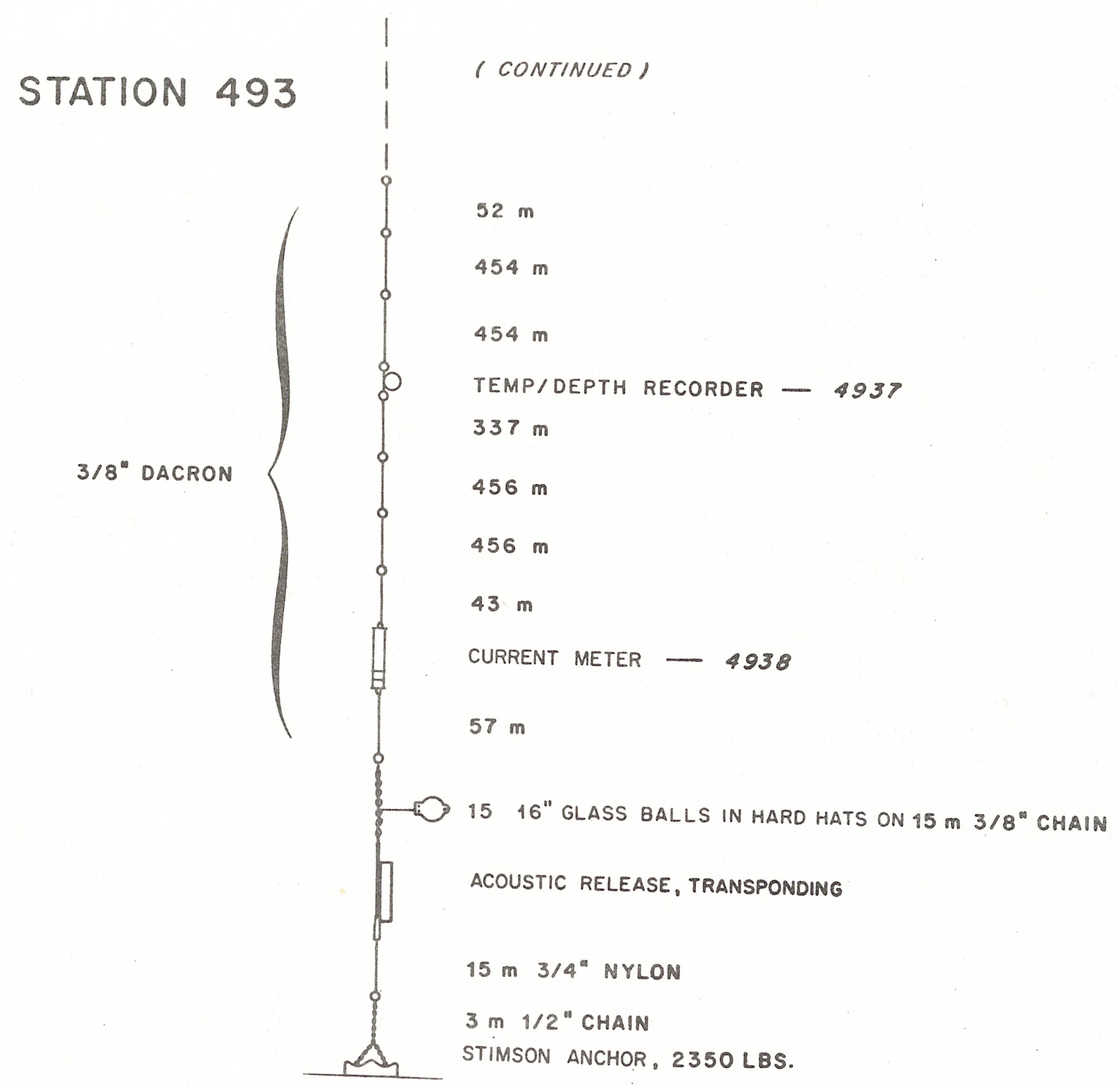




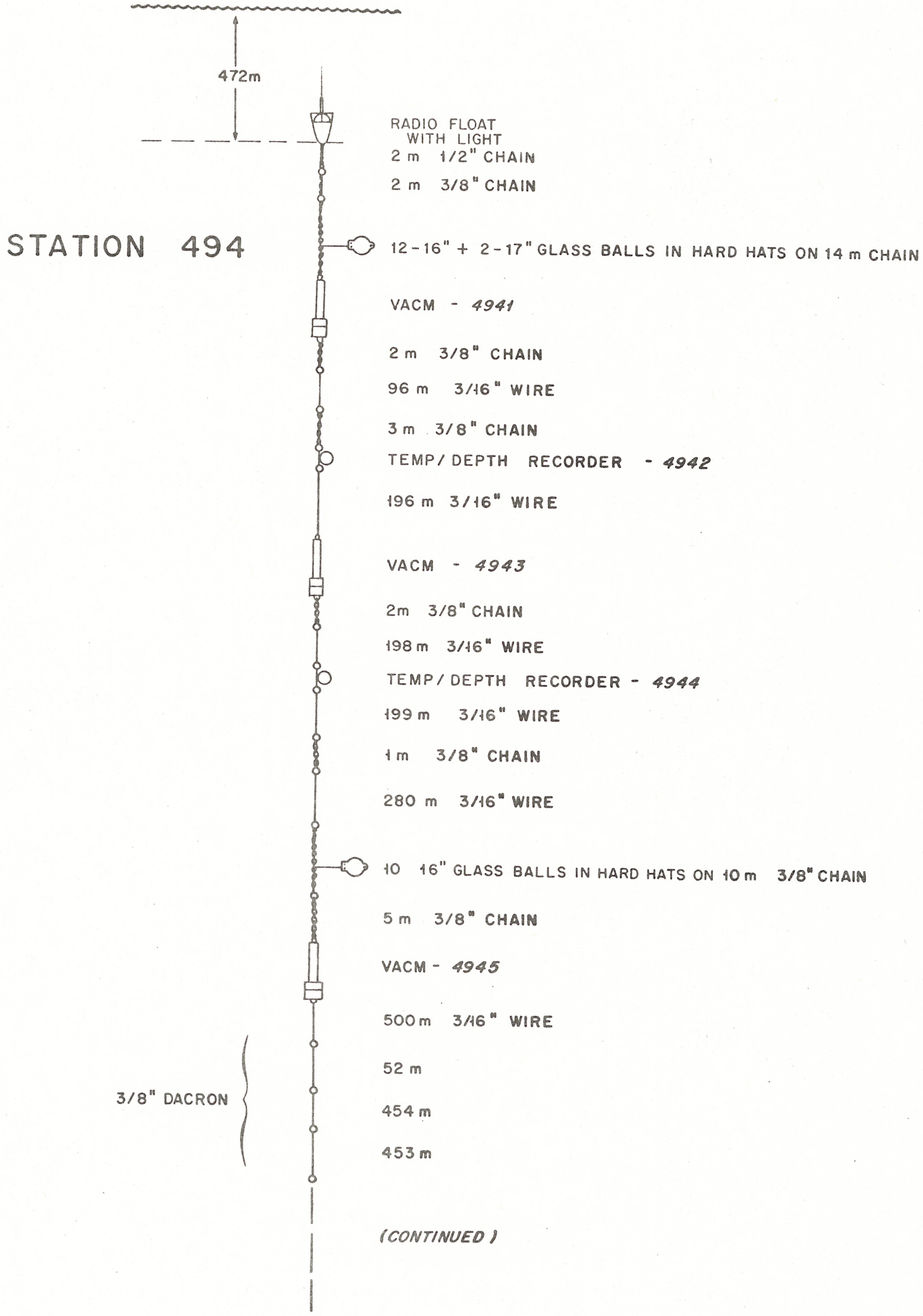




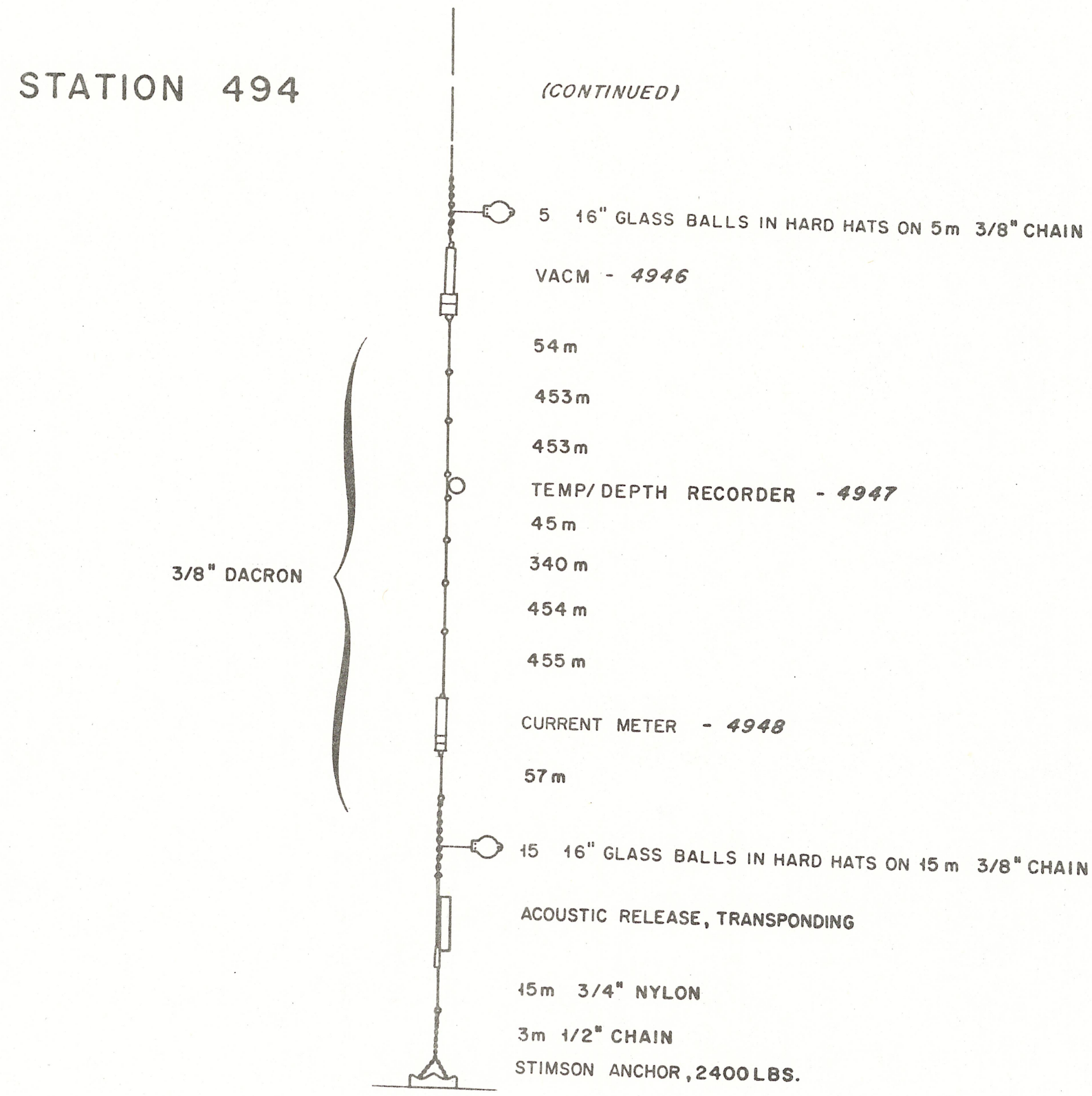




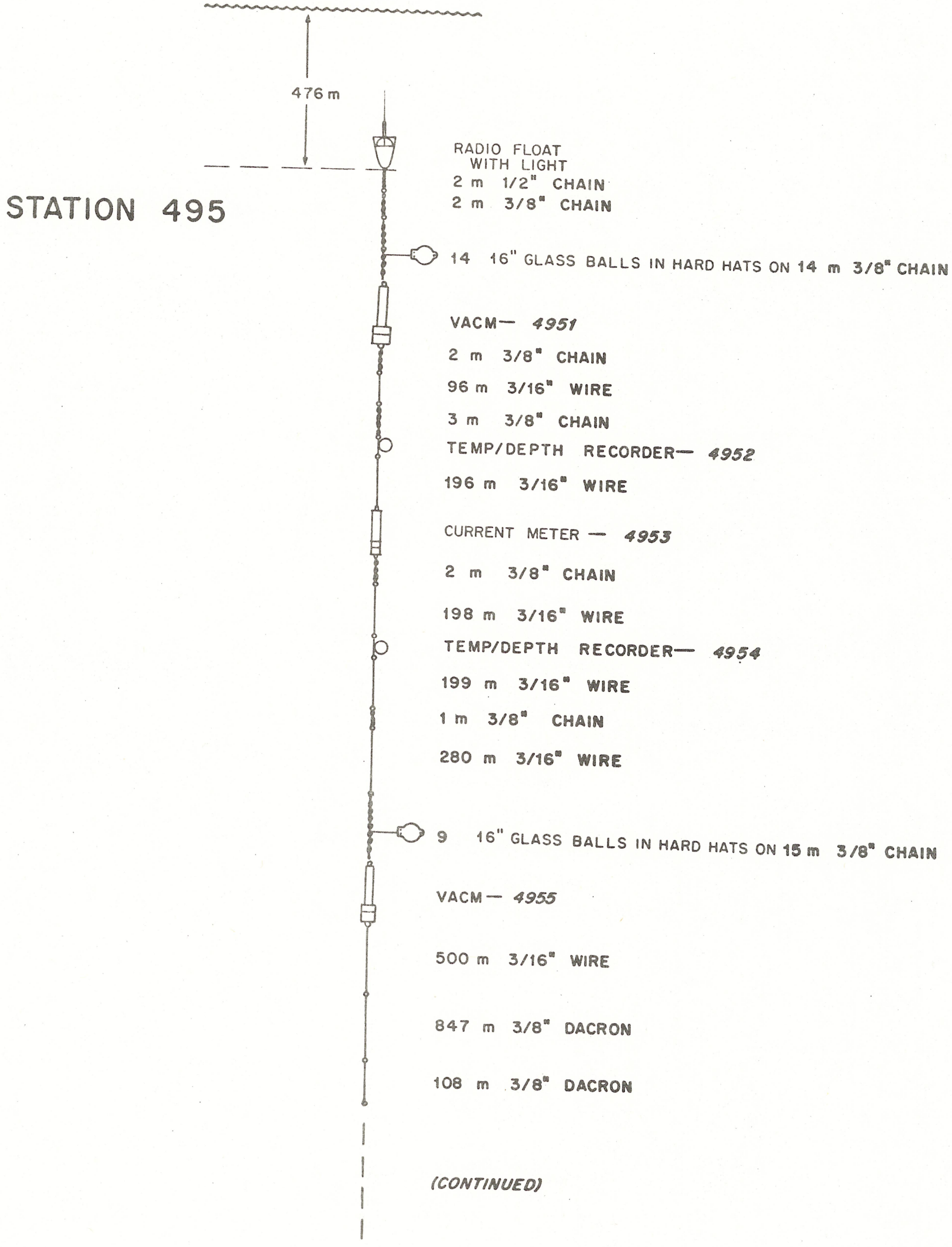


$-92-$

STATION 495

(CONTINUED)

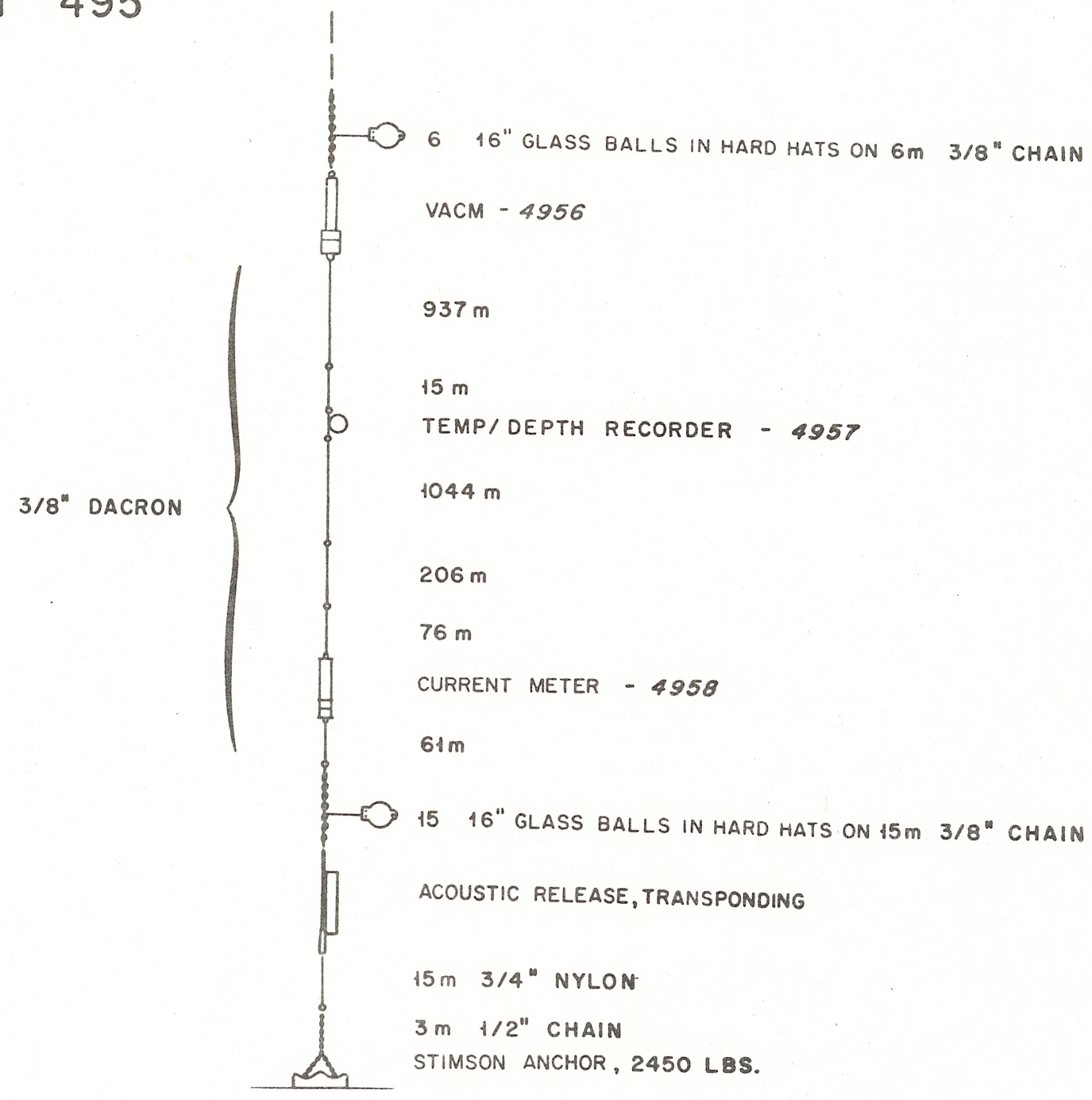




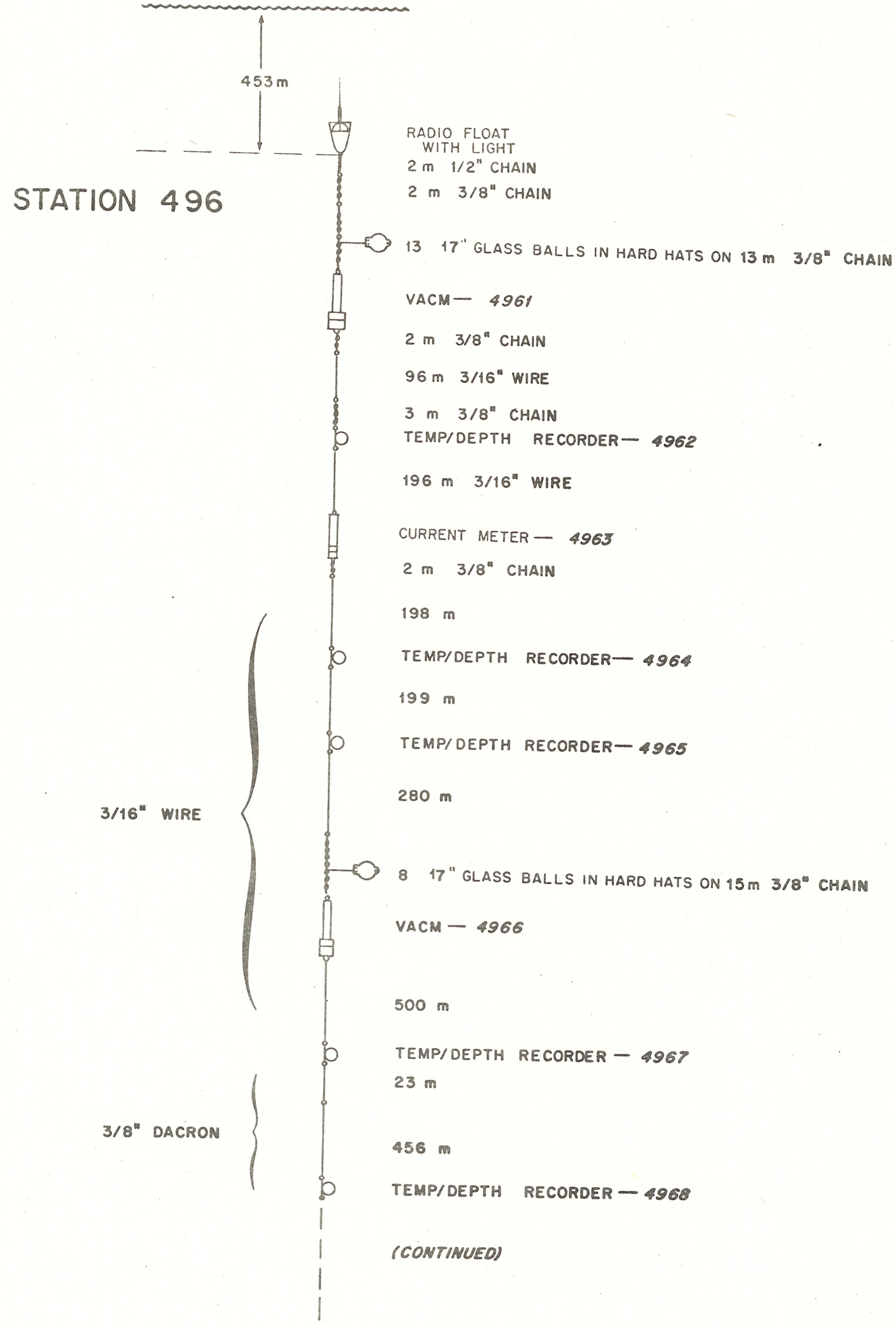


$-94-$

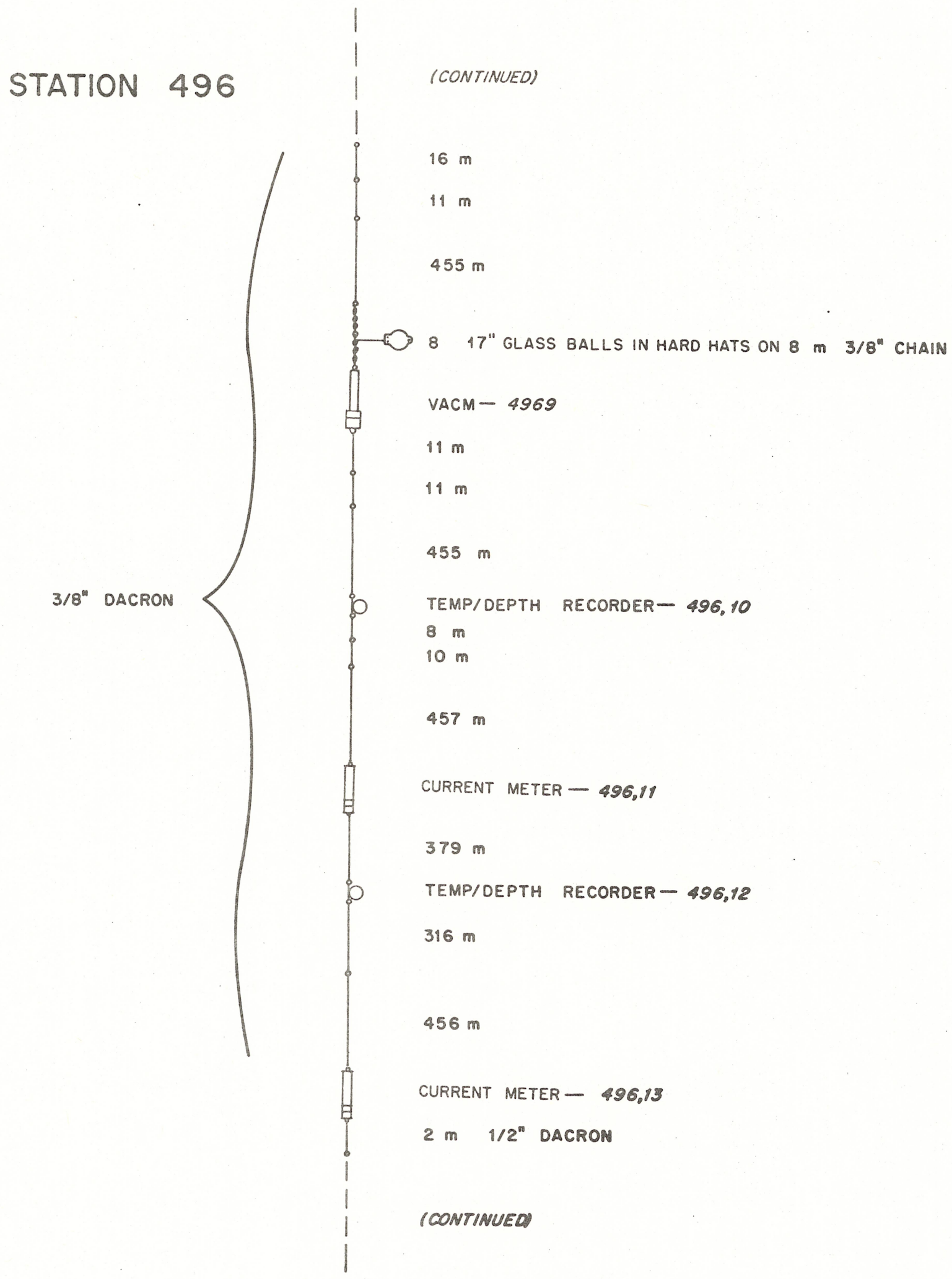


STATION 496

(CONTINUEO)

(1)

TEMP/DEPTH RECORDER- 496,14

57 m $3 / 8^{\prime \prime}$ DACRON

$1517^{\prime \prime}$ GLASS BALLS IN HARD. HATS ON $15 \mathrm{~m} 3 / 8^{\circ}$ CHAIN ACOUSTIC RELEASE, TRANSPONOING

$20 m 3 / 4^{\prime \prime}$ NYLON

3. $m$ 1/2" CHAIN

STIMSON ANCHOR, 2400 LBS. 

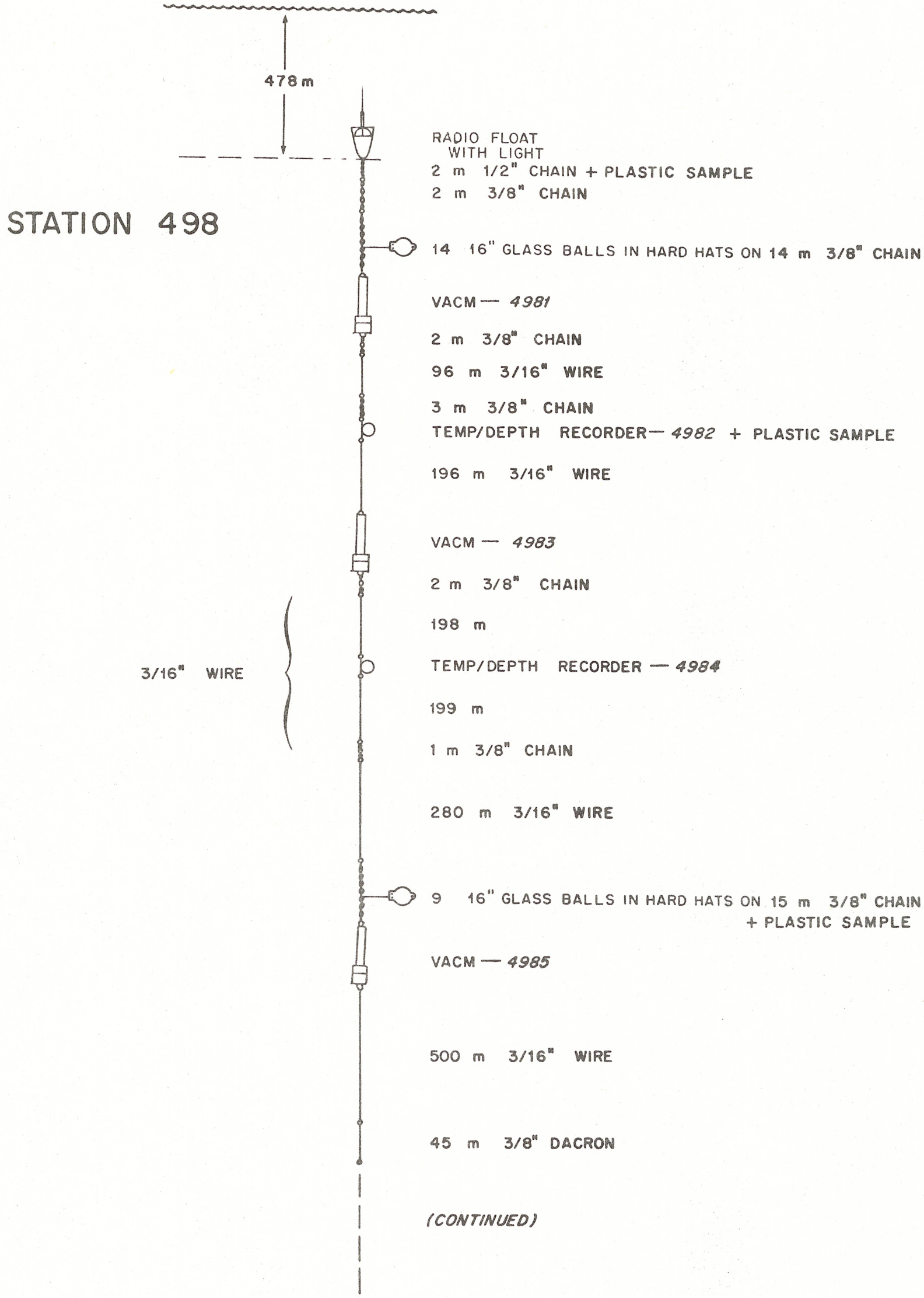


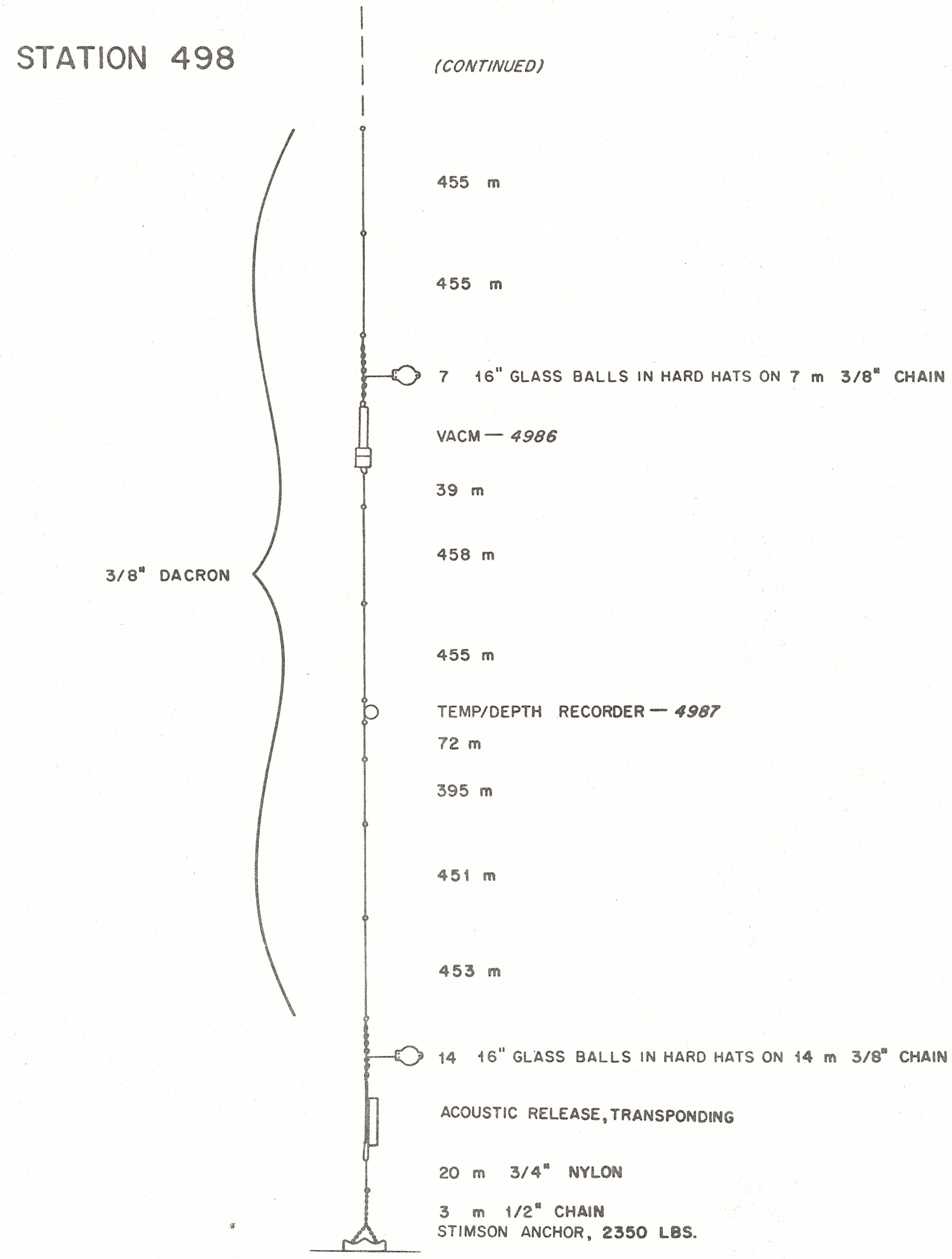




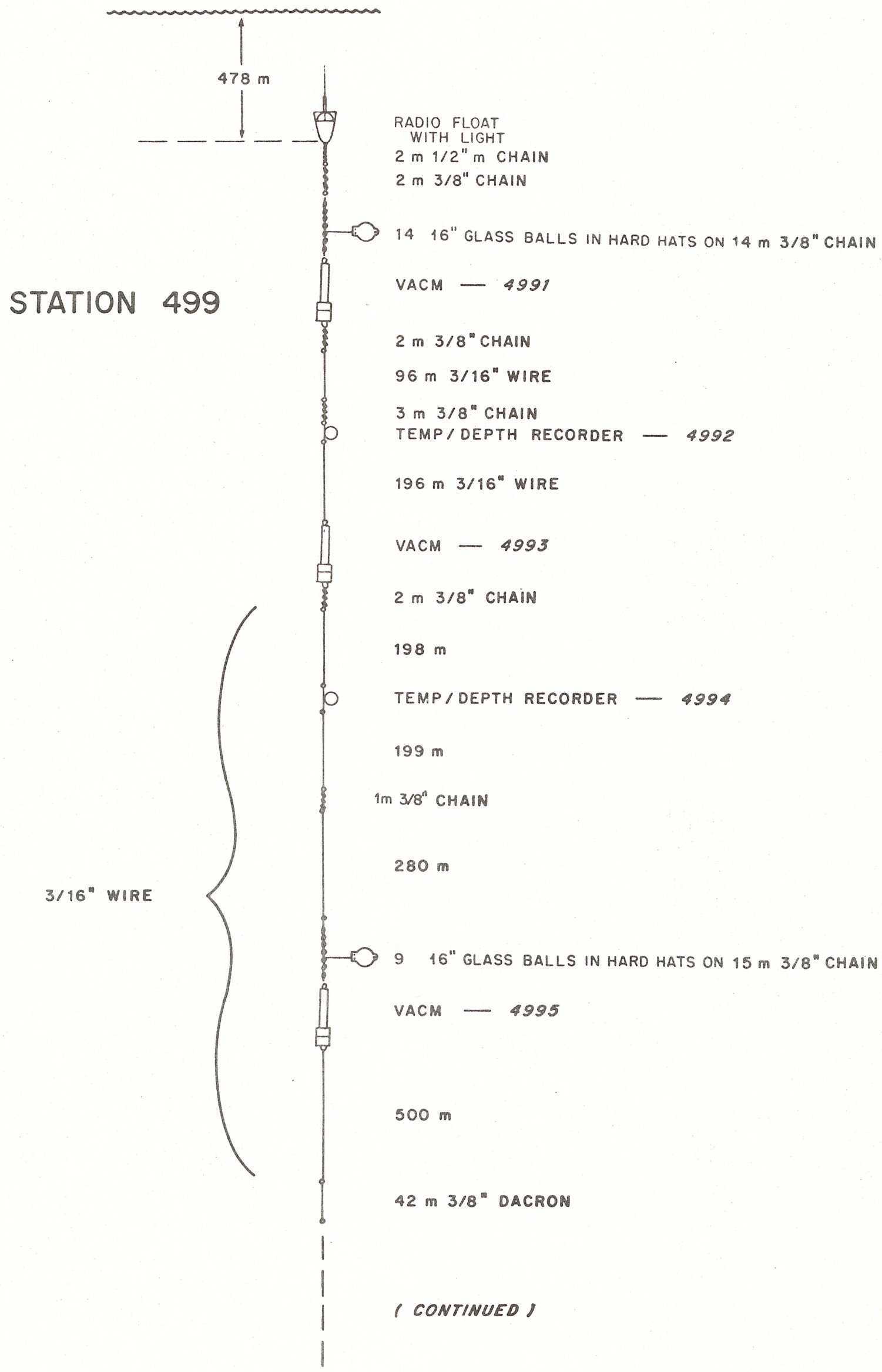




\section{STATION 499}

3/8" DACRON

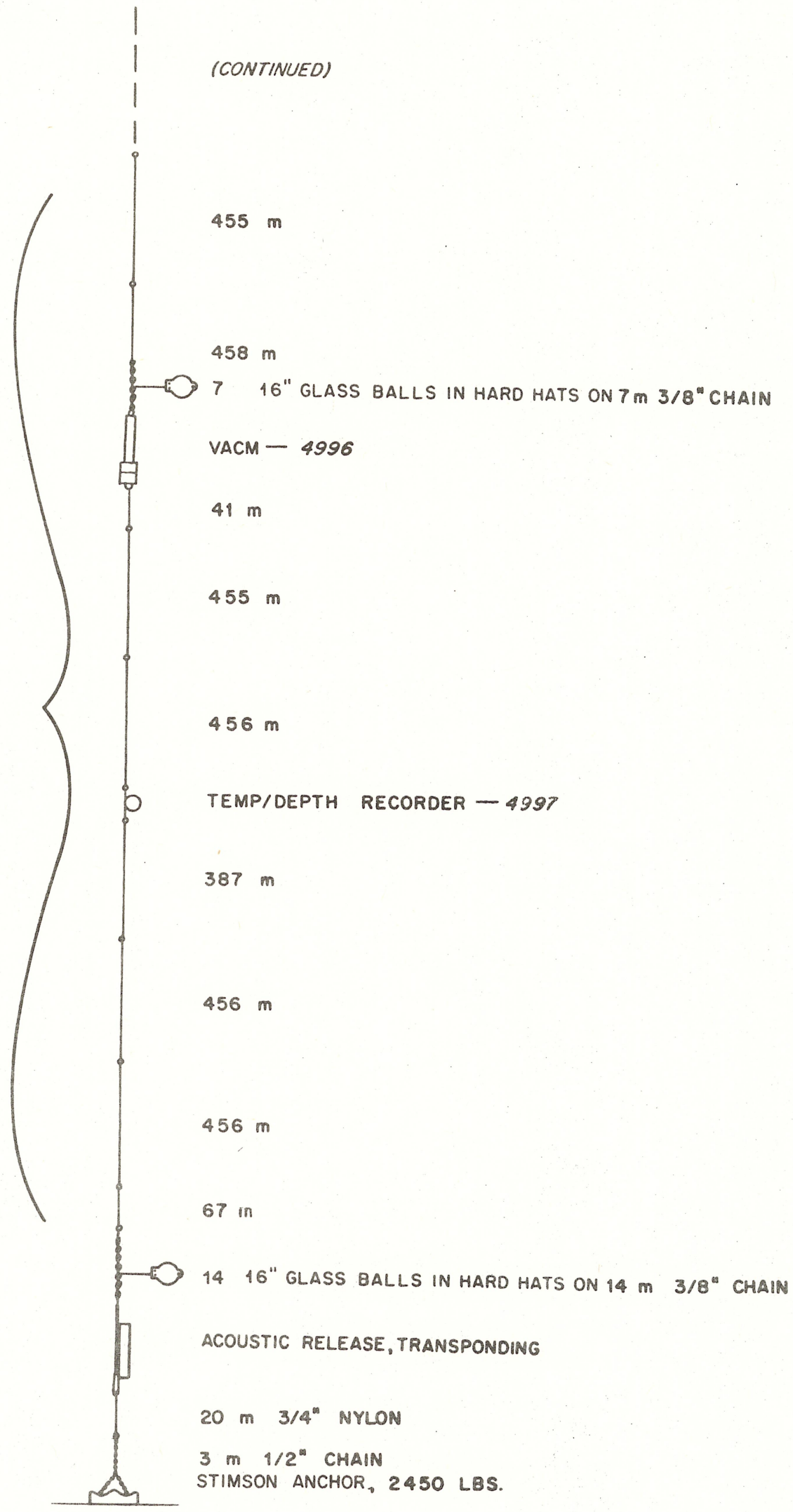


$-100-$

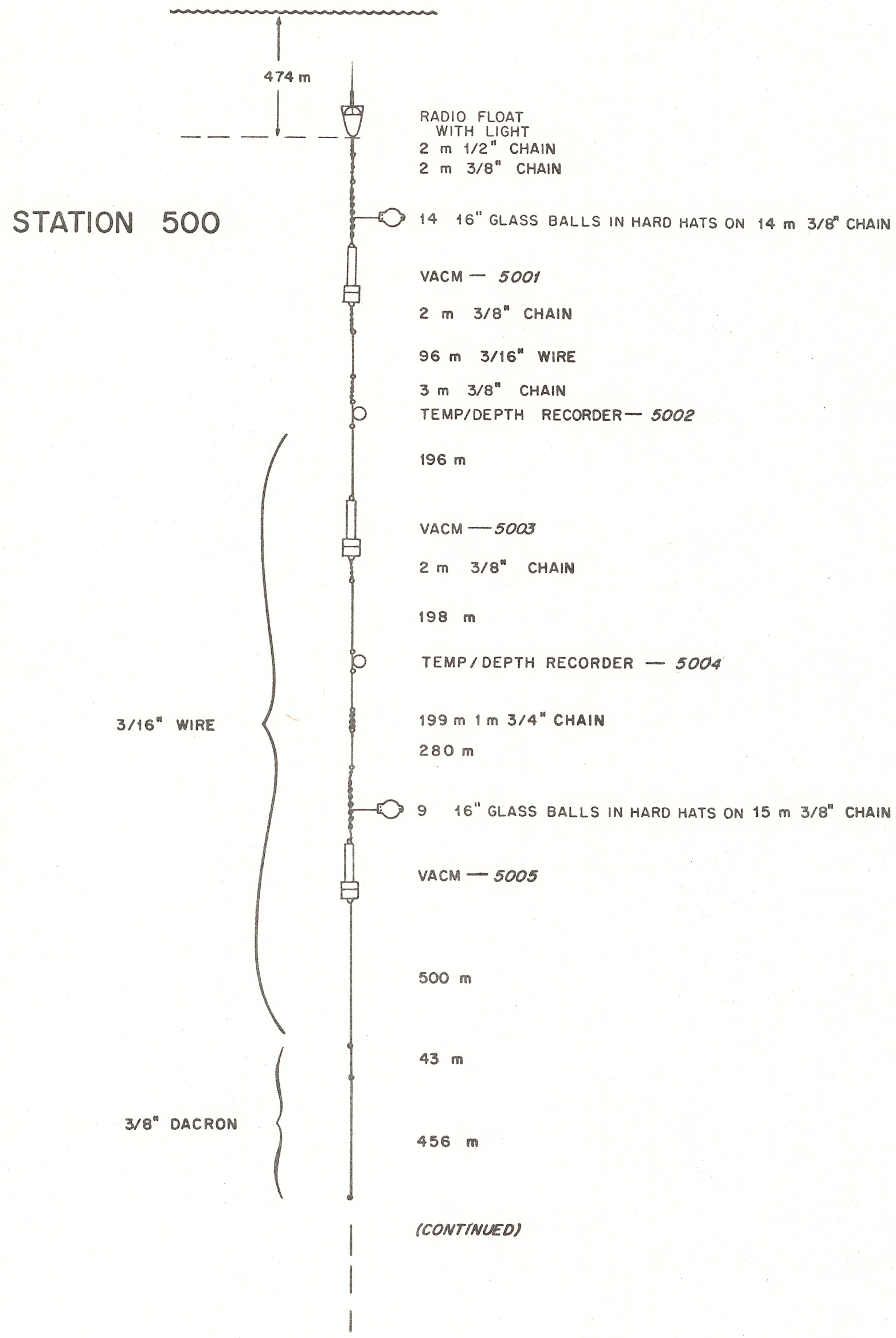


$-101-$

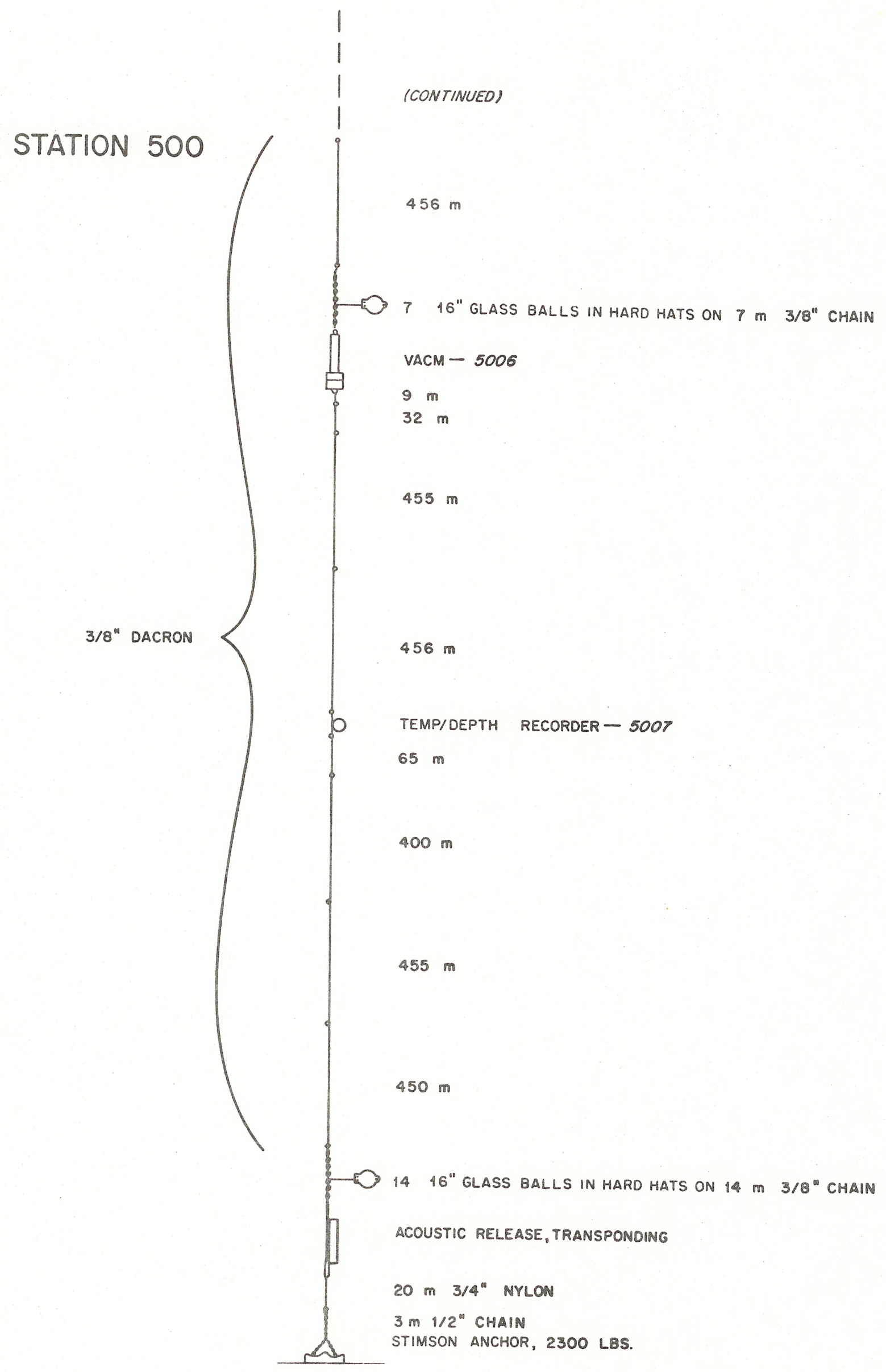




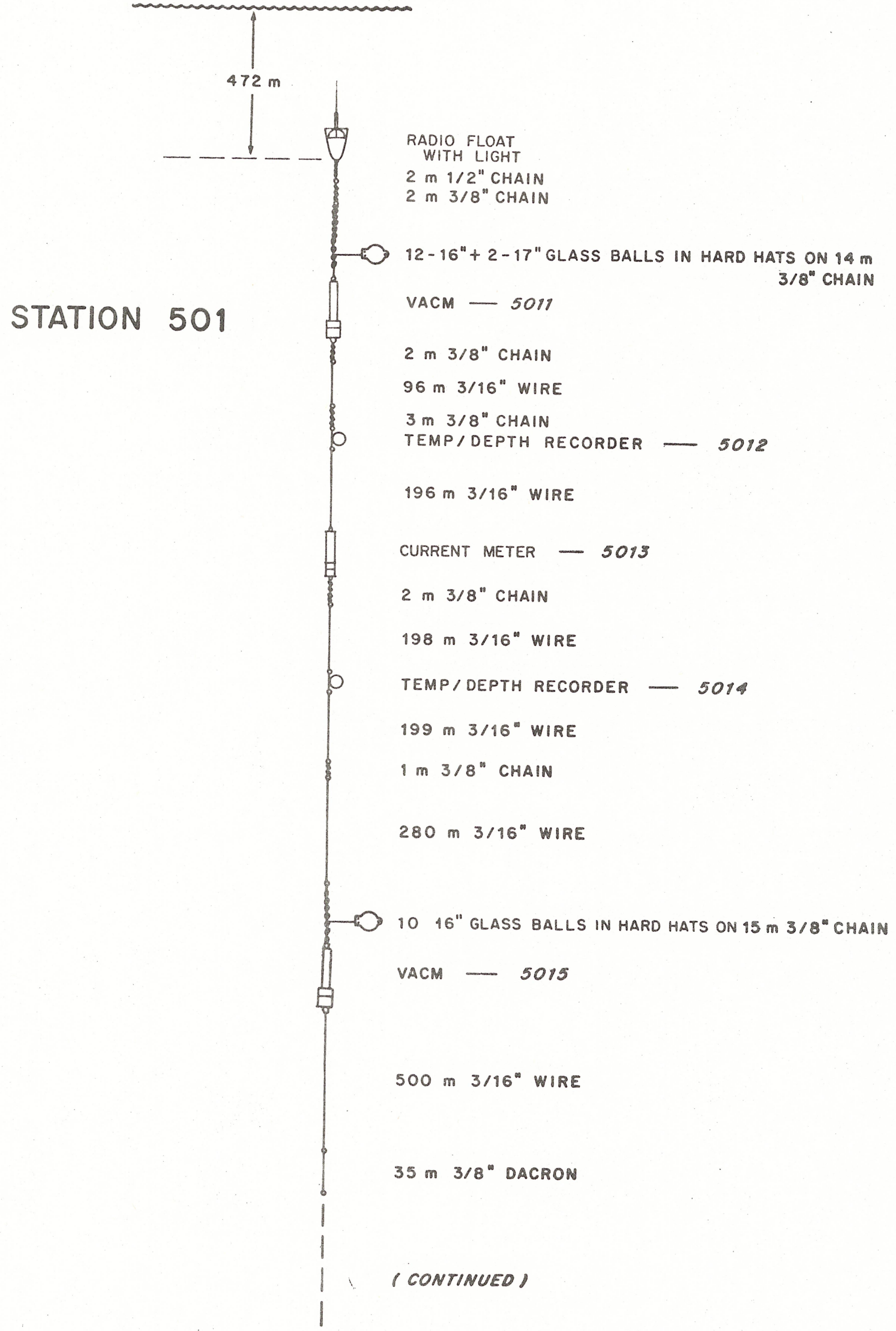


$-103-$

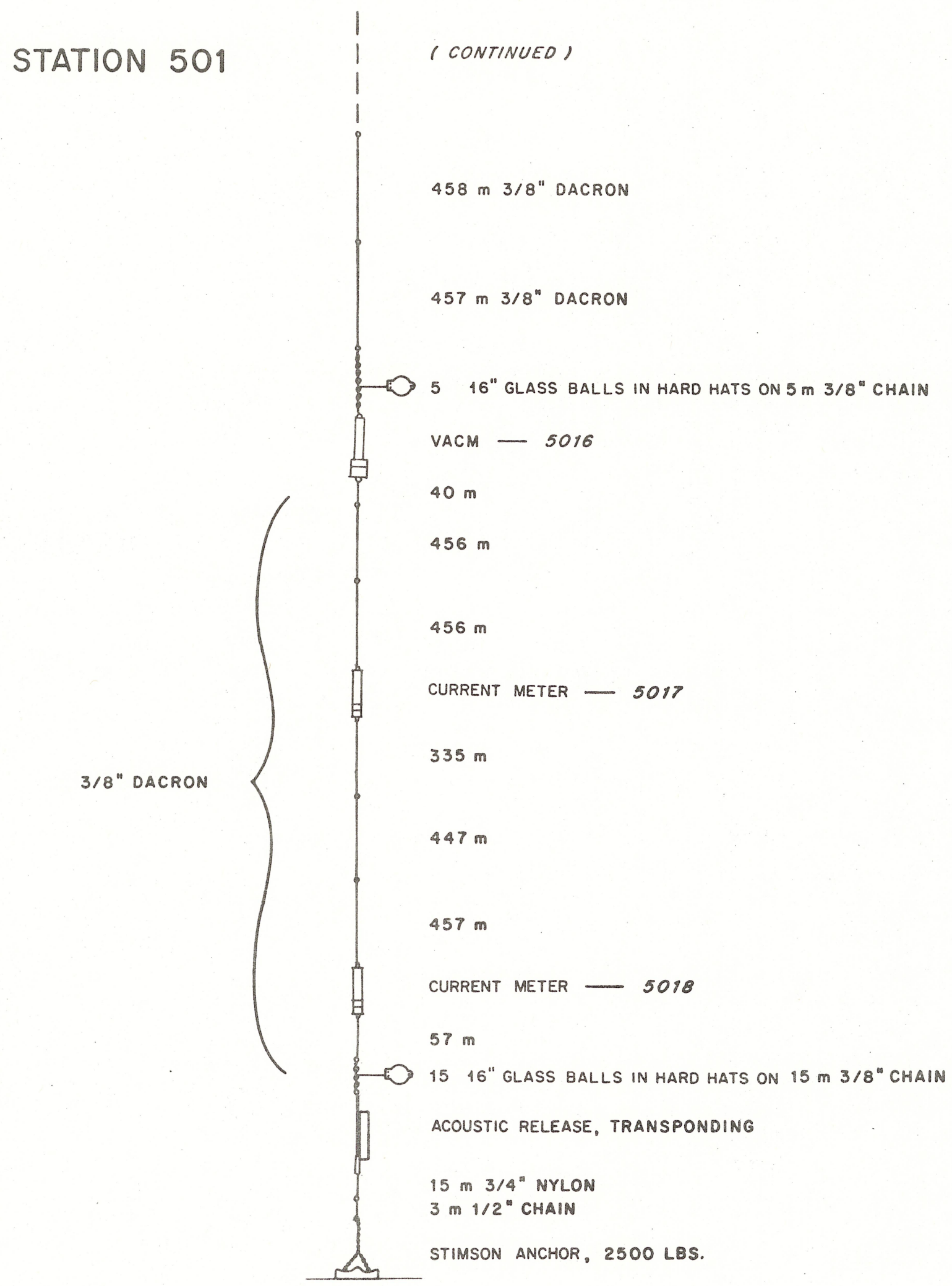




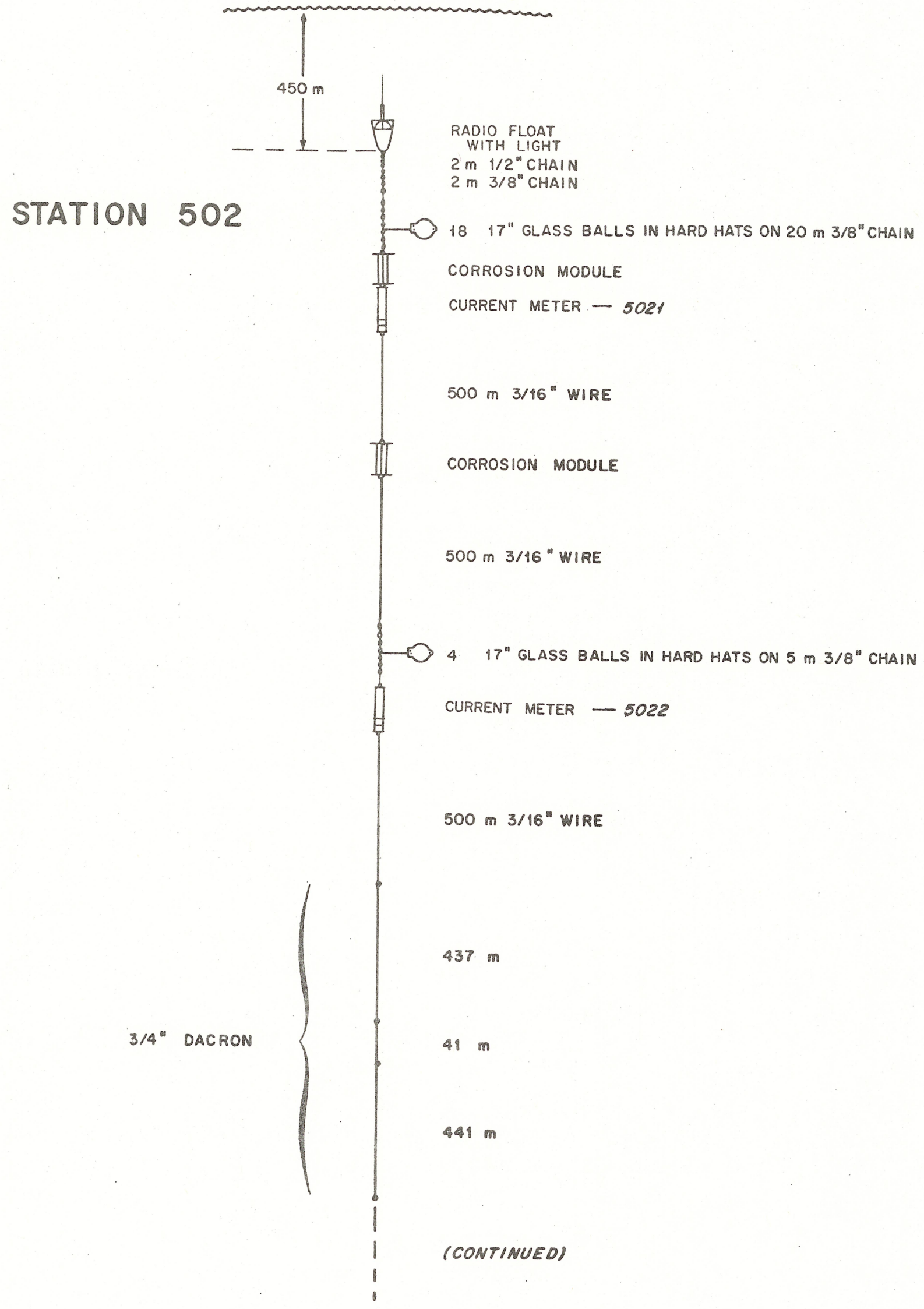


$-105-$

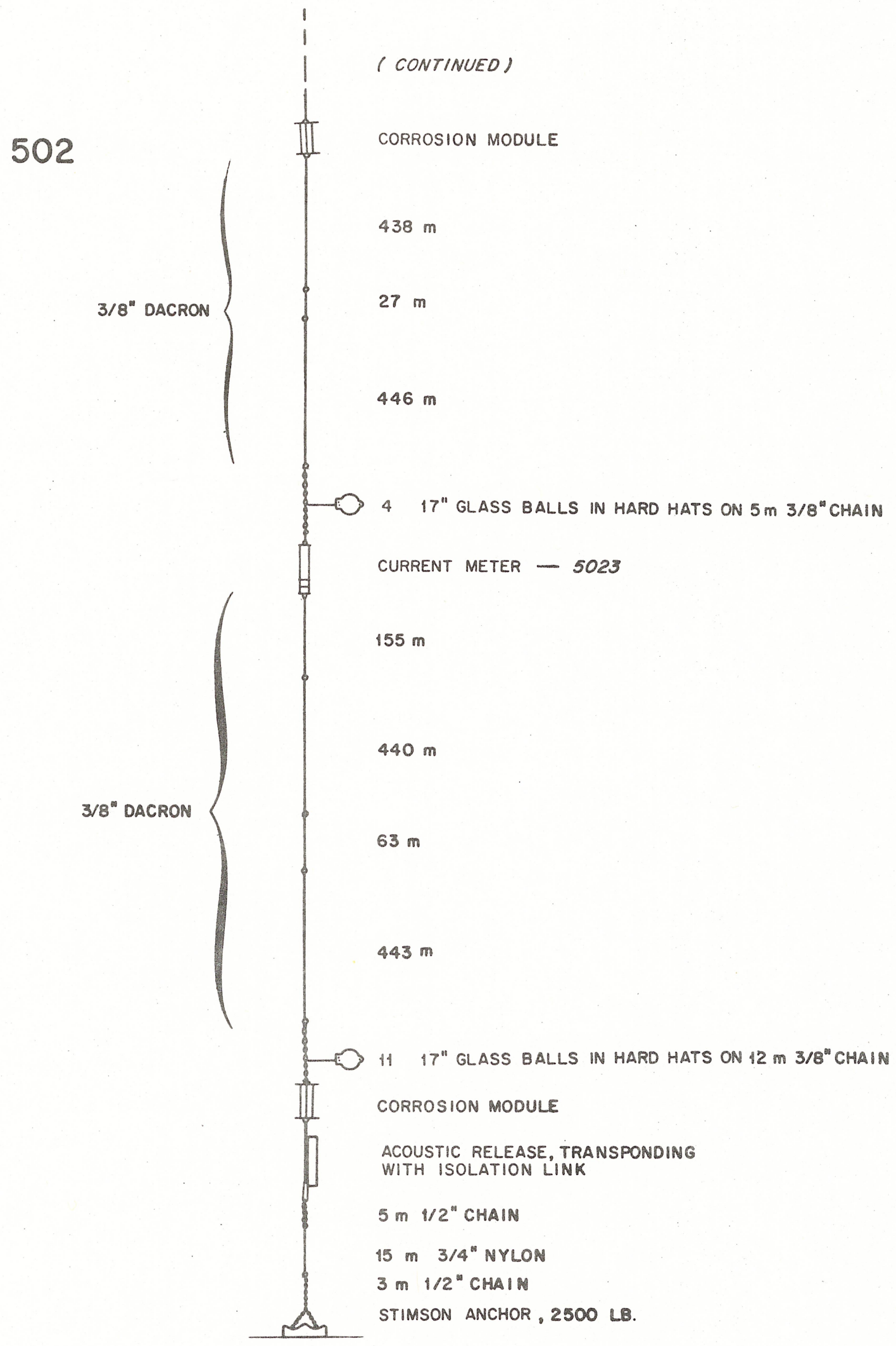




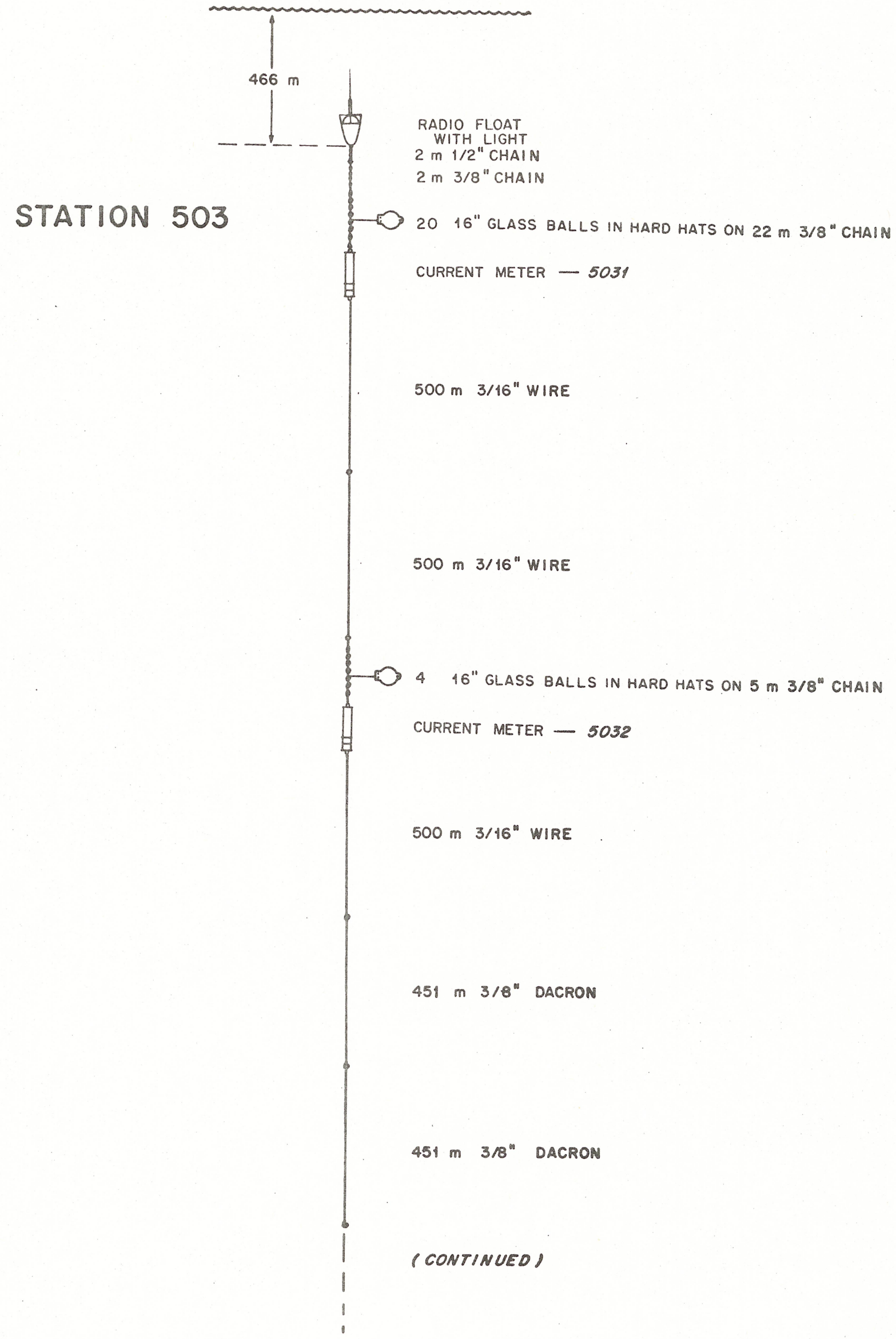




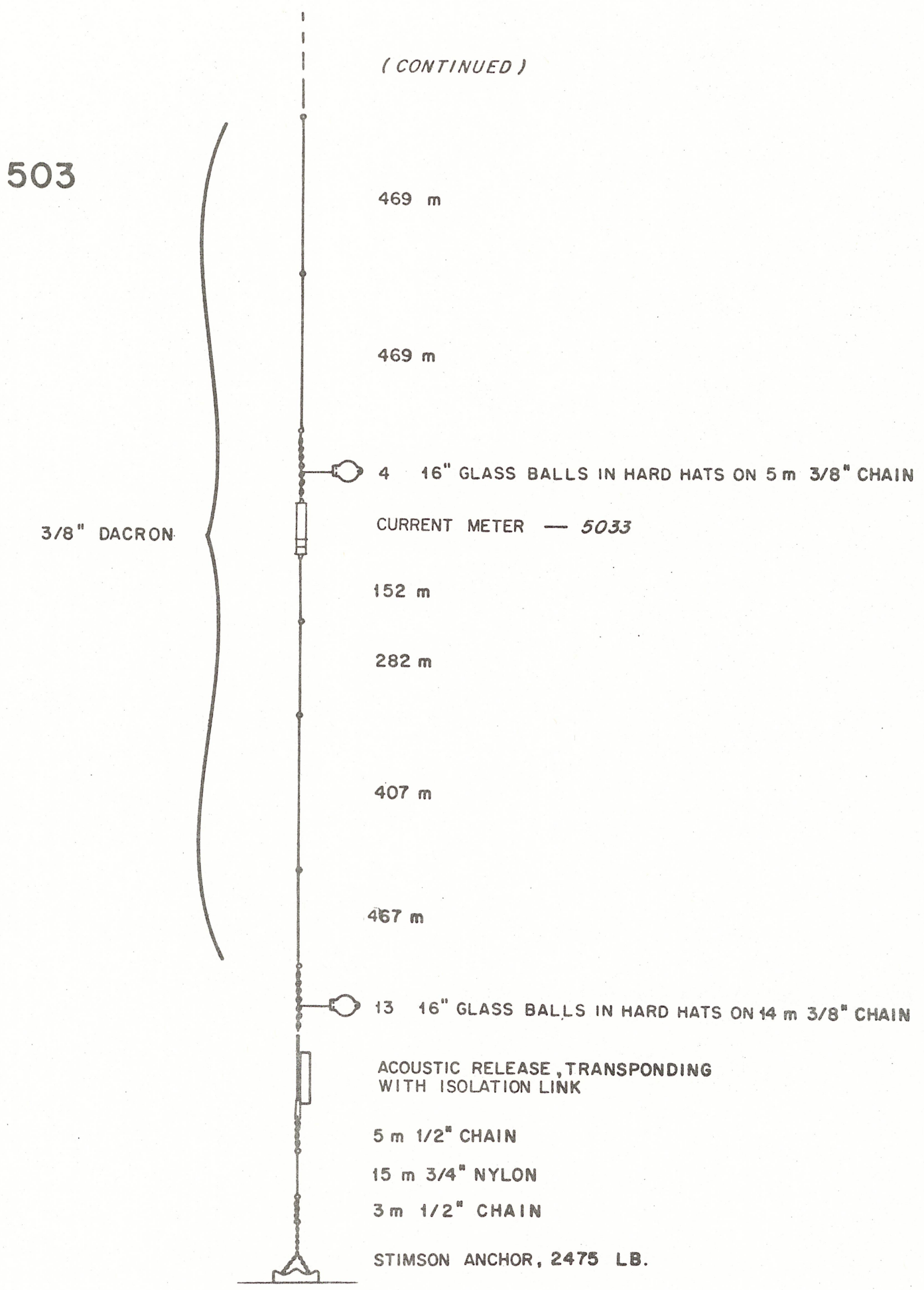




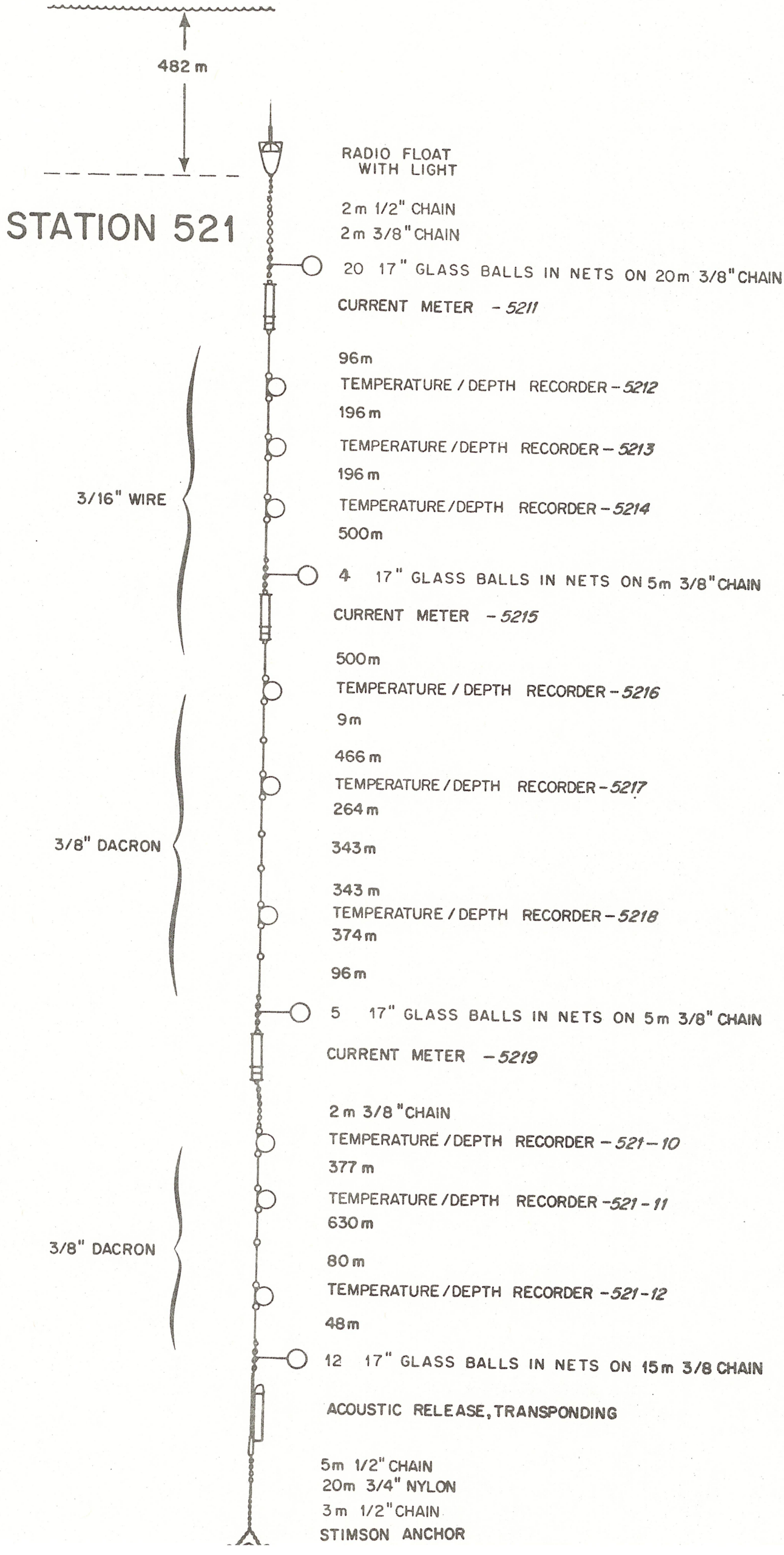




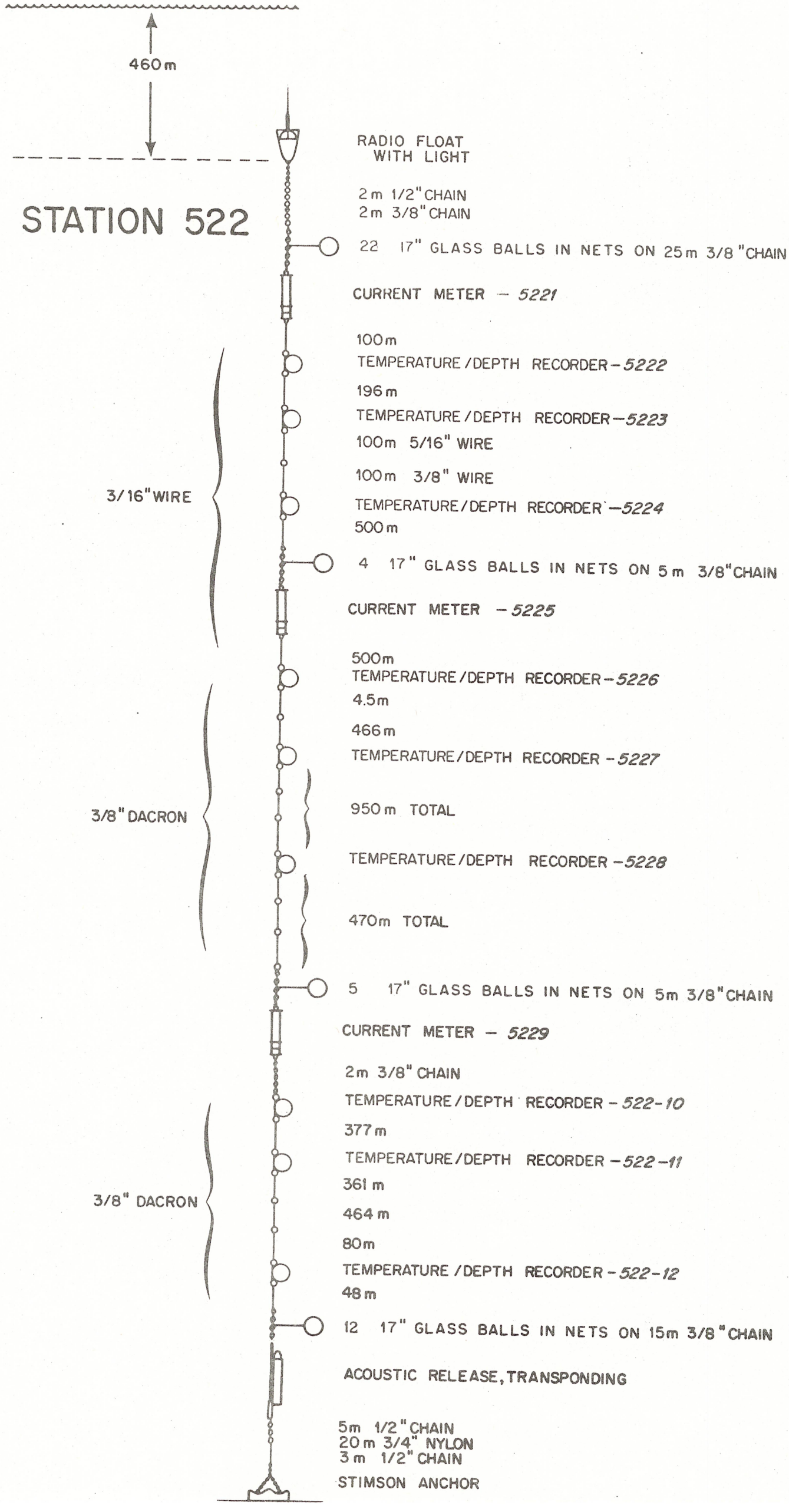


-110 -

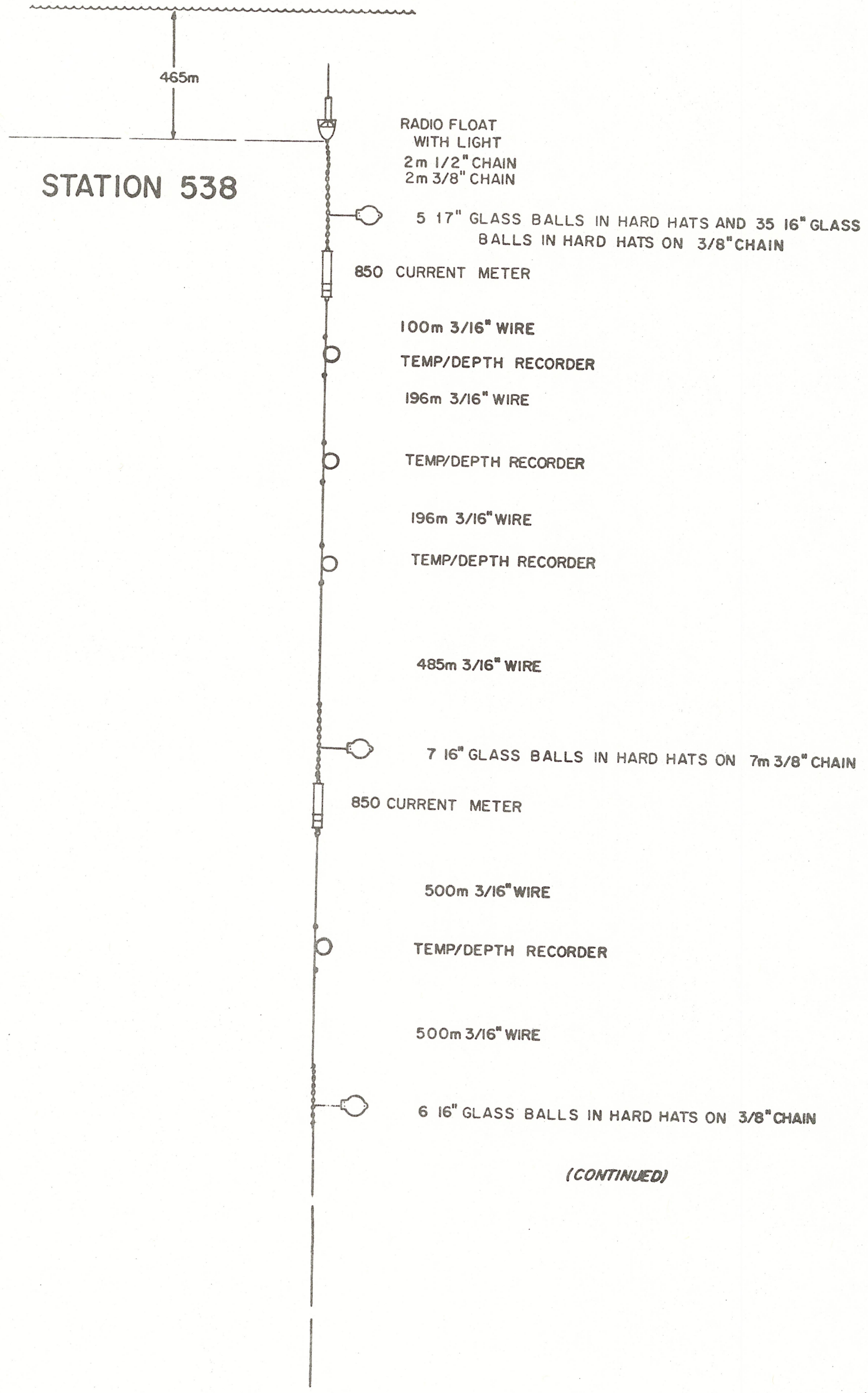




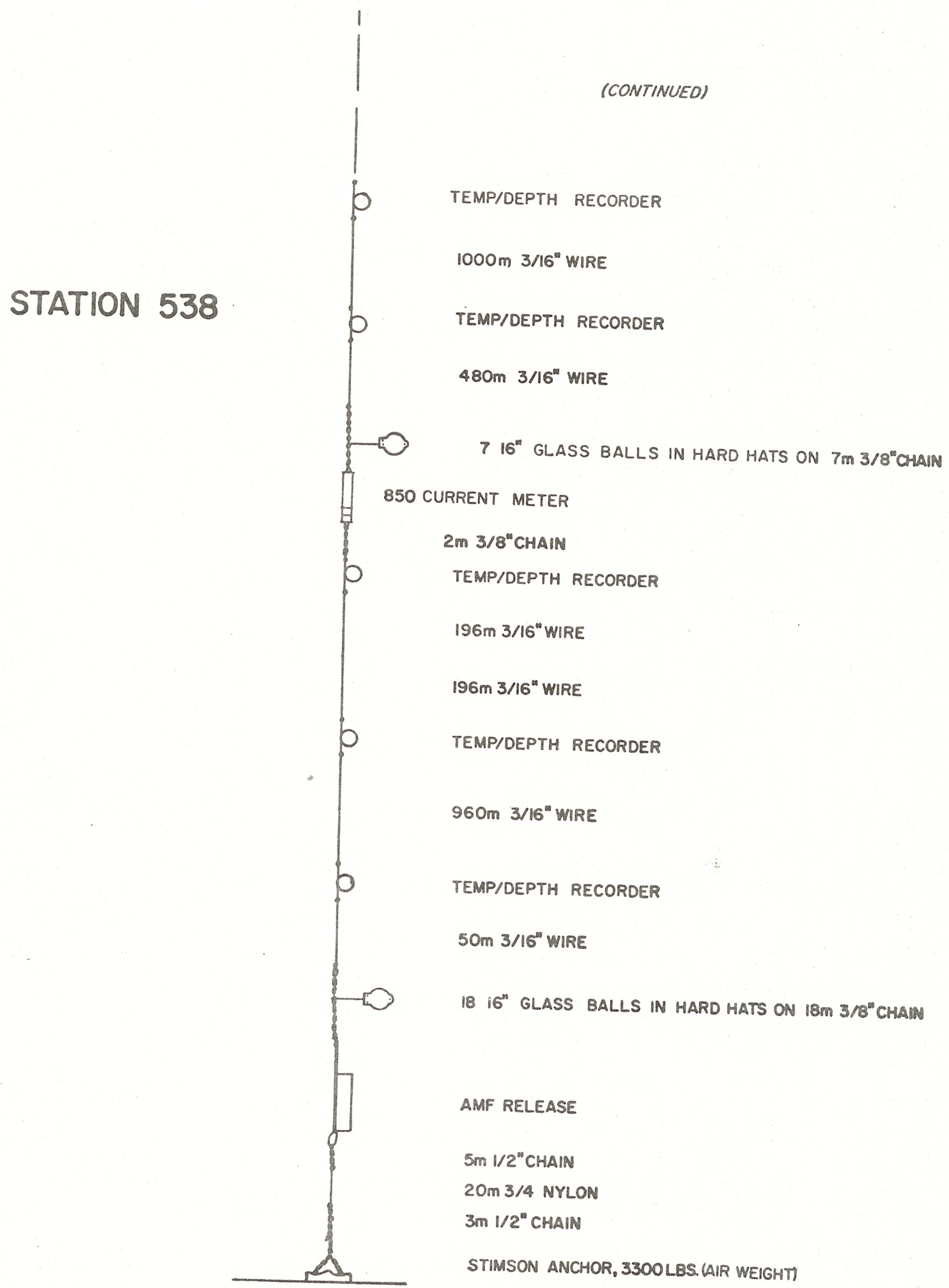




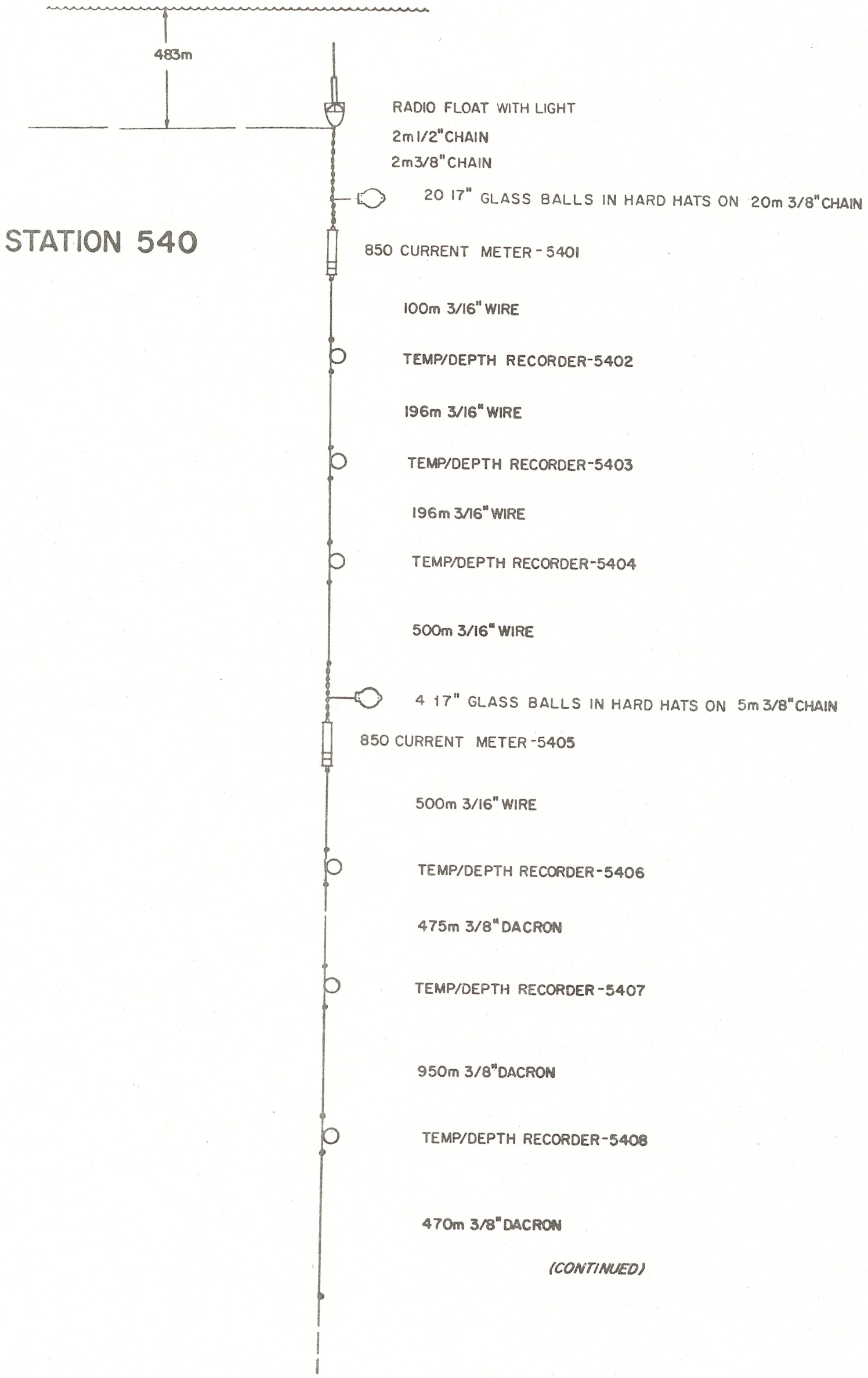




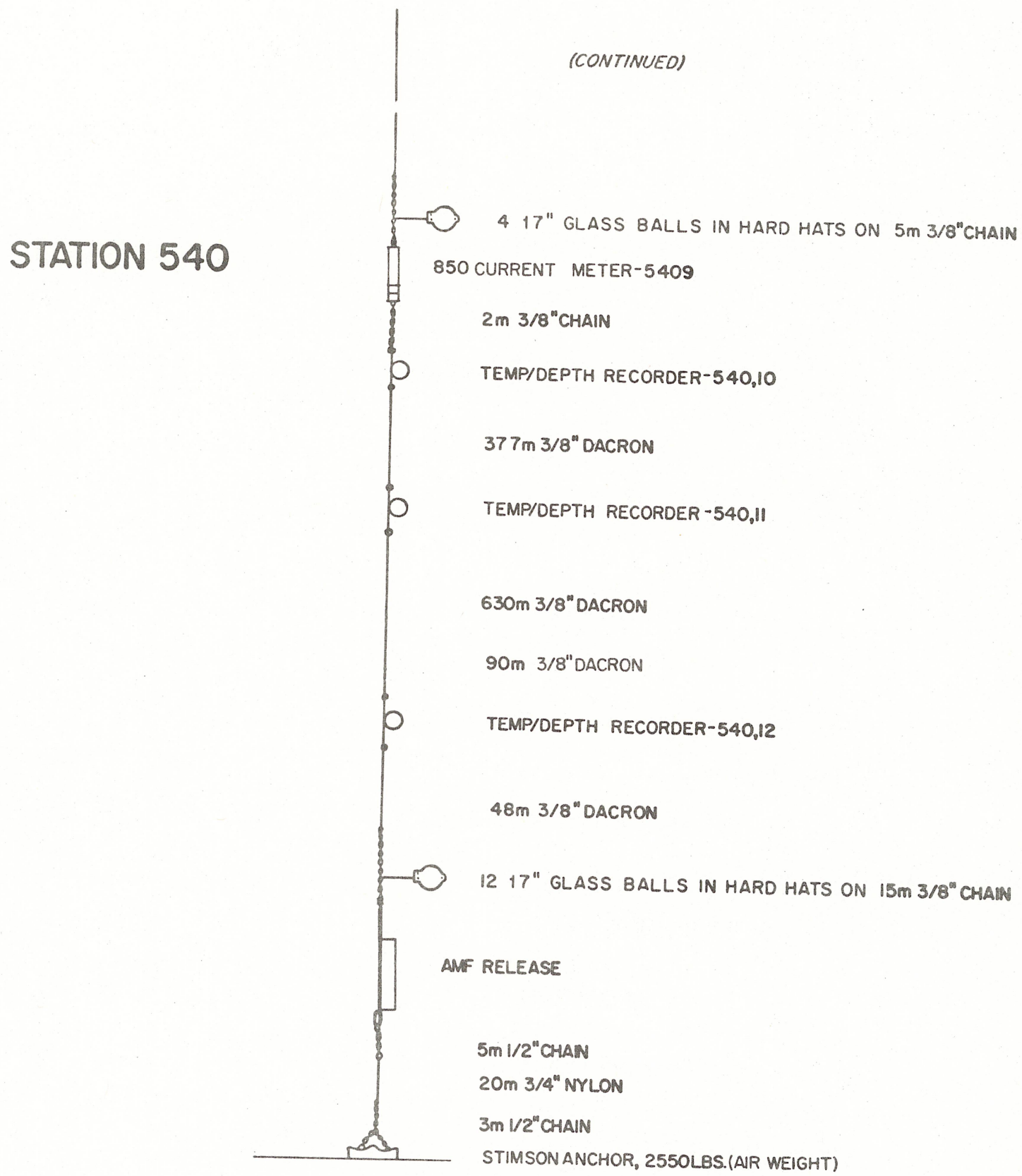




\section{MANDATORY DISTRIBUTION LIST}

FOR UNCLASSIFIED TECHNICAL REPORTS, REPRINTS, \& FINAL REPORTS PUBLISHED BY OCEANOGRAPHIC CONTRACTORS

OF THE OCEAN SCIENCE AND TECHNOLOGY DIVISION

OF THE OFFICE OF NAVAL RESEARCH

(REVISED JAN 。 1975)

1

Director of Defense Research and Engineering

Office of the Secretary of Defense Washington, DC 20301

ATTN: Office Assistant Director (Research)

Office of Naval Research

Arlington, VA 22217

3 ATTN: (Code 480)

1 ATTN: (Code 460)

1 ATTN: (Code 102-OS)

6 ATTN: (Code 102IP)

1 LCDR David Cacchione, (USN)

ONR Representative

Woods Hole Oceanographic Inst.

Woods Hole, MA 02543

1 Office of Naval Research

Branch Office

495 Summer Street

Boston, MA 02210

Director

Naval Research Laboratory

Washington, DC 20375

6 ATTN: Library, Code 2620

1 National Oceanographic Data Center

National Oceanic \& Atmospheric

Administration

Washington, DC 20235
12 Defense Documentation Center

Cameron Station

Alexandria, VA 22314

Commande $\mathrm{r}$

Naval Oceanographic Office

Washington, DC 20390

1 ATTN: Code 1640

1 ATTN: Code 70 


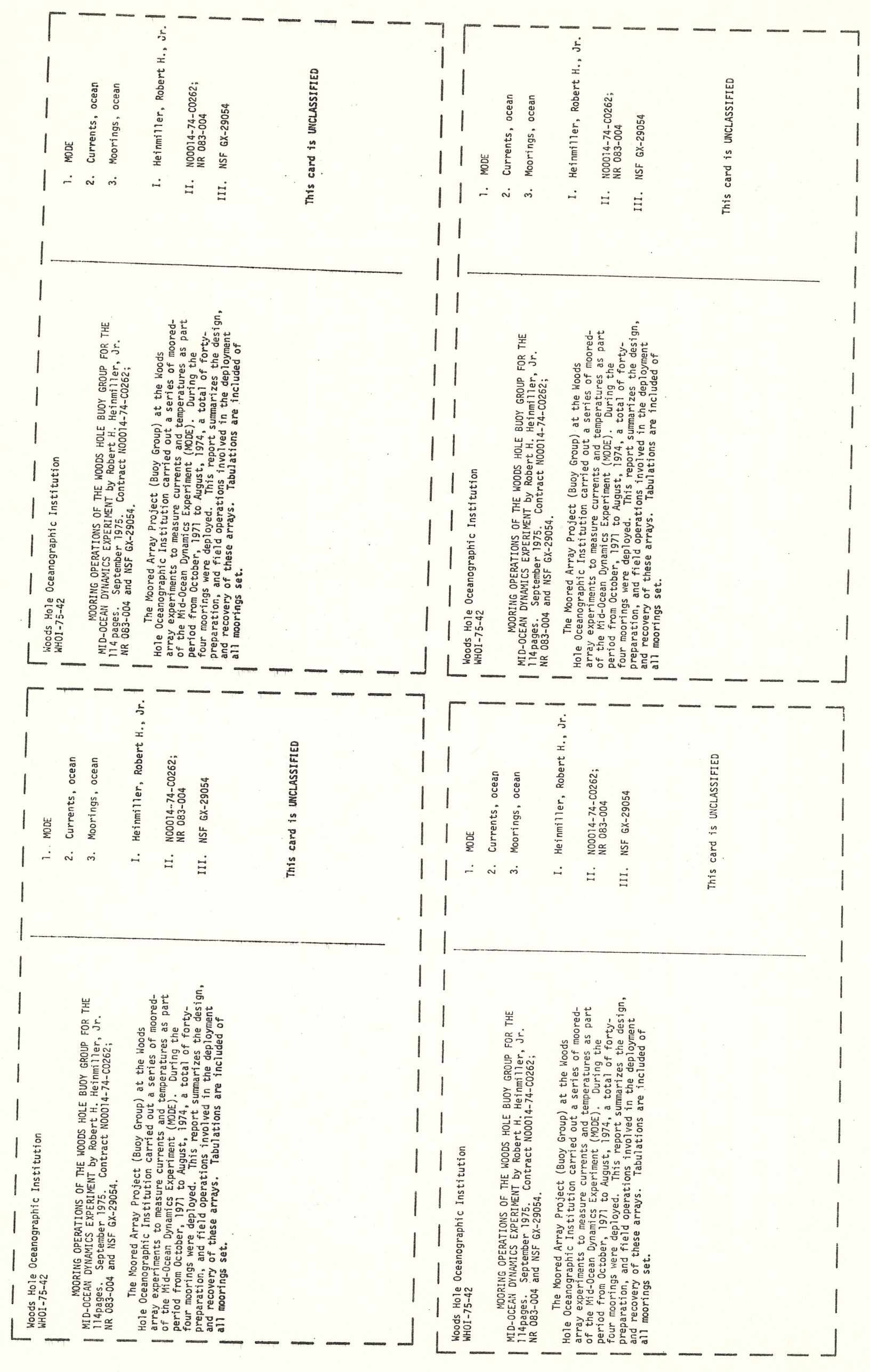


UNCLASSIFIED $\quad 9 / 5 / 75$

SECURITY CLASSIFICATION OF THIS PAGE (Whon Data Entered)

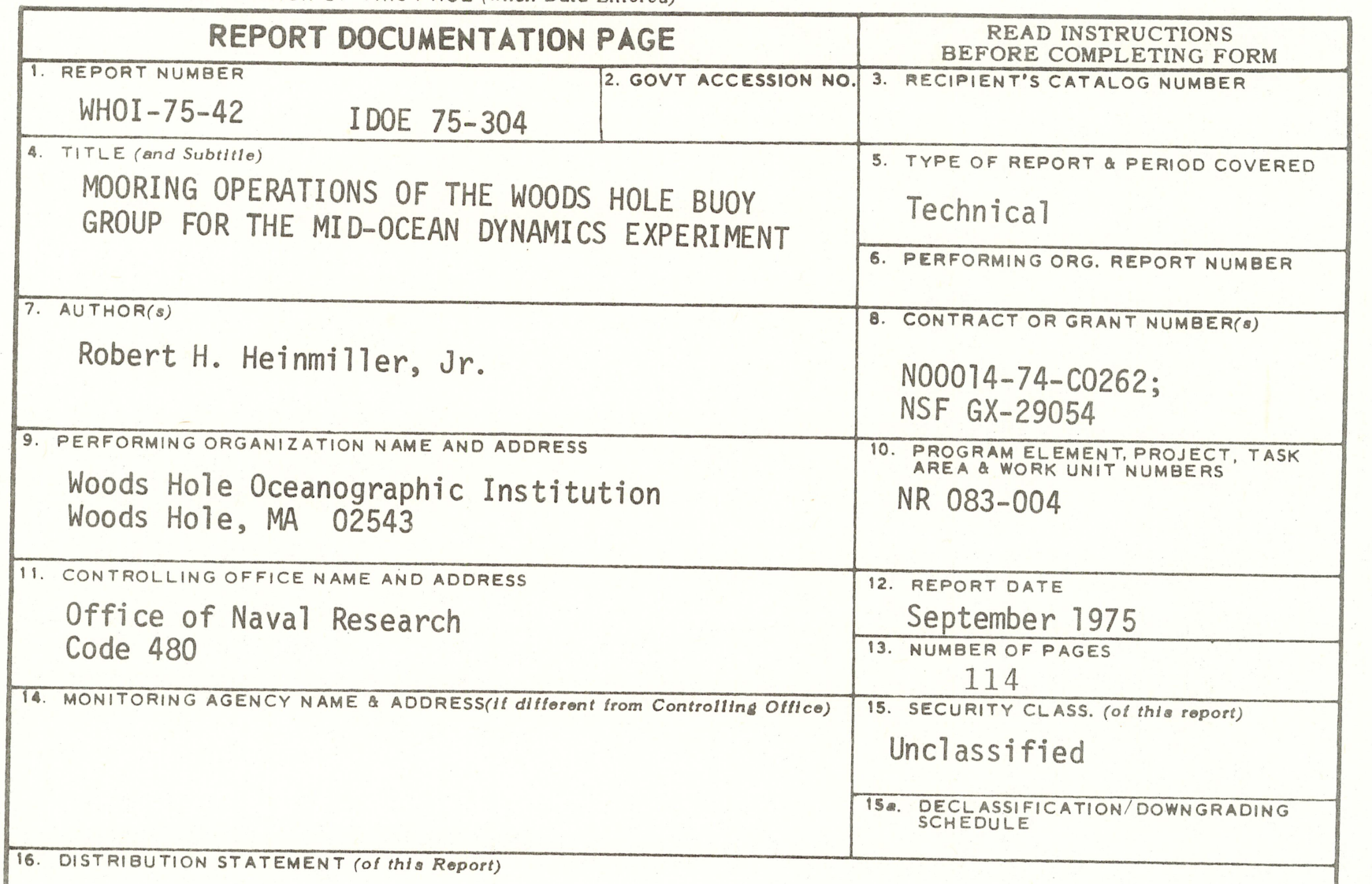

Approved for public release; distribution unlimited

17. DISTRIBUTION STATEMENT (of the abstract ontered In Block 20, if different from Report)

18. SUPPLEMENTARY NOTES

19. KEY WORDS (Continue on pevorse sido if nocessery and ldentlfy by block number)

1. MODE

2. Currents, ocean

3. Moorings, ocean

20. ABSTRACT (Continue on reverso olde if neceseary and identlfy by block number)

The Moored Array Project (Buoy Group) at the Woods Hole Oceanographic Institution carried out a series of moored-array experiments to measure currents and temperatures as part of the Mid-Ocean Dynamics Experiment (MODE). During the period from October, 1971 to August, 1974, a total of forty-four moorings were deployed. This report summarizes the design, preparation, and field operations involved in the deployment and recovery of these arrays. Tabulations are included of all moorings set.

DD FORM IJAN73 1473 EDITION OF I NOV 65 IS OBSOLETE
S/N $0102-014.6601$
UNCLASSIFIED $\quad 9 / 5 / 75$

SECUMITY CLASSIFICATION OF THIS PAGE (When Dat Entered) 